\author{
WSRC-TR--92-097-Rev. 1 \\ DE93 004301
}

\title{
RRTD
}

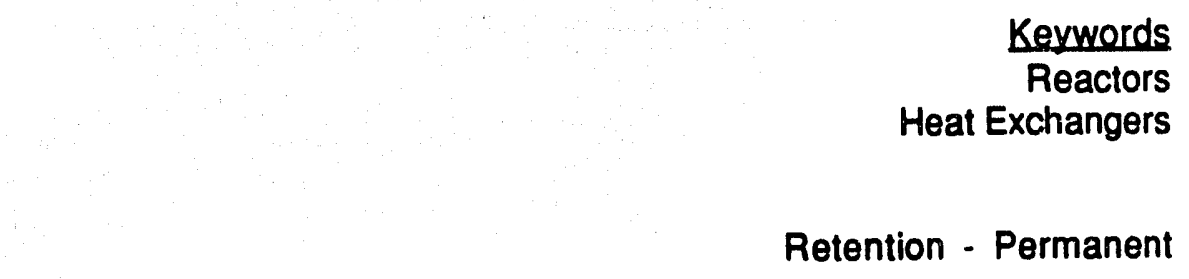

Heat Exchanger Restart Evaluation (U)

\author{
J. M. Morrison \\ C. W. Hirst \\ T. F. Lentz \\ Reactor Restart Technical Director Department
}

Issued: March 18, 1992 
DOCUMENT:

TULL:

DATE:

APPROVALS:
WSRC-TR-92-97, REVISION 1

HEAT EXCHANGER RESTART EVALUATION (U)

MARCH 18, 1992

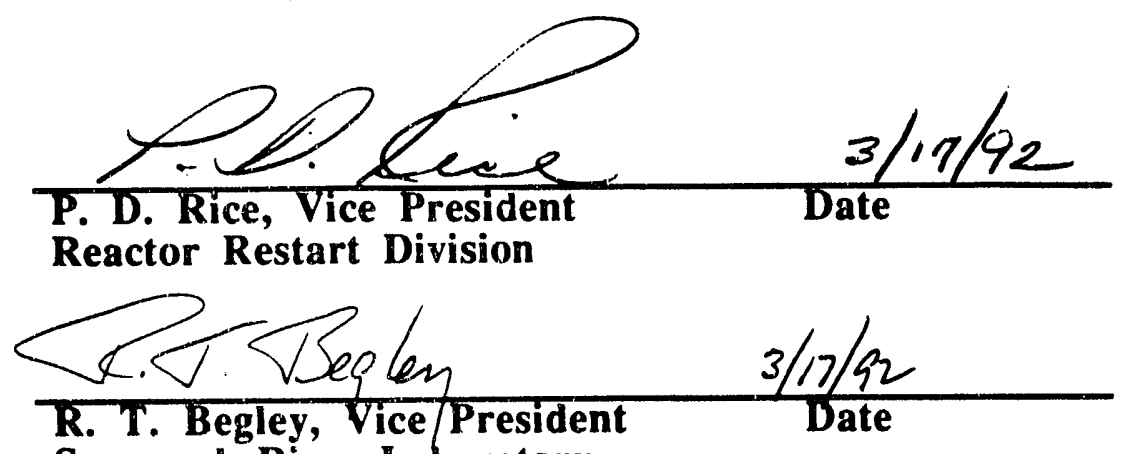

Savannah River Laboratory 
Document No.: WSRC-TR-92-97

Bevision

1

$\frac{\text { Page No. }}{3}$

1

1

14

1

1

1

6

40-73
Rev. No.: 1 Issue Date:

$3 / 18 / 92$

\section{Description of Revision}

Added paragraph beginning at bottom of page, noting a possible but unconfirmable increase in tendency for wear due to foreign objects. This possibility is a result of the lack of evidence of old wear scars, whereas three tubes showed evidence of recent wear.

Expanded third paragraph to provide additional detail concerning the $19 \%$ threshold for eddy current indications.

Added paragraph near the top discussing the lack of confirmation by the metallurgical examinations of a defect or leak near the middle of Tube 94-39, as had been indicated by the early helium leak tests.

Editorial correction in first paragraph.

Editorial corrections in first and third paragraphs in Section B.
Added Appendix 3, containing complete results of the metallurgical failure analysis program. 


\section{ACKNOWLEDGMENT}

This report in large measure reflects the efforts of a number of Westinghouse Savannah River Company technical personnel. The authors particularly wish to express their appreciation for the contributions provided by:
A. L. Boni
M. D. Brandyberry
G. L. Cauthen
C. D. Cowfer
J. F. Jordan
M. W. Loibl
M. R. Louthan
A. F. McFarlane
G. E. Mertz
J. D. Scarbrough

Additionally, expert consultation was provided by J. A. Begley, J. E. Esposito, and A. A. Raimondi of the Westinghouse Electric Corporation, Pittsburgh, PA. Finally, the efforts of P.S. Coffey in preparing the manuscript are gratefully acknowledged. 


\section{TABLE OF CONTENTS}

I. Introduction $\quad 3$

II. Executive Summary 3

III. Examination of Heat Exchanger 4A

A. Identification of Leaking Tube \& Subsequent Examination

B. Additional Examinations of Heat Exchanger 4A 6

IV. Metallurgical Examinations

A. Leaking Tube (94-38) 10

B. Non-Leaking Tubes 13

V. Tube Integrity Analysis

A. Analysis Per NRC Regulatory Guide 1.121 18

B. Wear Scar Parametric Study 19

VI. Heat Exchanger Tube Leakage History

$\begin{array}{llr}\text { A. } & \text { Overview of All Leaks } & 19 \\ \text { B. Significant Leaks and Corrective Actions } & 21 \\ \text { C. Leaks Caused by Wear Due to A Foreign Object } & 21 \\ \text { D. } & \text { Current Cooling Water Screening Process } & 21\end{array}$

VII. Compensatory Actions

A. Examinations of Installed K-Reactor Heat Exchangers 23

B. Sampling and Leakage Detection Program 24

C. Loose Parts Monitoring System 26

D. Procedures and Training 26

VIII. Safety Considerations

$\begin{array}{ll}\text { A. } & \text { Reactor Safety } \\ & 27\end{array}$

B. Potential Tritium Releases 27

$\begin{array}{ll}\text { IX. References } & 30\end{array}$

Appendix 1 Heat Exchanger 4A Examination Results 32

Appendix 2 Heat Exchanger 4A Tubesheet Inspection Maps 36

Appendix 3 SRL-MTS-920032, "Metallographic Evaluation of Tubes From K-Reactor 40 Heat Exchanger 4A" 


\section{INTRODUCTION}

On December 24, 1991, the K-Reactor was in the shutdown mode with full AC process water flow and full cooling water flow. Safety rod testing was being performed as part of the power ascension testing program. The results of cooling water samples indicated tritium concentrations higher than allowable. Further sampling and testing confirmed a Process Water System to Cooling Water System leak in heat exchanger 4A (HX 4A). The heat exchanger was isolated and the plant shutdown. Heat exchanger $4 \mathrm{~A}$ was removed from the plant and moved to C-Area prior to performing examinations and diagnostic testing. This included locating and identifying the leaking tube or tubes, eddy current examination of the leaking tube and a number of adjacent tubes, visually inspecting the leaking tube from both the inside as well as the area surrounding the identified tube. The leaking tube was removed and examined metallurgically to determine the failure mechanism. In addition ten other tubes that either exhibited eddy current indications or would represent a baseline condition were removed from heat exchanger 4A for metallurgical examination. Additional analysis and review of heat exchanger leakage history was performed to determine if there are any patterns which can be used for predictive purposes. Compensatory actions have been taken to improve the sensitivity and response time to any future events of this type. The results of these actions are summarized herein.

\section{EXECUTIVE SUMMARY}

The leak that occurred in heat exchanger 4A in K-Reactor released an estimated total of 5700 curies (Ci) of tritium, as tritiated water, to the Savannah River. The leak took place over a period of about 60 hours during December 22-25, 1991. A hypothetical individual located at the U. S. Highway 301 bridge over the river (about 20 miles south of the plant site), consuming 2 liters of river water per day for the duration of plume passage, would have received a dose from drinking the water of approximately $0.035 \mathrm{mrem}$ (Reference II.1). This is less than one one-hundredth of the EPA drinking water standard of $4 \mathrm{mrem} / \mathrm{yr}$. The leak in HX 4A posed no threat to the integrity and safety of the K-Reactor. The reactor was not operating, safety systems were not challenged, and the leak is well bounded by the current Safety Analysis Report.

An aggressive program was implemented immediately upon confirmation of the leak to determine its cause and significance to the integrity of the remaining heat exchangers in $\mathrm{K}$-Reactor. Heat exchanger $4 \mathrm{~A}$ was removed from the reactor system together with $\mathrm{HX} 4 \mathrm{~B}$ and $\mathrm{HX} 3 \mathrm{~B}$ which had shown slight indications of leakage throughout the last 2 years of plant operation but were well within acceptance criteria. All three heat exchangers, which were of the original SRS design, were replaced with new units of improved design and which passed leak testing criteria.

Heat exchanger 4A was staged to facilities in C-Area for investigation. The cause of the leak was determined to be wear of one of the 9000 stainless steel tubes (tube 94-38) located immediately adjacent to the inner tubesheet at the moderator outlet/cooling water inlet (cold) end of the heat exchanger. The wear had been caused by an unidentified foreign object rubbing against the outside (OD) of the tube, transverse to its axis. This wear had continued until a small rectangular hole 0.020 inches wide by 0.085 inches long opened up in the tube wall to cause the leak. An additional sample of 122 tubes near the bottom of the heat exchanger was examined with eddy current (ET) to determine their overall condition. Ten of these tutes were removed for further testing to quantify eddy current indications of wear and other modes of degradation. The damage site was localized and no indication of any contributing corrosion effects were found.

Wear scars were observed which were recently active and caused by the action of foreign objects against three tubes from HX $4 \mathrm{~A}$ tube bundle. No evidence of old, foreign object induced wear 
was noted. These observations suggest a possible increase in the tendency for wear in the peripheral tubes near the cooling water inlet. This suggestion is consistent with the fact that moderator leakage due to foreign object induced wear of heat exchanger tubing had not occurred since 1965. However, the data necessary to prove this suggestion are not available and neither the past or the present rate nor the frequency of foreign object induced wear can be predicated from the present observations.

Examination of the rectangular perforated flow distribution plate, which acts as a strainer in the cooling water inlet compartment of $\mathrm{HX} 4 \mathrm{~A}$, showed that some of the supports were significantly deformed. The cause of the deformation, which had no apparent physical connection to the tube leak, was investigated and is believed to have resulted from difficulties with its installation in 1965. The other K-Reactor heat exchanger distributor plate supports have been examined and none are deformed to any significant extent.

Only 10 leaks caused by a foreign object in the heat exchangers had occurred at SRS prior to the incident in December 1991. They occurred between 1956 and 1965. Six of them were caused by plastic bristles from brushes formerly used to clean the stationary screens in the cooling water basin. The brushes were eliminated long ago, hence, the type of tube wear that occlurred in HX 4A had actually been experienced only four times previously. Further, the SRS cooling water system is designed to minimize the likelihood of leaks caused by foreign objects entrained in the cooling water. The system includes three level of screens at the river pumphouses, traveling screens in the cooling water basin, stationary screens in the cooling water basin for emergency use, and the flow distributor plate in each heat exchanger. Nevertheless, some debris can still enter the heat exchanger as a result of screen damage, maintenance openings, etc. Further, a Loose Parts Monitoring System has been installed with sensors on each heat exchanger and is undergoing baselining to determine if additional early warning of impending leaks caused by foreign objects can be achieved.

Nonetheless, the possibility of future leaks from this or other causes cannot be eliminated. An aggressive program was therefore undertaken to upgrade the cooling water effluent monitoring capability to reduce the potential for release of tritiated water in the future. A new, state-of-the-art in-line tritium monitor was installed in the K-Reactor outfall. The frequency of effluent grab sampling was increased from once per 12-hour shift to once every 2 hours, and the tritium analysis instrumentation was relocated to the K-Reactor Building to reduce the time required to transport samples to the analytical laboratory. Corresponding changes were made to reactor operating procedures and operations personnel have been trained in their use. Overall, these upgrades should permit approximately a 20 fold reduction in tritium released should a similar size leak such as experienced in $\mathrm{HX} 4 \mathrm{~A}$ occur in the future.

Based on the above, the K-Reactor heat exchangers are considered in satisfactory condition for resumption of normal hydraulic operations. Briefly, this conclusion reflects:

- Reactor safety is not an issue because the December 1991 leak is much less than the design basis accident tube leak.

- The leak in HX 4A was within the envelope of SRS experience and was caused by a low probability event rather than by a generic, predictable mode of degradation.

- The cooling water system is designed to minimize the potential occurrence of leaks of this type. 
- The inlet flow distributor plates of the heat exchangers now installed in K-Reactor have been examined and are in satisfactory condition.

- $\quad$ All of the traveling screens in the cooling water basin have been examined and overhauled within the past two years. The cooling water basin is regularly drained and cleaned at extended outages.

- The tritium moniroring system in the cooling water effluent has been significantly upgraded, including installation of a state-of-the-art in-line tritium monitor, to improve sensitivity and response time to potential events. Corresponding improvements in procedures have been made and operators have been trained in their use.

- Except for the extent of wear in the tube that leaked and in two other tubes, the metallurgical condition of the rubing in $\mathrm{HX} 4 \mathrm{~A}$ is considered excellent.

\section{EXAMINATION OF HEAT EXCHANGER 4A}

\section{A. Identification of Leaking Tube \& Subsequent Examination}

The leaking tube was identified by combinations of helium and pneumatic testing using a bubble solution. Eddy current (ET) examination was the principal NDE method used to characterize the failure. The nature of the failure, its location and configuration were also characterized and recorded by remote visual means. Figure III- 1 is a picture of the hole taken by a video examination from the ID of the tube. The bobbin coil and rotating pancake coil (RPC) eddy current techniques were used. The bobbin coil identified an essentially throughwall indication and the RPC characterized the failure precisely in a three dimensional display. The location of the failure on the tube axis was correlated by further ET, helium leak test, and visual examination. This information was used to select a tube removal technique which would assure preservation of the failure for subsequent metallurgical evaluation.

\section{Figure III-1}

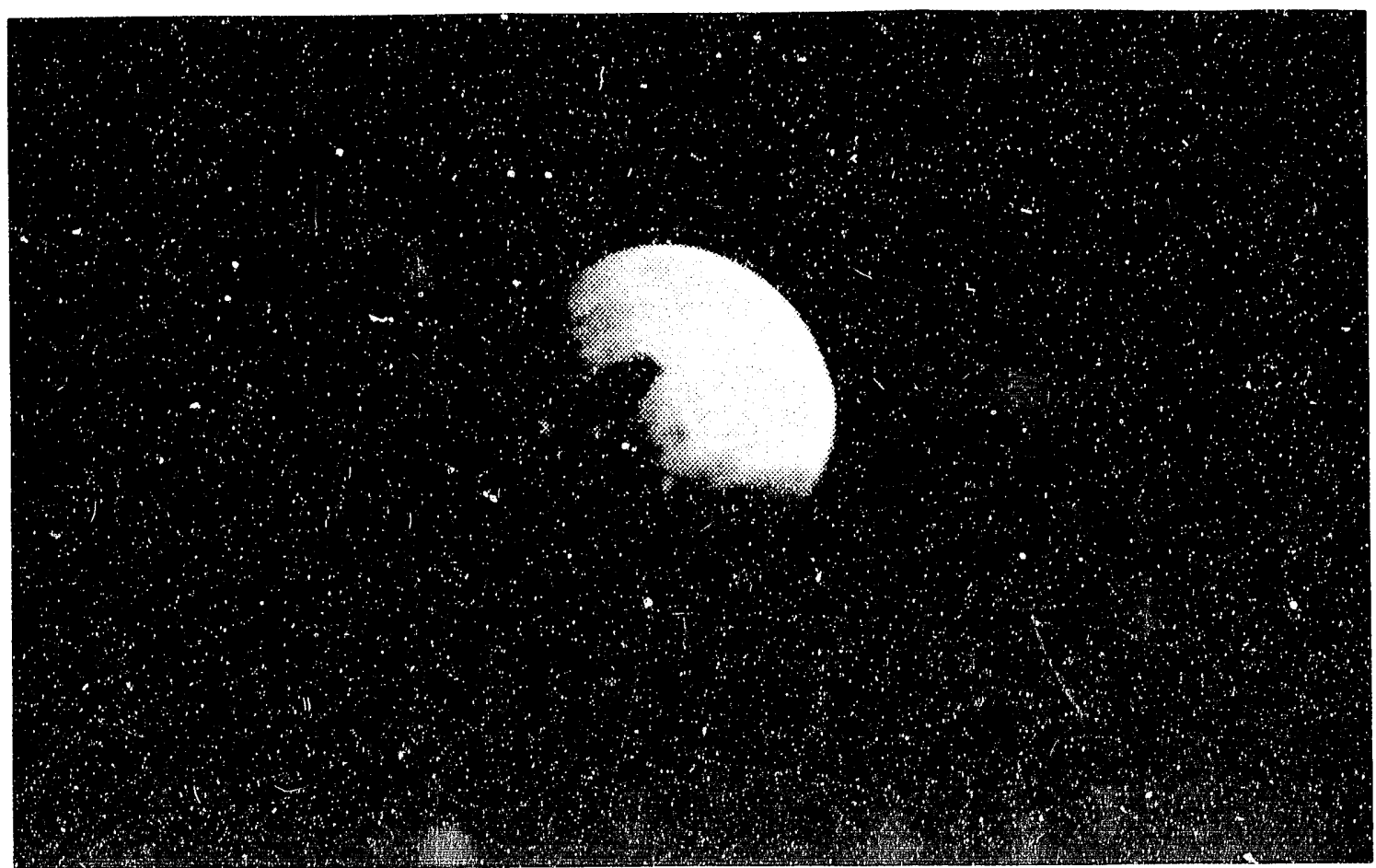




\section{B . Additional Examinations of Heat Exchanger 4A}

\section{Eddv Current Examinations of Additional Tubes}

An eddy current examination program was performed on 122 tubes in the leaking heat exchanger (Serial \# OH-7829). The purpose of the examination was to confirm the identification of the leaking tube. In addition the examinations were utilized to determine tube wear condition in the heat exchanger cooling water inlet region. The results of the examinations are annotated in Appendix 1.

The eddy current was accomplished utilizing three techniques, "bobbin," "6 by 1 ," and "rotating pancake coil (RPC)." The bobbin probe is most sensitive to axial indications. The " 6 by 1 " probe is used to locate and characterize circumferential indications. This is mainly a qualitative type of examination intended to flag indications of flaws. The "6 by 1" technique is not used to quantify the depth of the indication or its source. The rotating pancake coil is motor driven and rides along the ID surface of the tube. It is very sensitive to tube wall degradation and other anomalies and gives an excellent pictorial display of the examination results, Figure III-2. While the bobbin and "6 by 1" were utilized for the full tube length, the RPC technique was used to examine approximately 15 " into the hot or cold end of the tube bundle. In all cases calibration standards with simulated defects (wear, circumferential notches and drilled holes) were utilized to quantify indications of degradation.

Appendix 2 contains additional figures which show the location of the tubes examined by eddy current, tubes with bobbin probe indications greater than 19 percent, tubes with indications from the RPC probe, and a figure showing the tubes that were pulled for metallurgical examination. Indications greater than $19 \%$ (i.e., at least $20 \%$ ) are displayed because with only one exception, all eddy current indications less than $20 \%$ appeared to be caused by work hardening associated with surface burnishing rather than actual wear.

\section{Cooling Water Side Video Examination}

Remote visual examinations of heat exchanger $4 \mathrm{~A}$ shell side were conducted to assess debris and to locate the object(s) which caused wear observed on the leaking tube and two (2) other tubes with wear identified by ET. The foreign object which caused the leak has not been located. Efforts to locate this item included core drilling an access to the top of the cooling water flow distributor plate and subsequent removal of the distributor plate.

The video records document the fact that debris exists in the shell or $\mathrm{CW}$ side of heat exchangers. The video records also show that the bottom outer row of heat exchanger tubes (taken out of service by welded plugs) provides a backup filter to the flow distributor plate, because the $1 / 4$ inch spacing between tubes acts to limit large foreign object access to the outer rows of tubes.

Visual examination of the cooling water inlet nozzles on the heat exchanger cooling water inlet compartment revealed scale build up and other debris, which had partially plugged the perforated flow impingement plate and flow distributor plate. Thirty (30\%) to $40 \%$ of the flow impingement plate (not to be confused with the flow distributor plate) holes were plugged with debris. PVC pipe fragments and other debris trapped by the cooling water flow distributor plate were also present.

A thorough examination of the material removed from the heat exchanger revealed that it consisted of approximately one pound of loose debris that included scale, clams, rust, leaves, and small stones. Foreign objects also included two pieces of PVC pipe approximately 3 to 4 inches long, a 
Figure III-2

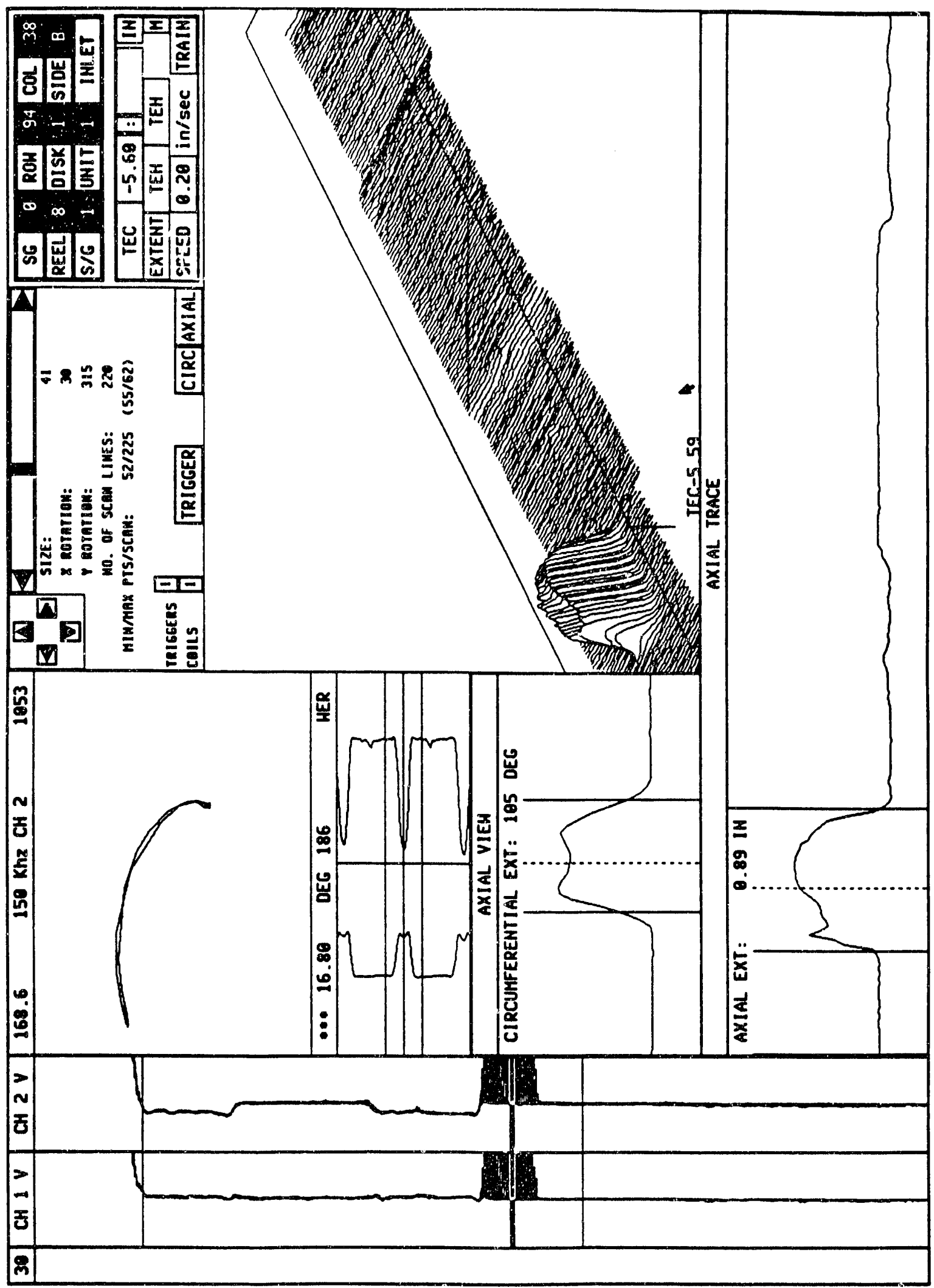


paint brush, safety glasses, plastic cigar tip, etc. The PVC pipe is presumed to be from a sodium hypochlorite (used to kill clam larvae and biological growth) injection line that failed in 1990.

\section{Cooling Water Elow Distributor Plate Examination}

Following confirmation of process water leakage from heat exchariger $4 \mathrm{~A}$, the heat exchanger was removed from service to investigate the cause of the leakage. Visual examination of the inlet cooling water compartment of HX 4A showed that many of the flow distributor plate supports were deformed (Reference III.1). Figure III-3 shows a typical heat exchanger cooling water flow distributor plate staged prior to installation during the 1964-1966 overhaul program.

Determination of the cause of the deformed flow distributor plate supports in HX $4 \mathrm{~A}$ is not conclusive for all deformed areas (Reference III.2). The deformation could be the result of either installation difficulties or hydraulic force such as from water hammer or flow distributor plate blockage. Some of the deformed areas clearly appear to be the result of improper installation. At the same time there is no record that this exchanger ever experienced a water hammer and very little pluggage of the flow distributor plate was found.

Previous analysis had been perforrned to determine the expected forces required to cause deformation of various heat exchanger components (References III.3 and III.4). These analyses indicated that the support straps are the weakest component in the cooling water flowpath. Additionai analyses indicate that a differential pressure of over 8 psi across the strainer would be required to cause the deformation observed (References III.5 and III.6). These analyses also showed that in order to cause a differential pressure of 8 psi across the strainer, the strainer would have to have a pluggage of $\sim 70 \%$. Blockage of this magnitude would have also reduced the flow sufficiently to pick up the safety computer flux tilt alarm on the heat exchanger, alerting the operators . the situation. Thus, there is little evidence to support the theory of blockage as the cause of defo, ation.

Structural evaluations indicate that the applied hydraulic force would cause plastic deformation of the flow distributor plate assembly which would be limited by the first baffle plate after a flow distributor plate movement of approximately two inches. In the unlikely event that the flow distributor plate assembly were to contact the bottom row of tubes (plugged in the old heat exchangers and solid rods in the new units), calculations indicate that the tubes would readily absorb the impact ( 56 psid is required to yield a tube) and prevent any further flow distributor plate movement. No plausible scenario has been identified $t$ connect the observed flow distributor plate deformation in $\mathrm{HX} 4 \mathrm{~A}$ directly with the tube leak. 
Figure III-3

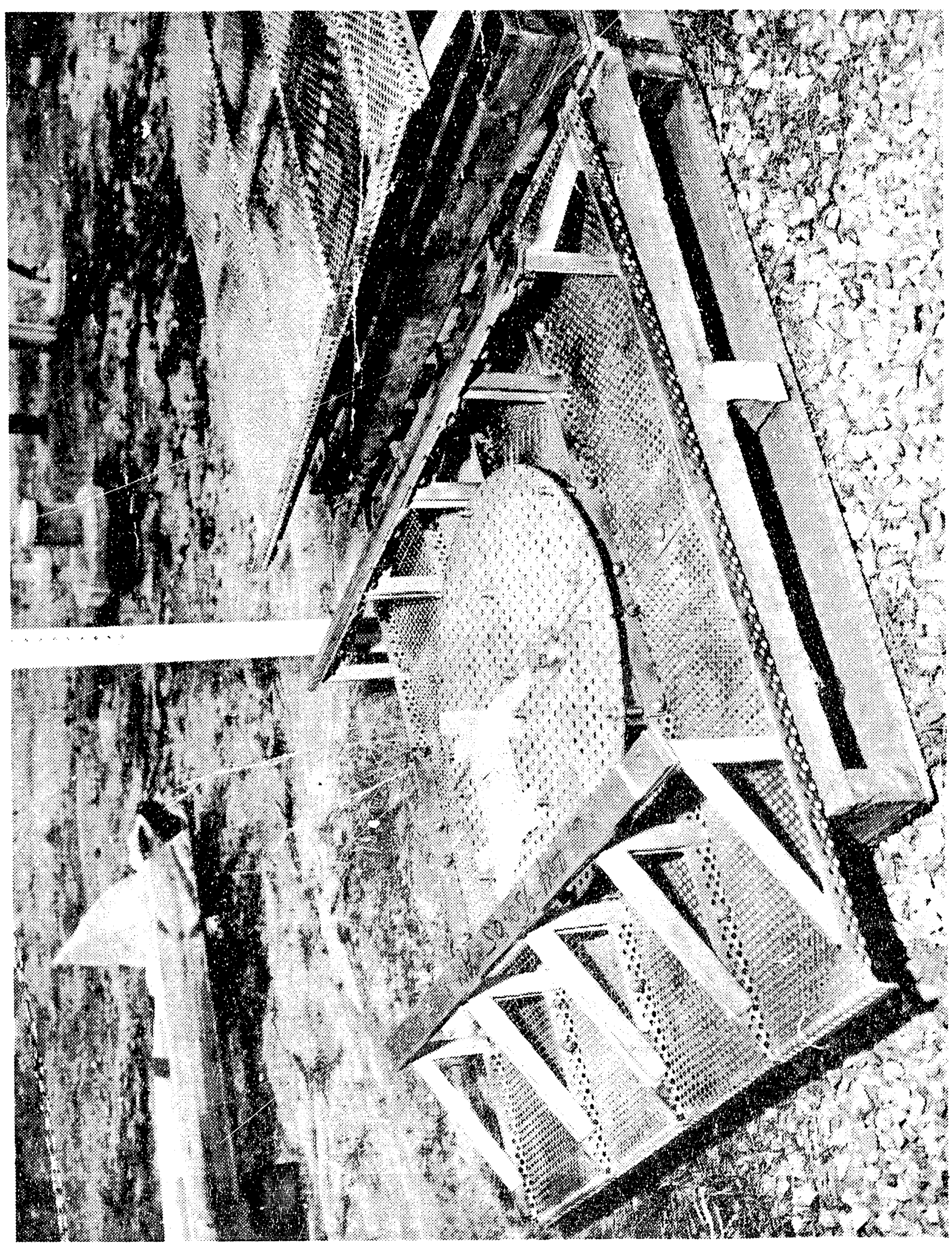




\section{METALLURGICAL EXAMINATIONS}

\section{A. Leaking Tube (94-38)}

Tube 94-38 was remuved from the heat exchanger by core drilling through the tube sheet. This procers was selected because tube wear had been identified in the region adjacent to the tube-toinner tube sheet interface at the moderator outlet end of the heat exchanger. Core drilling provided the maximum assurance that the tube removal operation would not cause additional damage to the worn portion of tube. The core drilling operation does cause damage to adjacent tubes, therefore, tube 93-43 which had been selected as a baseline tube because of the lack of eddy current indications, and tube 94-39 which contained several eddy current indications at tube-baffle interfaces were removed prior to core drilling. The wear section of tube 94-38 and the associated tube sheet are shown in Figure IV-1. The wear section of the tube was examined by scanning electron microscopy (SEM) and then mounted and serial sectioned for microscopic examination of the tube-wear area cross section.

Wear surfaces were apparent on both the tube (Figure IV-1) and tube sheet (Figure IV-2). The scanning electron microscopy of the tube wear surface revealed a very smooth, flat surface. Wear tracks, apparent at high magnifications, were approximately perpendicular to the tube axis and suggested that the relative motion of the two surfaces varied by as much as \pm 15 degrees.

\section{Figure IV-1}

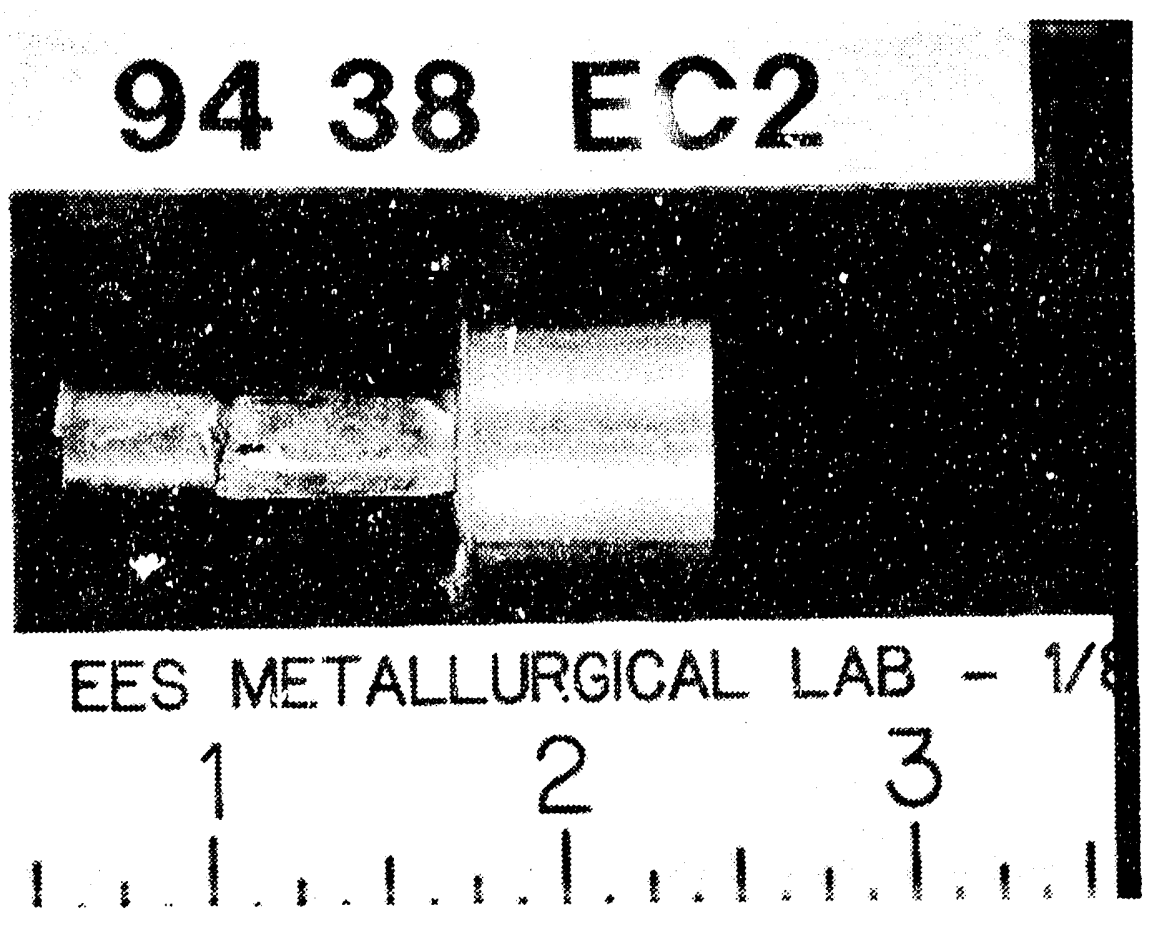


Figure IV-2

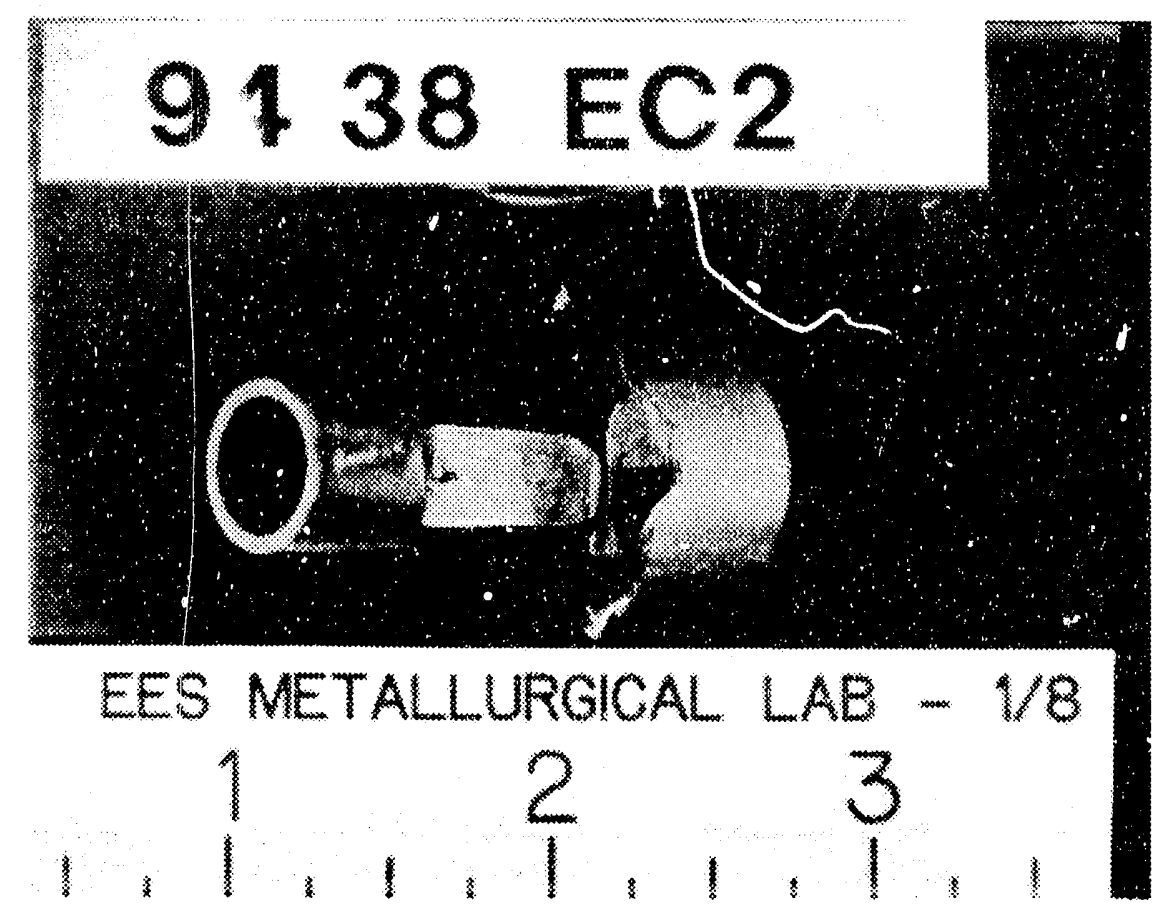

The foreign object that caused the wear on tube 94-38 has not been recovered; however, the shapes of the wear scars on both the tube and tube sheet have helped provide an indication of the size and shape of the foreign object, where it was in contact with the tube and tubesheet. This wear scar pattern suggests that tubes other than tube 94-38 were also in contact with the object. Evidence for that contact was provided by video tapes made during the pre-extraction examination of the wear area in tube 94-38.

The video tapes showed an area of apparent wear on one of the tubes in row 95 . This tube row is the lower periphery of the tube bundle. Because of previous operational experience, all tubes in row 95 are plugged; thus localized wear of these tubes is not significant to reactor operations. The wear indication was below and immediately to the right of tube 94-38. The foreign object may have been too large to pass through the $3 / 8$ inch diameter holes in the flow distributor plate, and in that case would either have had to enter the tube bundle through gaps between the flow distributor plate and the heat exchanger shell, or have been present before installation of the distributor plate.

The wear surface on tube 94.38 was polished to a finish of at least 600 grit. This very fine surface finish, the flatness of the wisar scar, and the observation of wear tracks perpendicular to the tube length suggest that the 0.8 inch long wear scar on the tube was made by an object of similar length. If the foreign object had been significantly shorter than 0.8 inches, the probability of a flat, smooth wear scar across the entire worn region of the tube would have been very low. 
The leak site had apparently been damaged from the $\mathrm{ID}$, probably during the eddy current examination of the tube. The very thin, wom flaps of metal extending above the wear surfaces on the right side of the hole (Arrow A, Figure IV-3) possibly were forced up when a RPC eddy current probe examined the leak site. The bubble, barely apparent on the left side of the leak site (Arrow B in Figure IV-3) and the apparent deformation of much of the thinned section of the tube are also attributed to the passage of the RPC eddy current probe (rotating at $300 \mathrm{rpm}$ ).

The actual leak path was a rectangular hole approximately 0.020 inches wide and 0.085 inches long. Any metal that was above the wear surface during the incident should have been forced down by the continuing wear process. The protrusion of the metal flaps allowed the thickness of the remaining section to be estimated during the initial SEM examination. The sample was too large to permit its rotation (in the electron microscope chamber) so that the flap was perpendicular to the scanning beam, but the thickness could be estimated at ten to fif. zen microns. Serial sectioning through the worn area of the tube confirmed the ligament thickness and demonstrated that the wear surface on the foreign object was sufficiently smooth to wear the tube surface to a thickness of less than one grain diameter before the tube was penetrated. These observations demonstrate that the ligament required to contain the $\mathrm{D}_{2} \mathrm{O}$ moderator in the tube under these wear conditions is less than ten microns. Hydraulics estimates indicate that the actual area of the hole in tube 94-38 is greater than would be expected based on the amount of tritium released. Possibly, this could be accounted for by changes in the hole size during the leak, by pressure exerted by the foreign object still in contact with the tube, and/or enlargement due to passage of the RPC eddy current probe through the tube.

\section{Figure IV-3}

\section{B}

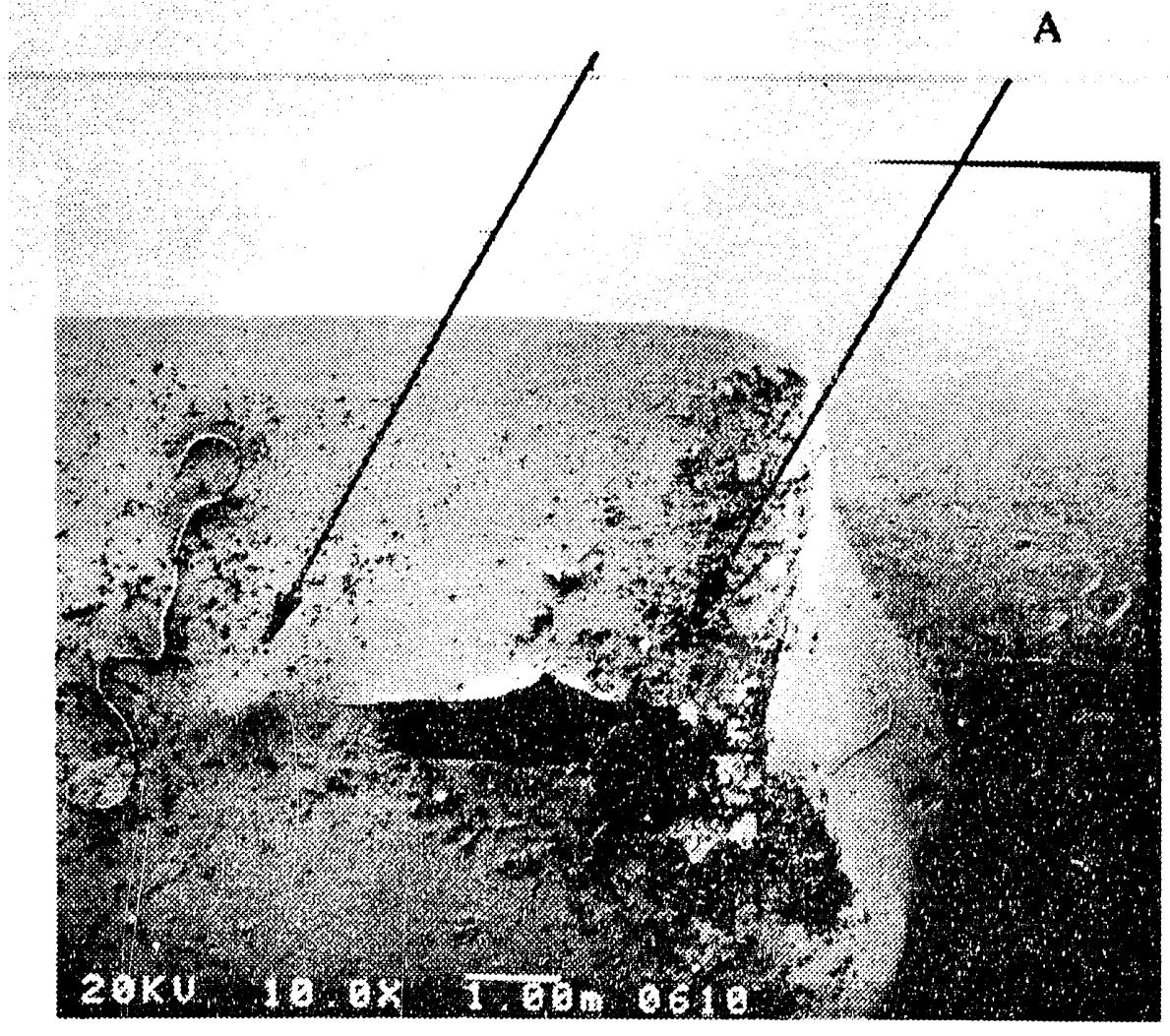


The metallurgical evaluation of the leak site in tube 94-38 demonstrates that the leak was caused by wear which was induced by the presence of a foreign object in the secondary cooling water. The offending object has not been identified, however, size and shape estimates based on the wear scars suggest that the object may have been too large to have passed through the $3 / 8$ inch diameter holes in the flow distributor plate plate immediately beneath the tube bundle and above the cooling water inlet. The smooth, flat wear surface suggests that the wear process removed very little material with each cycle. However, in the absence of identification of the offending object, there is no technical basis for estimation of the wear rate.

\section{B . Non-Leaking Tubes}

\section{Corrosion Induced Degradation}

The metallurgical evaluations of selected sections of 10 additional tubes removed for examination provided no evidence of intergranular attack, stress corrosion cracking, crevice corrosion, pitting or microbiologically influenced corrosion. Penetrant testing and macroscopic examination revealed no indications of corrosion induced degradation on either the outer or inner surfaces of any of the tube sections examined. Microscopic examination of both longitudinal and transverse cross sections also confirmed the absence of corrosion degradation. The focus of these examinations for corrosion induced effects was tube sections associated with tube sheets and baffles because the crevices in these areas should increase the potential for corrosion in those areas compared to other portions of the tubes. Operational history of other heat exchangers also indicated that these areas were the most likely areas to experience corrosion induced degradation.

The eddy current examinations had provided indications of possible degradation near the tube sheet interface of tubes 94-59 and 93-45. Visual and macroscopic examination of these areas in these two tubes revealed no evidence of stress corrosion cracking or any other significant metallurgical defects. Penetrant testing of both inner and outer tube surfaces also provided no evidence of crack like defects. The metallurgical quality of these two tubes was further confirmed by serial sectioning the tube-to-tube sheet regions. The only defect found during this detailed examination was a smäll groove, approximately 0.001 inches deep on the outer surface and near the tube-totube sheet crivice of tube 94-59.

Similar metallurgical examinations, except for the serial sectioning through the tube-to-tube sheet regions were conducted on tubes 94-49, 93-43, 95-51, 94-38 and 92-48. No evidence of cracking, pitting, crevice corrosion or other metallurgical defects was found in any of these tubes. The lack of corrosion induced degradation in the tube-to-tube sheet region is consistent with the very low levels of leakage that this heat exchanger had experienced throughout its operational history. These observations suggest that, except for the few foreign object induced wear sites identified, the tubes in this heat exchanger were in excellent condition.

\section{Baffle Wear}

The baffle positions on most of tube sections removed from this heat exchanger were apparent because of differences in the surface films in the baffle-to-tube crevice and because of minor artifacts in the surface films. Two tubes, 94-39 and 93-71, were removed because eddy current examination indicated baffle wear. The eddy current examinations had indicated a possibility of minor wear on tube 94-39 at baffles 5,6 and 9, and of significant wear on tube 93-71 at baffle 9 . Penetrant testing of the outer surfaces of sections of 94-39 that contained these three baffle areas showed no indications and wall thickness measurements showed no significant wall thinning. 
Metallurgical examination of these sections from tube 94-39 confirmed the wall thickness measurements and provided no indications of corrosion damage.

The leak check of specific tubes in the tube bundie (see 'HE AXIAL FLOW REAC' column in Appendix 1) indicated a very low level helium leak near the fifteen foot position of Tube 94-39. This tube was the only tube other than the leaker (Tube 94-38) that had such an indication and because of this and indications of baffle wear, the tube was extracted from the tube bundle. However, this leak was not confirmed during the metallurgical evaluation of the extracted tube. Visual examination of the outer and inner tube surfaces revealed no evidence of wear in that area. Subsequent laboratory attempts to confirm the presence of either a leak or a tube defect included edảy current inspection and leak testing. Neither examination found any evidence of tube degradation. These results suggest that the original helium leak indication was probably a false signal, although there is a very small chance that the defect, if real, either was too small to be detected by the laboratory tests or was masked by the tube extraction process, which included sectioning the tube at two locations approximately six inches from the fifteen foot position.

The visusl examination of tube 93-71 confirmed the presence of baffle wear at baffle 9. Much of the circumtcrence of the baffle wear surface was covered with the dark film that is typical of type 304 stainless sieel surfaces exposed to river water for significant periods of time. The most significant circumtercitial wear was approximately $46 \%$ of the tube wall. The wear surfaces in this area were totally cove-ed with the river water induced film, demonstrating that the wear process was inactive during the recent hydraulic operations. Portions of the tube in the circumferential baffle region had the shiny and burnished appearance of active wear. The maximum wear in these active regions was $30 \%$ of the tube wall, with most of the region showing only $5 \%$ wear. The $30 \%$ wear regions were extensions of deeper, old circumferential wear scars and probably resulted from wear during previous operations.

The physical measurements of baffle wear demionstrated that the eddy current indications were very conservative, probably because of martensite transformations induced in the tube walls during the burnishing operations. Throughout the metallurgical evaluations, no evidence was found for any degradation not detected by the eddy current examinations. The actual depth of defects which were identified by the eddy current examinations for baffle wear was consistently less than suggested as summarized in Table IV-1.

\section{Eoreign Object Wear in Other Tubes}

\section{Outer Surface Wear}

Two tubes, 92-65 and 93-49, were removed because eddy current indicated significant outer surface wall thinning, not associated with baffles or tube sheets. Physical measurement of the wear depth in both of these tubes confirmed the eddy current indications, Table IV-2. The wear depth in tube $92-65$ was $40 \%$. The measured depth in $93-49$ was $62 \%, 10 \%, 38 \%$, and $12 \%$. The wear scars in these two tubes appeared recent, and other areas of tube burnishing by foreign objects were apparent. The topological characteristics of the wear tracks in tube 93-49 suggested that although the wear appeared recent, the process was probably inactive at the time of the December incident. The shape of the wear scars on tube 93-49 suggests that the offending object was long and thin, similar to a wire. The four wear scars could have resulted from a single object moving down the tube during hydraulic operation. The tarnish films on the wear scars support this hypothesis by suggesting that the four scars were formed one after another, the oldest scar having the darkest tarnish film. However, proof of this hypothesis is virtually impossible. 
The two scars from tube 92-65 had tarnish films on the scar surfaces which suggest that these wear processes may also have been inactive by the time of the December incident. Contamination on this tube has prevented the scanning electron microscopy of the wear tracks.

\section{Inner Surface Wear}

The only inner surface eddy current indications on any of the tubes examined were two indications on tube 93-71. These two indications were both inner surface wear associated with the "point" contact between the core rod and the inner surface of the tube. The depth of wear at both locations was approxim ly 0.017 inches or $34 \%$ of the tube wall. Due to the purity of the process water, it is not possible to determine the age of the wear activity based on surface film. No evidence was found for pitting, stress corrosion or intergranular attack by the moderator.

The report containing the detailed results of the metallurgical investigations in their entirely is included herein as Appendix 3. 


\section{Table IV-1}

\section{Measured Depths of Baffle Wear}

$\begin{array}{lccc}\begin{array}{c}\text { Tube } \\ \text { Number }\end{array} & \begin{array}{c}\text { Baffle } \\ \text { Number }\end{array} & \begin{array}{c}\text { Eddy Current } \\ \text { Indication }\end{array} & \begin{array}{c}\text { Actual Physica } \\ \text { Measurement }\end{array} \\ 92-48 & & \begin{array}{c}\text { no wear noted } \\ 8 \%\end{array} & \\ 92-65 & 7 & \text { no wear noted } & \text { burnishing } \\ 93-43 & 1 & 20 \% & \text { not measured } \\ 93-45 & 5 & 18 \% & \text { not measured } \\ & 6 & 21 \% & \text { not measured } \\ 93-49 & 1 & 20 \% & \text { not measured } \\ & 2 & 11 \% & \text { not measured } \\ & 3 & 7 \% & \text { not measured } \\ & 5 & 5 \% & \text { not measured } \\ & 9 & 17 \% & \text { not measured } \\ & 10 & 17 \% & \text { not measured } \\ & 11 & 21 \% & \text { burnishing } \\ & 13 & 10 \% & \text { burnishing } \\ 93-71 & 8 & 13 \% & \text { burnishing } \\ & 9 & 66 \% & 46 \% \text { (filmed) }\end{array}$

(The deepest wear under baffle 9 was old and had filmed over. The shiny or burnished regions, indicative of recent wear, were $30 \%$ of the wall on one side of the tube and $5 \%$ of the wall on the other side.)

$\begin{array}{lccl}94-38 & 5 & 11 \% & \text { not measured } \\ 94-39 & 5 & 23 \% & \text { burnishing } \\ & 0 & 15 \% & \text { burnishing } \\ \text { burnishing } \\ 94-49 & 9 & 15 \% & \text { not examined for baffle wear } \\ 94-51 & & 5 \% & \text { not measured } \\ 94-59 & 7 & & \text { no wear noted }\end{array}$




\section{Table IV-2}

\section{Measured Depths of Foreign Object}

Induced Tube Wear

Tube

Number

92-48

92-65

93-43

93-45

93-49

93-71

94-38

94-39

94-49

94-51

94-59

\section{Eddy Current Indications}

no foreign object wear noted $40 \%$

$15 \%$

no foreign object wear noted no foreign object wear noted

$$
50 \%
$$$$
23 \%
$$

$$
\begin{gathered}
\text { inner surface wear } \\
\text { two locations, } 27 \% \text { and } 34 \% \\
98 \% \text { (the leaker) } \\
19 \% \\
\text { no foreign object wear noted } \\
\text { no foreign object wear noted } \\
\text { no foreign object wear noted }
\end{gathered}
$$

\section{Actual Phroical Measurement}

$40 \%$

$10 \%$

$62 \% \& 10 \%$

$38 \%$

$12 \%$

$34 \%$, both locations

(wear cause by core rod)

$100 \%$

no wear detected 


\section{TUBE INTEGRITY ANALYSIS}

Each process water heat exchanger has approximately 9000 tubes of 0.5 inch diameter and 0.049 inch wall thickness. Minimum structural tubing requirements are consistent with commercial practice with PWR steam generator tubing. Postulated tubing defects with $0.5 \mathrm{lb} /$ day calculated leakage were compared to the structural requirements, demonstrating adequate structural margins against gross tube rupture. A parametric wear scar study, based on national codes and standards, determined the minimum structural requirements for highly localized wall thinning.

\section{A. Analysis Per NRC Regulatory Guide 1.121, "Basis for Plugging Degraded PWR Steam Generator Tubes"}

Commercial nuclear practice with FWR stean generator tube plugging criteria was used for guidance in performing this analysis (Reference V.1). It is important to note that the SRS reactors are low energy systems with normal operating pressures of 203 psig at $130^{\circ} \mathrm{F}$, while a PWR is a high energy system with operating pressures near 2200 psig at $600^{\circ} \mathrm{F}$. Clearly, PWR steam generators have loadings which are more severe than the SRS heat exchangers.

The commercial basis for plugging PWR steam generator tubing is defined by Regulatory Guide 1.121 which is explicitly limited to PWRs. However, where applicable, this guideline was applied to the current evaluation of the SRS heat exchanger tubing integrity.

Consistent with the Regulatory Guide 1.121 criteria, both wastage (wall thinning) and cracking were addressed. Structural limits on wall thinning and crack size were developed to preclude gross rupture. The wall thinning criteria are based on ASME Section VIII, which is the design code for the SRS heat exchanger. ASME Section XI criteria, with the loadings and factors of safety recommended by Regulatory Guide 1.121 were applied to develop the allowable crack size criteria. Allowances for corrosion or crack growth were not included in this analysis.

Normal operating loads consist of internal pressure, dead weight, hydraulic drag and thermal forces. Accident conditions consist of seismic and water hammer loadings. These loadings were conservatively combined and bound the loadings specified in Regulatory Guide 1.121.

Structurally, the heat exchanger tubing is over designed. The allowable normal operating pressure for the tubing is $3600 \mathrm{psig}$. Normal uperating pressure is approximately $200 \mathrm{psig}$ and the system design pressure is 300 psig. The minimum wall thickness for the design pressure, using minimum material properties, is 0.0037 inches.

The ASME Section XI limit load criteria in Appendix C-3320 and C-3340 were used with Regulatory Guide 1.121 factors of safety (3 for normal operation and 1.5 for accident conditions) to determine the allowable sizes of postulated circumferential and axial flaws. Allowable flaw sizes were calculated for: 1) the nominal wall thickness of 0.049 inches, and 2) a region previously thinned by wastage with a postulated wall thickness of 0.025 inches. The non-mechanistic combination of wastage and cracking is used to determine the sensitivity of the allowable flaw length to variations in wall thickness.

The critical flaw size of circumferential throughwall flaws is greater than $50 \%$ of the tubing circumference $(\approx 0.8 \mathrm{inch})$, for tubing 0.025 inches and thicker. The critical flaw depth for a circumferential part-throughwall flaw is $90 \%$ of the remaining tubing thickness, for tubing 0.025 
inches and thicker. The allowable size of circumferential flaws is relatively insensitive to variations in the wall thicknesses between 0.049 and 0.025 inches.

The critical flaw length of a throughwall axial flaw is 2.0 inches for 0.049 inch thick tubing and 0.74 inches for 0.025 inch thick tubing. Interpolation can be used to determine the critical flaw lengths for intermediate tubing thicknesses. The critical flaw depth of part-throughwall axial flaws is $85 \%$ of the remaining tubing thickness for tubing between 0.049 and 0.025 inches thick.

The IGSCC Leak Rate Model was used to calculate the tube leakage with various assumed throughwall crack sizes. For the 0.049 inch thick tubing, the crack lengths required to obtain $0.5 \mathrm{lb} /$ day leakage (the criteria for heat exchanger replacement) are between 0.3 and 0.6 inches. Since the critical flaw size is larger than the leakage flaw size, the tubing has adequate structural margins and will leak without breaking. This calculation is supported by the past 37 years of reactor operating experience in which 63 leaks were detected in the heat exchanger tubing without a double ended guillotine break.

\section{B . Wear Scar Parametric Study}

A parametric study of the critical flaw size of a wear scar was performed using ASME Code Case N-480 criteria for local wall thinning. This study demonstrates that the minimum thickness of a very small area is 0.0011 inches for normal and accident conditions (300 psig) and that the allowable thickness for a 0.02 inch transverse by 0.085 inch axial wear scar is 0.0032 inches. These calculated local thicknesses are less than the minimum thickness for gross wall thinning which is 0.0037 inches. (See V.A above)

The allowable wear scar for normal operating conditions of a tube on the cold end of the heat exchanger with a differential pressure of 110 psi was also examined. The critical thickness for a very small wear scar is 0.00065 inches and the allowable thickness for a 0.02 inch transverse by 0.085 inch axial wear scar is 0.0017 inches; whereas, the minimum thickness for gross wall thinning is 0.0022 inches.

These analyses demonstrate that for small wear scars even less tube wall thickness is required to maintain integrity than for normal design or accident conditions.

\section{HEAT EXCHANGER TUBE LEAKAGE HISTORY}

\section{A. Overview of All Leaks}

Prior to the leak in HX 4A that occurred in K-Reactor in December 1991, there had been 63 recorded instances of heat exchanger leakage since startup of the five SRS reactors in 1954-55. In most of these instances, including all of those prior to 1974, the moderator leakage rates were typically measured in $\mathrm{lbs} / \mathrm{hr}$ and are considered significant. For purposes of this report, a leakage rate is classified as "significant" if it is sufficient to cause the reactor to be shutdown immediately for isolation and repair or replacement of the leaking heat exchanger. Various measures outlined herein were implemented to eliminate these recurring problems, with the result that beginning in 1974 the predominant mode of heat exchanger tube degradation has been long-term stress corrosion cracking (SCC) of the tubes. Leakage is trended over periods of months and years and the current practice is to replace any heat exchanger at the next scheduled outage when such leakage 
reaches $0.5 \mathrm{lb} /$ day. Stress corrosion cracking is an environmental and life limiting mechanism rather than a safety problem.

\section{B . Significant Leaks and Corrective Actions}

Forty-six (46) of the 63 heat exchanger leakage incidents are classified as significant. All but one involved tube leaks and were due to a variety of causes:

Vibration against baffle plate

Structural failure (crack in 3-in. drain nozzle, Nov. 1956)

Vibration fatigue

Vibration by core rod

Wear by foreign object

Pitting corrosion

Chloride stress corrosion from neoprene seals

Unknown

As shown, most of the significant leaks were caused either by vibration of a tube against a baffle plate or by wear due to a foreign object in contact with a tube. The remaining causes were primarily isolated occurrences, for example:

- an improperly installed core rod in a tube vibrated and caused a leak in the leak collection space in 1972;

- three instances of pitting corrosion occurred in the 1976-77 time period in K and C Areas;

- a drain nozzle weld developed a crack shortly after initial startup in P Area;

- chloride from neoprene seals caused numerous tube leaks in the leak collection space on three occasions in R, P, and C Areas within a 6-month period beginning in May 1960;

- two instances of vibration fatigue occurred in 1961 and 1964.

Beginning with the first instance of tube leakage in June 1955, various corrective actions were implemented to eliminare these problems, including:

- $\quad$ plugging tubes vulnerable to vibration wear (total of 210 tubes per heat exchanger);

- reversing flow direction to extend life by retarding corrosion limitations;

- eliminating chloride-bearing elastomer seals by material substitution and design modifications;

- circulating inhibitor solution between tube sheets to retard corrosion;

- installing a cooling water inlet flow distributor plate to reduce vibration wear at the baffle plates and to capture foreign objects entrained in the cooling water;

- installing improved screens in the cooling water basin to remove foreign objects. 
The above improvements were completed by late 1966 and essentially eliminated nearly all significant leaks, the only exceptions being the improperly installed core rod in 1972 and the three cases of pitting corrosion in 1976-77. No other significant leaks occurred until the recent leak in K-Reactor in December 1991, which was caused by wear due to a foreign object.

\section{Leaks Caused by Wear Due to a Foreign Object}

As summarized above, prior to the December 1991 leak in HX 4A, there had been ten significant heat exchanger tube leaks attributed to a foreign object in contact with a tube. Six of the foreign objects were plastic bristles from brushes used to clean the screens in the cooling water basin. Other foreign objects included a welding electrode, tie rod spacer, insulated wire, and a small stone. Data for each of the ten cases are summarized in Table VI-1.

The potential for further failures due to plastic bristles was eliminated by redesigning the screen cleaning mechanism and by dissolving any bristles possibly remaining in the heat exchangers with dimethylformamide (DMF). Thus only four significant leaks caused by other foreign objects occurred over the entire SRS reactor service life until the December 1991 leak.

\section{Current Cooling Water Screening Process}

The cooling water system is designed to minimize the entry of foreign objects into the process water heat exchangers. Screens of various types are located at various points.

- River pumphouses: Three levels of screens are installed to minimize entrainment of foreign objects. A chain link fence across the mouth of the intake canal guards against very large objects. A bar screen consisting of $1 / 4$-inch rods on 3 -inch centers is located in the pumphouse intake. The bar screen in turn is backed up by traveling screens that have a 3/16-inch mesh.

- Cooling water basin: The 25 million gallon cooling water basin itself provides some capability for the settling of any heavy objects entering the basin. Sluice gates containing traveling screens with a $1 / 8$-inch mesh connect the three basin compartments to the two cooling water pumpwells. Other sluice gates contain stationary screens also with a $1 / 8$-inch mesh, but these are normally closed and are only for emergency use.

- Heat exchangers: Each of the 12 heat exchangers has a rectangular flow distributor assembly positioned inside the cooling water inlet compartment. It is located between the inner tube sheet and baffle 12,2 inches below baffle 13. This assembly consists of a circular 28-inch diameter perforated impingement plate facing the CW inlet, which is bolted in turn to a rectangular perforated flow distributor plate (Figure III-3). All perforations are 3/8-inch in diameter. This assembly is designed to spread the inlet CW flow evenly across the tube bank as well as to provide screening capability for the bulk of the CW flow. In practice, there is a clearance gap ranging up to as much as about one-inch between the rectangular distributor plate and the HX structure (shell, baffle, and tube sheet), therefore, its effectiveness as a strainer is less than ideal. The tube bank itself, with $1 / 4$-inch spacing between tubes, is even more effective as a strainer for foreign objects.

The flow distributor assemblies were first installed in the original heat exchangers during the major overhaul program during 1964-66. Since this overhaul included inverting the heat exchangers and reversing the direction of flow, the distributor assembly was installed 
in what was formerly the CW outlet compartment, therefore, it is highly unlikely that foreign objects were initially present in the new inlet. No leaks from foreign object wear subsequently occurred until the December 1991 event in K-Reactor. The object causing the wear has not been identified and it is not possible to determine when it entered HX 4A following the installation of the flow distributor assembly.

Table VI-1

Heat Exchanger Leaks Caused By A Foreign Object

\begin{tabular}{lcclcr}
$\begin{array}{l}\text { Failure } \\
\text { No. }\end{array}$ & Reactor & $\begin{array}{c}\text { Date of } \\
\text { Failure }\end{array}$ & \multicolumn{1}{c}{ Object } & $\begin{array}{c}\text { Max. Leak Rate } \\
\text { (Lbs/Hour) }\end{array}$ & $\begin{array}{c}\text { D 20 Loss } \\
\text { Total Lbs }\end{array}$ \\
\hline $2 \mathrm{P} 1$ & $\mathrm{P}$ & $2 / 17 / 56$ & Welding Electrode & 18.0 & 1500 \\
$24 \mathrm{C} 3$ & $\mathrm{C}$ & $7 / 31 / 61$ & Tie Rod Spacer & 1.8 & 32 \\
$29 \mathrm{R} 7$ & $\mathrm{R}$ & $8 / 31 / 63$ & Insulated Wire & 1.1 & 60 \\
$30 \mathrm{~K} 6$ & $\mathrm{~K}$ & $11 / 19 / 63$ & Plastic Bristle & 6.1 & 47 \\
$32 \mathrm{~L} 9$ & $\mathrm{~L}$ & $4 / 25 / 64$ & Plastic Bristle & 3.3 & 8 \\
$33 \mathrm{C} 5$ & $\mathrm{C}$ & $6 / 13 / 64$ & Plastic Bristle & 5.6 & 240 \\
$35 \mathrm{~L} 10$ & $\mathrm{~L}$ & $8 / 11 / 64$ & Plastic Bristle & 16.2 & 125 \\
$36 \mathrm{C} 7$ & $\mathrm{C}$ & $9 / 13 / 64$ & Plastic Bristle & 5.6 & 288 \\
$40 \mathrm{~K} 10$ & $\mathrm{~K}$ & $12 / 18 / 64$ & Plastic Bristle & 3.4 & 48 \\
$42 \mathrm{C} 10$ & $\mathrm{C}$ & $11 / 14 / 65$ & Stone & 6.0 & 19
\end{tabular}




\section{COMPENSATORY ACTIONS}

\section{A. Examinations of Installed K-Reactor Heat Exchangers}

\section{Examination of Cooling Water Inlets}

Subsequent to the discovery of flow distributor plate support deformation in $\mathrm{HX} \mathrm{4A}$, visual examinations of the other K-Reactor heat exchangers (References VII.1, VII.2 and VII.3) of the same manufacture and service were performed in-place in K-Reactor. These examinations revealed little or no deformation of flow distributor plate supports in those heat exchangers. The interior condition of these heat exchangers was clean with a slight to solid slime coating on the shell surfaces. Various small debris consisting of plastic pieces, PVC chunks, small steel parts, pieces of wood and rubber, leaves, clams and small rocks were also seen in the inlet of the heat exchangers.

\section{Examination of Replacement Heat Exchangers}

Five replacement heat exchangers were examined externally and internally and then leak tested. The external examinations were performed to determine if exposure to the environment during onsite storage for the last five years had initiated any adverse effects. No problems were found.

Internal examinations were performed on both the process water side and cooling water side. All of the heat exchangers contained a residue on the cooling water side that at first was described only as a thick black sticky substance. Investigation and subsequent analysis confirmed that the substance was dehydrated deionized soap. The soap was used by the vendor as a lubricant when sliding the tube bundle into the heat exchanger shell. The residue was removed and the heat exchanger wiped clean with alcohol.

In one instance a mechanical jack was found in the cooling water outlet end (below the tube bundle where an inspection port is located) of a new heat exchanger. The vendor was brought in to discuss both the soap and the jack. The jack had been inadvertently left in the heat exchanger after it was used to align the tube bundle (already attached to one tube sheet) with the other tube sheet. The shell, tubes, tube sheets, and baffles were examined for dents or other evidence of impact by the jack in the event it had bounced or slid during transportation of the heat exchanger. No evidence of damage was found.

The heat exchangers were vacuum dried prior to being leak tested using a helium leak test technique. All three of the replacement heat exchangers installed in K-Reactor passed the helium leak test acceptance criteria of $1 \times 10^{-4} \mathrm{Std}-\mathrm{cc} / \mathrm{sec}$ as indicated below:

$\begin{array}{ll}\text { Serial No. } & \text { Leakage Rate } \\ \text { D-1689-5 } & 3 \times 10^{-7} \text { Std-cc/sec } \\ \text { D-1689-3 } & 8 \times 10^{-5} \mathrm{Std}-\mathrm{cc} / \mathrm{sec} \\ \text { D-1689-7 } & 5 \times 10^{-5} \mathrm{Std}-\mathrm{cc} / \mathrm{sec}\end{array}$




\section{B. Sampling and Leakage Detection Program}

The K-Reactor sampling and leakage detection program has been upgraded to provide improved sensitivity and response to a heat exchanger tube leak. These improved requirements have been incorporated in the Plant Operating Specification (POS), as well as in revised training for the plant operators and support personnel.

The regulations and guidelines which govern the operation of the site include requirements for aqueous releases to the Savannah River. These come in several levels with respect to the severity of the event and the consequential release.

\section{Bequirements}

The following standards are used to judge the impact of a heat exchanger leak to the effluent cooling water.

\section{1) DOE Order 5480.6}

For design basis events, DOE Order 5480.6 leads to the application of Nuclear Regulatory Commission criteria. For infrequent incidents (ANS 51.1, Condition III), the criteria of 10CFR100 apply.

Heat exchanger tube rupture is an ANS Condition III design basis event discussed in the SAR. Reactor scram and AC motor trip reduces the amount of heavy water lost to well within the 10CFR 100 iimits.

\section{2) DOE Order 5400.5}

DOE Order 5400.5 limits the liquid release at the site boundary to a dose of $100 \mathrm{mrem} / \mathrm{yr}$. Experience at the Savannah River Plant has shown that this limit is much less restrictive than the EPA regulation for liquid releases directly into the Savannah River.

3) 40CFR141 - Water Pollution Control; National Primary Drinking Water Regulation; Radionuclides.

The EPA regulation on radiological contamination of drinking water limits the dose to water users to $4 \mathrm{mrem} / \mathrm{yr}$. Since two communities about 100 miles downstream from SRS use the Savannah River for drinking water, this limi: is applicable and in fact is limiting for liquid releases.

4) SRS Annual Guides.

SRS Annual Guides, ar: ALARA-driven release guides established by SRS staff based on historical data. The release guides are normally very demanding goais with very low limits on allowable release.

\section{Old Monitoring and Sampling Program}

The sampling and detection program which was in place at the time of the December 1991 heat exchanger leak consisted of the following elements and processes:

1) Cooling water sample and analysis program 
2) Cooling Water Gamma Monitor

The cooling water sample and analysis program which took samples every 12 hours, with sample analysis being completed within the next 8 hours, could detect leaks as low as $0.5 \mathrm{lb} / \mathrm{hr}$. A 0.5 $\mathrm{lb} / \mathrm{hr}$ leak could be identified and isolated in 22.5 hours.

The Cooling Water Gamma Monitor, which is only effective during reactor operation at power levels above $250 \mathrm{MW}$, can detect leaks of about $20 \mathrm{lb} / \mathrm{hr}$. A $20 \mathrm{lb} / \mathrm{hr}$ leak can be identified and isolated in 1.5 hours.

\section{Present Monitoring and Sampling Program}

With the addition of the new in-line monitor, there are three ways in which heat exchanger tube leaks are detectable:

1) The In-line Tritium Monitor

2) Cooling water sample and analysis program

3) Cooling Water Gamma Monitor

1) The In-line Tritium Monitor has a minimum reliable detectable level of about $2 \times 10^{-3}$ microCi/ml (about $20 \mathrm{lb} / \mathrm{hr}$ ) for a counting instrument setting which has an integration period of one hour. System flow delays lead to an instrument response time of 1.5 to 2 hours.

If the In-line Tritium Monitor indicates a required action, the time to isolate a leak is 3.5 hours, made up as follows:

\section{$0 \quad$ leak initiates}

$2 \mathrm{hr} \quad$ alarm from In-line Tritium Monitor

$2.5 \mathrm{hr}$ samples taken from reacior building $\mathrm{CW}$ effluent to provide redundant indication and earh CW header to locate the leak

$3 \mathrm{hr} \quad$ analysis of samples available in CCR

$3.5 \mathrm{hr} \quad$ reactor shutdown and leaking CW header isolated

A more rapid response for the In-line Tritium Monitor is available for larger leaks with a ten-minute integration. With this setting a sensitivity of about $40 \mathrm{lb} / \mathrm{hr}\left(3.6 \times 10^{-3} \mathrm{microCi} / \mathrm{ml}\right)$ is available with corresponding time to isolation of 2.5 hours.

The POS action level is set at any alarm from the In-line Tritium Monitor.

2) The cooling water sample and analysis program which takes samples every 2 hours, has a reliable sensitivity of $5 \times 10^{-5} \mathrm{microCi} / \mathrm{ml}$, corresponding to about $0.5 \mathrm{lb} / \mathrm{hr}$. This frequency was selected to ensure that more probable leaks, those with leak rates less than 10 pounds per hour, would be detected and isolated before leaking even as much total radioactivity as the larger leaks detected earlier by the in-line tritiun monitor. A $0.5 \mathrm{lb} / \mathrm{hr}$ leak can be identified and isolated in 4.5 hours. The isolation time is composed of the following actions:
$0 \quad$ leak initiates
$2 \mathrm{hr}$
$3 \mathrm{hr}$ next sample taken (per procedure to meet $3 \mathrm{hr}$ interval)
$3.5 \mathrm{hr}$ analysis of sample available in CCR samples taken from reactor building $\mathrm{CW}$ effluent and each $\mathrm{CW}$ header to provide redu dant indication and location information 
$4 \mathrm{hr} \quad$ analysis of samples available in CCR

$4.5 \mathrm{hr} \quad$ reactor shutdown and leaking CW header isolated

In the event that there is a failure to meet the specified surveillance requirements for effluent water sampling, an additional 1 hour for obtaining and analyzing a sample is permitted by the POS. This is acceptable because the grab sample system including the 1 hour delay is still equivalent to the In-line Tritium Monitor. The grab sample will catch a leak too small for the In-line Tritium Monitor to detect before 110 pounds have escaped.

By procedure, if the In-line Tritium Monitor is out of service, the frequency of effluent sampling is increased to every hour. This provides the same isolation time ( $3.5 \mathrm{hr})$ as for the In-line Tritium Monitor for leaks below $40 \mathrm{lb} / \mathrm{hr}$, with the better sensitivity of sampling analysis. Leaks above 40 $\mathrm{lb} / \mathrm{hr}$, which would be isolated an hour earlier with the In-line Tritium Monitor, are very unlikely to occur.

3) As stated earlier, the Cooling Water Gamma Monitor can detect leaks of about $20 \mathrm{lb} / \mathrm{hr}$, such that identification and isolation can be completed in 1.5 hours.

\section{Loose Parts Monitoring System}

The Loose Parts Monitor (LPM) was determined to be necessary prior to continuing power ascension testing. It is designed to monitor each of 12 heat exchangers (PW and CW inlet on each one) as well as the reactor tank (each of 6 pump suction inlet pipes) for a total of 30 monitoring points. Spare sensors and signal conditioners used by the existing VAM (Vibration Acoustic Monitor) were connected to a new computerized data acquisition system designed by SRL's Equipment Engineering Section (EES). The system has been installed since January 25, 1992. At present, "baselining" is continuing, i.e., monitoring the equipment as the reactor goes through power ascension and steady-state operation. This process will take several months before alarm thresholds can be set for voltage and frequency responses.

\section{Procedures and Training}

WSRC has aggressively pursued the review of procedures, personnel, and equipment in relationship to environmental sensitivity. Two main groups were established to review these areas and provide solutions. A Chemistry Task Group was formed to assess samples taken from effluent streams for sample frequency, sample equipment, sample basis, responsibilities, and notifications. A second team, headed by the K-Reactor Plant Manager, reviewed all routine procedures, administrative procedures, and abnormal condition control procedures. This team provided lists of procedures and recommended changes to these procedures to provide enhanced communications and sensitivity to environmental considerations. These improvements have been implemented.

Training programs have been developed and implemented for the In-line Tritium Monitoring System, a review of the Critiques and Lessons Learned, and a procedure overview for tritium sampling and leak detection. This training was given to the Reactor Shift Crew, Health Protection Department, and Laboratory Analysis personnel. Additionally, in-plant drill scenarios were written and conducted to assure that the environmental sampling program has been implemented satisfactorily. All shift personnel were trained. 
WSRC has reviewed the notification responsibilities from the initial time an event is discovered until the appropriate regulatory notifications are made. WSRC has strengthened programs associated with the Reactor Restart Division and Environmental Protection Department interface. In addition, administrative notification procedures were upgraded to ensure proper communication during the exchange of information at this interface. Training was conducted for the Environmental Spill Coordinators on the lessons learned from this event and on regulatory reportable trip points.

\section{SAFETY CONSIDERATIONS}

\section{A. Reactor Safety}

The safety margin of the K-Reactor as analyzed and detailed in the "K-Reactor Safety Analysis Report" is valid. The leak in heat exchanger $4 \mathrm{~A}$ posed no threat to the safety of the $\mathrm{K}$-Reactor, nor posed any challenge to any of the safety systems in the plant. This conclusion is supported by the tube integrity analysis, the detailed metallurgical examinations of the leaking and non-leaking tubes and the observed condition of the remainder of heat exchanger 4A.

The tube integrity analysis indicates the heat exchanger tubes can still perform their function of providing a barrier to contain the process water for all postulated transients identified in the Safety Analysis Report with a wall thickness as low as 0.0037 inch, compared to the nominal wall thickness of 0.049 inches.

The metallurgical examination of the leaking tube demonstrates the inherent strength of these tubes under these operating conditions. The tube wall was mechanically being removed by the foreign object being excited during cooling water flow. As the process proceeded, the tube wall in the area of the foreign object became thinner, and ultimately, the foreign object wore a hole in the tube and the leak occurred. The hole in the tube wall as examined did not indicate any increase in hole size due to internal pressure, which would have been evident if the tube was very highly stressed due to the reduced wall just prior to the hole emerging.

These analyses and metallurgical examinations demonstrate the inherent robustness of the heat exchangers to provide the reactor with a margin of safety that is equivalent to a commercial nuclear power reactor.

\section{B . Potential Tritium Releases}

The real consequence of this heat exchanger tube leak was the amount of tritiated water which was released to the K-Reactor outfall and eventually to the Savannah River. The operating history of the SRS reactors over the past thirty-five years of operation has shown that there have been occasional leaks from the heat exchangers which vary from small leaks to leaks in excess of $40 \mathrm{lb} / \mathrm{hr}$. To date, only 64 leakage events have occurred in over 1000 heat exchanger-years of operation.

\section{Safety Analysis Report}

The K-Reactor Safety Analysis Report (SAR) (Reference VIII.1) addresses heat exchanger leaks in Section 15.6.1. The postulated leak is a five-hour duration, $100 \mathrm{gpm}$ leak from a double-ended 
break of a single heat exchanger tube. Ultimately, this accident, as analyzed, is found not to exceed the SAR offsite dose acceptance criteria.

This scenario is acknowledged in the SAR to be very conservative since:

1) No breaks of this type or magnitude have occurred in the history of SRS operation.

2) The leak is caused by a double-ended guillotine break of an unrodded heat exchanger tube. Only 10 of the 9000 tubes in a heat exchanger are unrodded.

3) Automatic shutdown systems would scram the reactor within 5 minutes (versus the hour assumed) and the operators would then trip the $\mathrm{AC}$ motors as part of the automatic scram response. This would terminate the outflow of primary coolant to the secondary side, although isolation of the heat exchanger would still need to be accomplished.

4) No credit is given to the Cooling Water Gamma Monitors (non-safety grade), or the reactor tank level scram (limiting single failure).

The December 1991 leak would not have caused the Cooling Water Gamma Monitors to alarm or have required a reactor trip since the reactor was not operating at power. Nevertheless, it was identified and corrected with a release of primary coolant (containing approximately $5700 \mathrm{Ci}$ of tritium) which was well under the assumed $2.4 \mathrm{MCi}$ release in the SAR. Furthermore, procedures have been tightened to identify future leaks with less delay. Thus, the leak which occurred is well bounded by the current K-Reactor safety case as described in the SAR.

A very low frequency of occurrence for the SAR scenario as analyzed has been assessed and vrill be discussed in the PRA seztion below.

\section{Environmental Impact Statement}

The SRS Reactor Environmental Impact Statement (EIS) (Reference VIII.2) discusses heat exchanger leaks in Section 4.1.3.1.4. The predicted consequences of a heat exchanger leak are not explicitly calculated because this event is considered to be bounded by a DEGB LOCA of the primary system. The DEGB LOCA releases the entire coolant inventory from the primary system. The activity in this released inventory may follow several pathways out of the reactor building (stack, holding tanks, retention basin). Both the December 1991 heat exchanger leak and the postulated scenario in the SAR release much less of the reactor primary coolant inventory than the DEGB LOCA analyzed in the EIS. Thus, the safety case for operation of K-Reactor as presented in the EIS is not impacted.

\section{Probabilistic Risk Analysis}

The Probabilistic Risk Analysis (PRA) (References VIII.3 and VIII.4) for the K-Reactor discussed large heat exchanger tube leaks $(>5000 \mathrm{gpm})$. Based on site experience and information from the Reactor Materials Program, leaks of this magnitude were judged to be incredible events $\left(<<10^{-6}\right.$ per reactor year). A recent assessment of the frequency of heat exchanger leaks of approximately $50 \mathrm{gpm}$ concluded that the frequency of a leak of this magnitude (based on site experience) was also negligible ( $<10^{-6}$ per reactor year) (Reference VIII.5). Thus, the initiator frequency for the $100 \mathrm{gpm}$ leak postulated in the SAR analysis is also $<10^{-6}$ per reactor year. This is the initiating 
frequency only and does not credit subsequent shutdown and isolation activities. A heat exchanger leak of the magnitude analyzed in the SAR is therefore a very rare event.

A recent analysis of credible leak sizes (considering compound causes and multiple simultaneous tube leaks) and their probabilistic distribution of occurrence frequencies has concluded the following (Reference VIII.6):

$\begin{array}{ll}\text { HX leak size } & \text { frequency (per reactor year) } \\ >0.036 \mathrm{gpm} & 0.013 \\ >0.072 \mathrm{gpm} & 0.004 \\ >0.160 \mathrm{gpm} & 0.0005\end{array}$

The PRA is concerned with initiators which lead to accidents which may cause reactor core damage. Small leaks such as those listed above are not considered to be accident initiators. This is primarily due to the amount of time which would be necessary to allow the leak to degrade the reactor state to a point at which some automatic or manual action would be required to prevent core damage. At a $0.16 \mathrm{gpm}$ leak rate, it would be days before any action would be required to prevent core damage. Coupled with the many manual and automatic systems which would have to fail to detect the leak (Cooling Water Gamma Monitors, In-line Tritium Monitor, effluent sampling program, tank level and blanket gas scram systems, etc.), the $5 \times 10^{-4}$ per year initiating frequency for this level of leakage would cause a negligible increase in the overall K-Reactor core melt frequency. Also, as discussed previously, larger leaks from the system which would require quicker response have occurrence frequencies which make them negligible contributors to core melt frequency.

Thus, neither the December heat exchanger leak nor any subsequent analysis results change the risk analysis results for $\mathrm{K}$-Reactor.

\section{Conclusions}

It is evident from the above discussions that the December heat exchanger leak at K-Reactor falls well within the bounds set by the current safety documentation for the reactor. The scenarios postulated in the SAR and the EIS are still considered to be conservative or bounding, and there is no perceptible effect on the core melt frequencies calculated in the PRA. 


\section{REFERENCES}

II.1 WSRC-RP-92-186, "Emergency Response Monitoring Activities and Environmental Impacts of The K-Reactor Aqueous Tritium Release of December 1991," February 7, 1992.

III.1. SSD-QCM-920072, "Heat Exchangt 4 A Cooling Water Inlet Nozzle Hardware," W. S. Ehrhart, January 28, 1992.

III.2. RRD-PSI-920005, "Safety Considerations Relevant to Deformation of Strainer Supports in Cooling Water Inlet of Process Heat Exchangers," J. M. Morrison, et al., January 17, 1992.

III.3. Memorandum, "Reactor Heat Exchanger - Relative Strength of Internal Components Subjected to Differential Pressure Loading (U)," J. P. Veldman, March 13, 1989.

III.4. SRL-MTS-921021, "Load Capacity of the PWS Heat Exchanger Inlet Strainer Supports (U)," G. E. Mertz, January 24, 1992.

III.5. SRL-MTS-921026, "A Comparison of the 4A Heat Exchanger Inlet Strainer Deformadion to Finite Element Results (U)," R. F. Miller, January 31, 1992.

III.6. NES-ETH-920012, Revision 1, "Pressure Drop Across the Shell Side HX Inlet Distributor (U)," M. R. Duignan, February 18, 1992.

V.1. WSRC-TR-92-72, "Savannah River Reactor Process Water Heat Exchanger Tube Structural Integrity Margin," G. E. Mertz, D. M. Barnes and R. L. Sindelar, February 1992.

VII.1. SSD-QCM-920071, "Heat Exchanger 4B Cooling Water Inlet Nozzle Hardware," W. S. Ehrhart, January 28, 1992.

VII.2. SSD-QCM-920074, "Heat Exchanger 3B Cooling Water Inlet Nozzle Hardware," W. S. Ehrhart, January 28, 1992.

VII.3. SSD-QCM-920081, "Heat Exchangers 1A, 2A, 2B, 3A, 5A and 5B Cooling Water Inlet Nozzle Hardware," W. S. Ehrhart, January 30, 1992.

VIII.1. Savannah River Site K-Reactor Safety Analysis Report, Westinghouse Savannah River Co., Aiken, SC, Amendment 2, November, 1991.

VIII.2. DOE/EIS-0147, Final Environmental Impact Statement; Continued Operation of K-, L-, and P-Reactors, U. S. Department of Energy, December, 1990.

VIII.3. WSRC-RP-89-570, Savannah River Site Probabilistic Risk Analysis of Reactor Operation, Level 1 Internal Events, Westinghouse Savannah River Co., June, 1990.

VIII.4. WSRC-RP-89-570, Savannah River Site Probabilistic Risk Analysis of Reactor Operation, Level 1 External Events, Westinghouse Savannah River Co., June, 1990. 
VIII.5. SRL-PRA-910054, "Estimates of the Frequency of Leaks in the Heat Exchanger Tubes Using a Lognormal Distribution Fit to Site Data for Small Leaks," D. S. Cramer, February 28, 1991.

VIII.6. WSRC-TR-92-96, "Probability of Heat Exchanger Leaks", D. S. Cramer, E. P. Shine, W. J. Copeland, February 28, 1992. 


\section{APPENDIX 1}

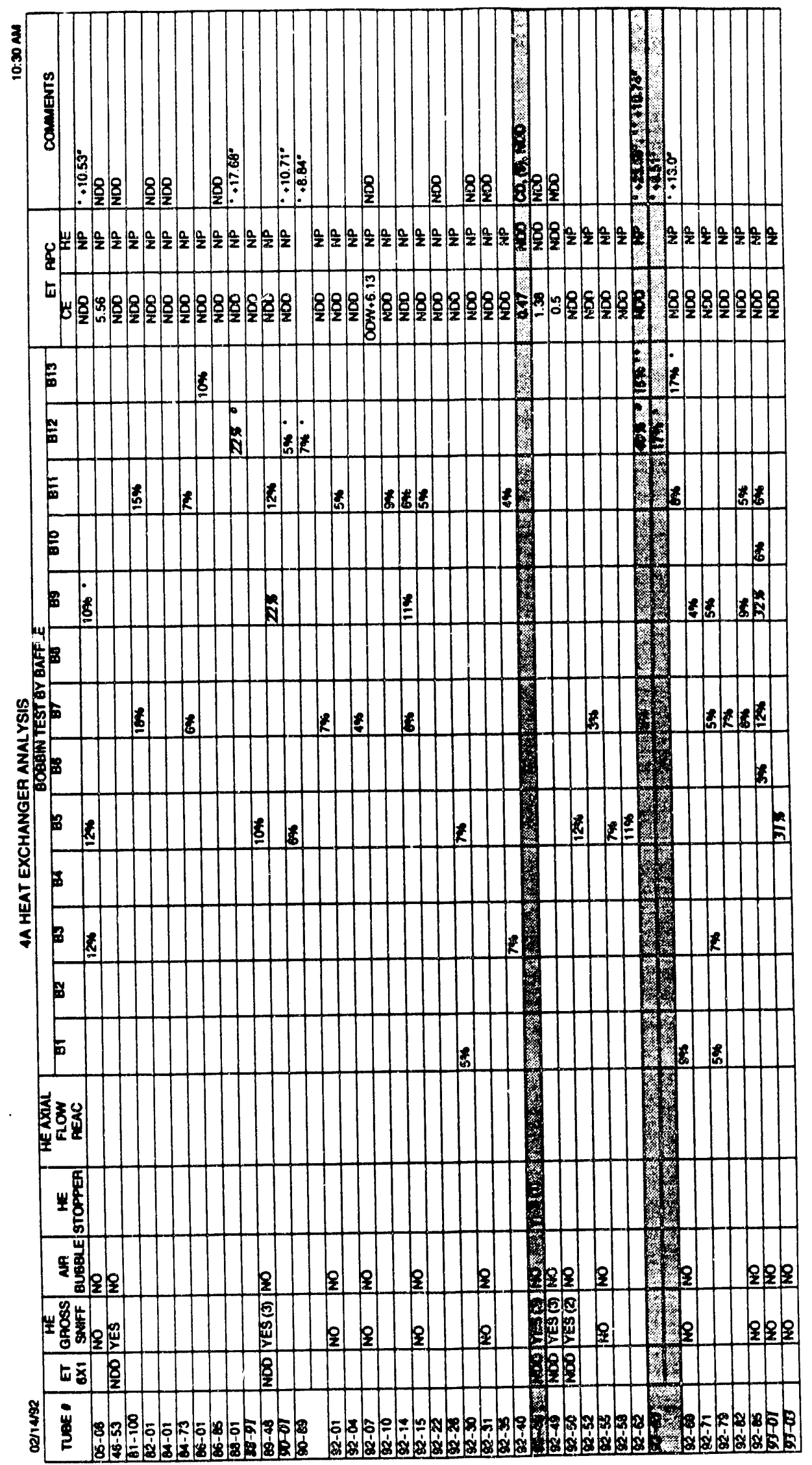


APPENDIX 1 (Cont.)






\section{APPENDIX 1 (Cont.)}

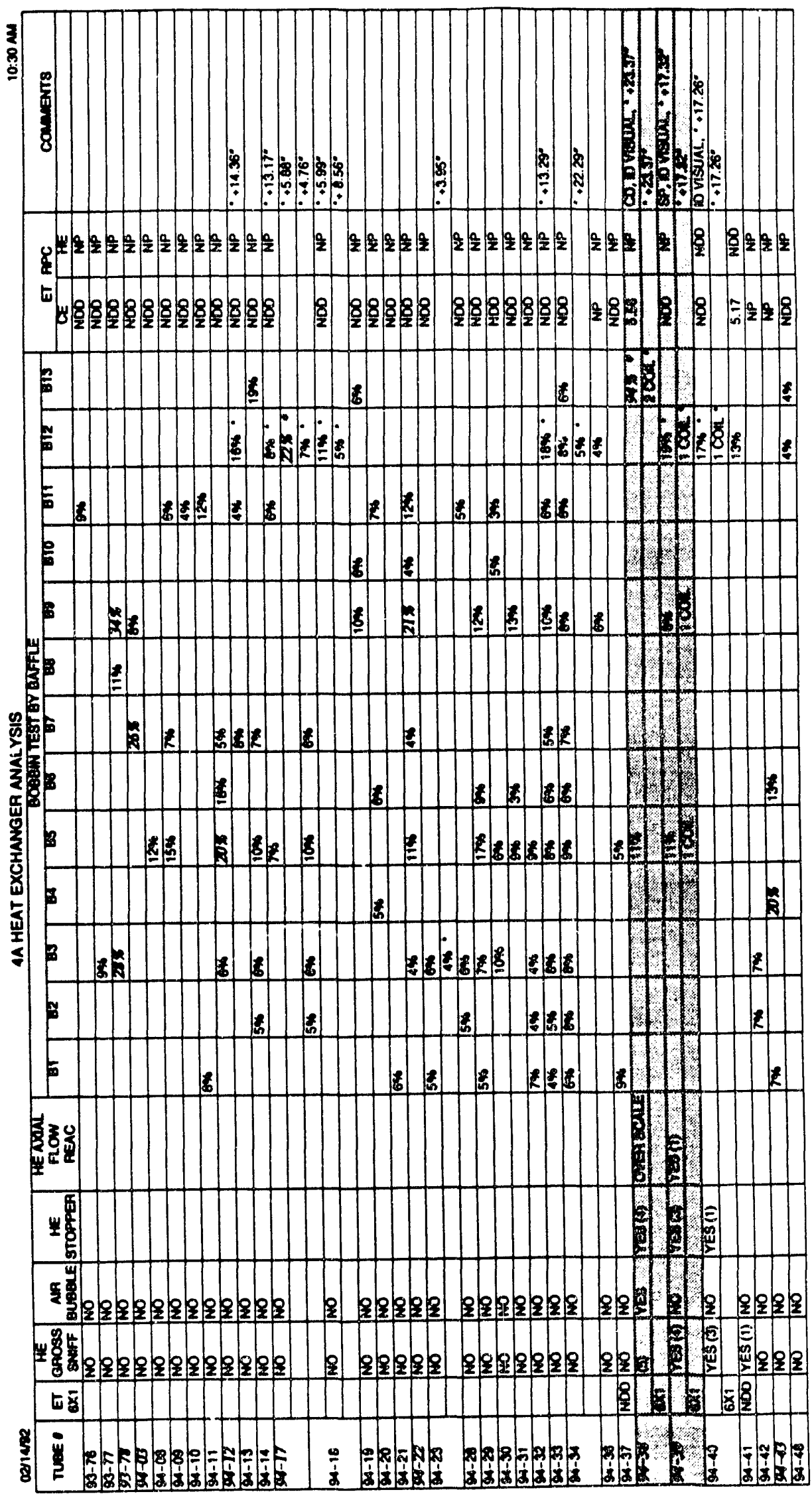


APPENDIX 1 (Cont.)

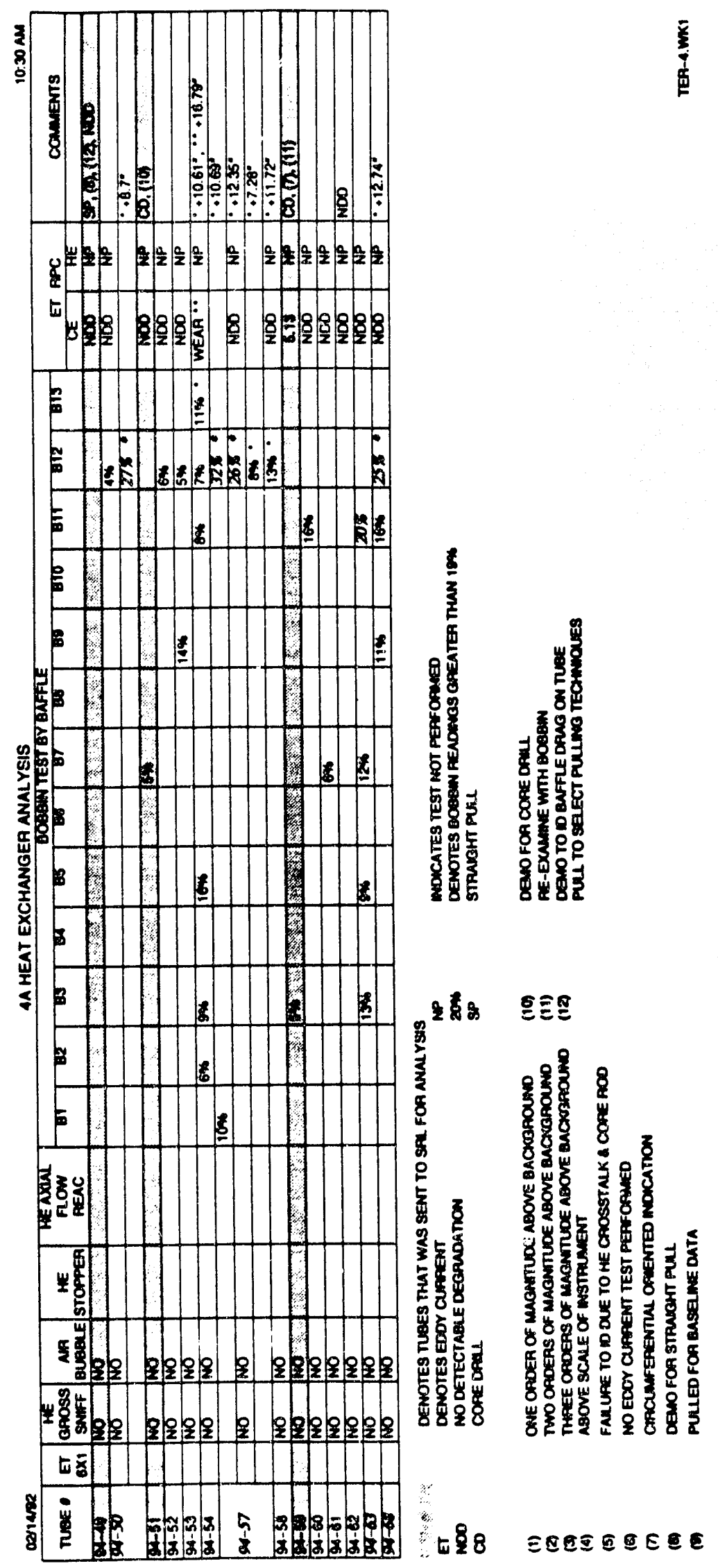




\section{APPENDIX 2}

COLUMN $\longrightarrow$
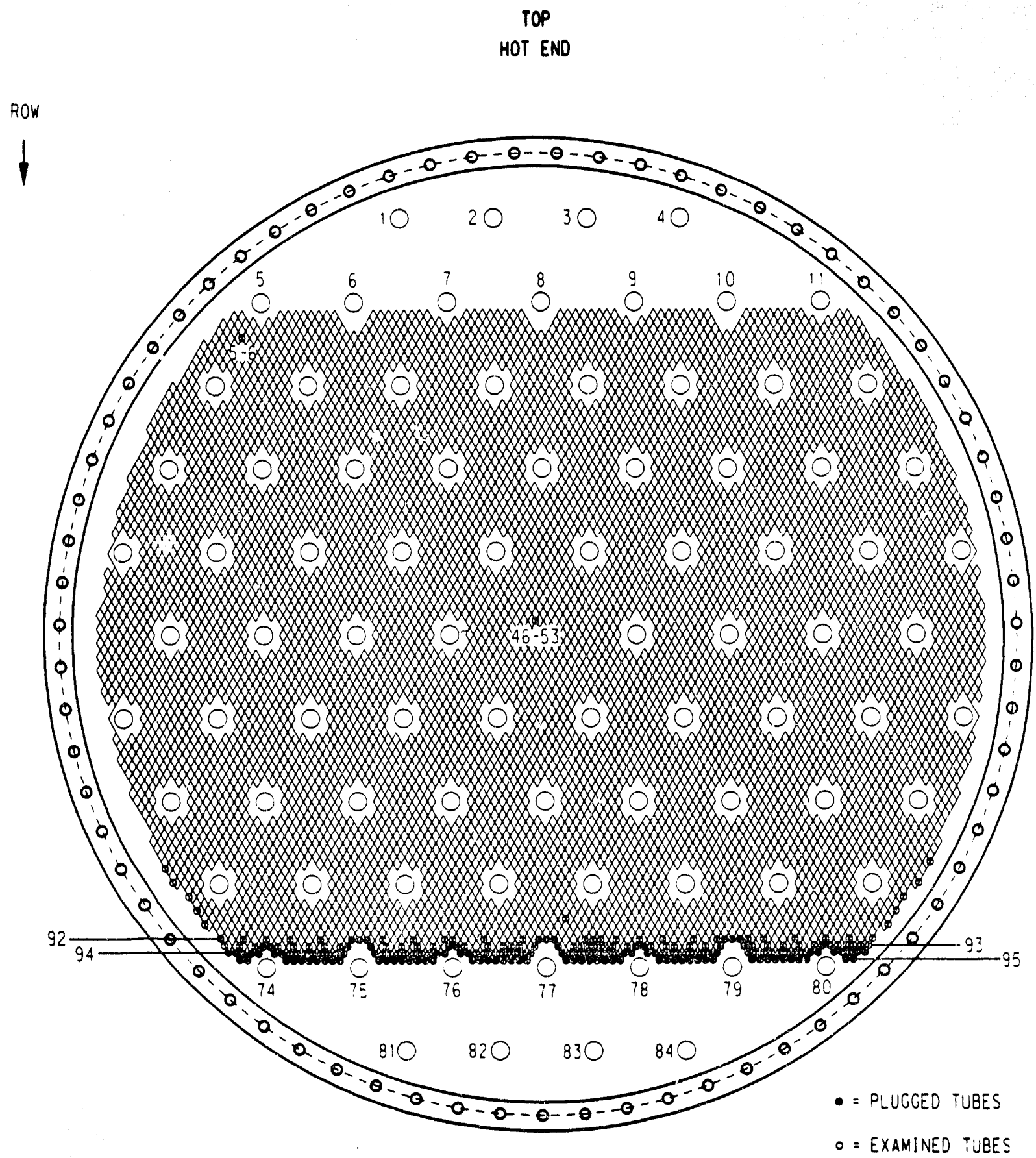


\section{APPENDIX 2 (Cont.)}

COLUMN

ROW

1

HOT END

TOP

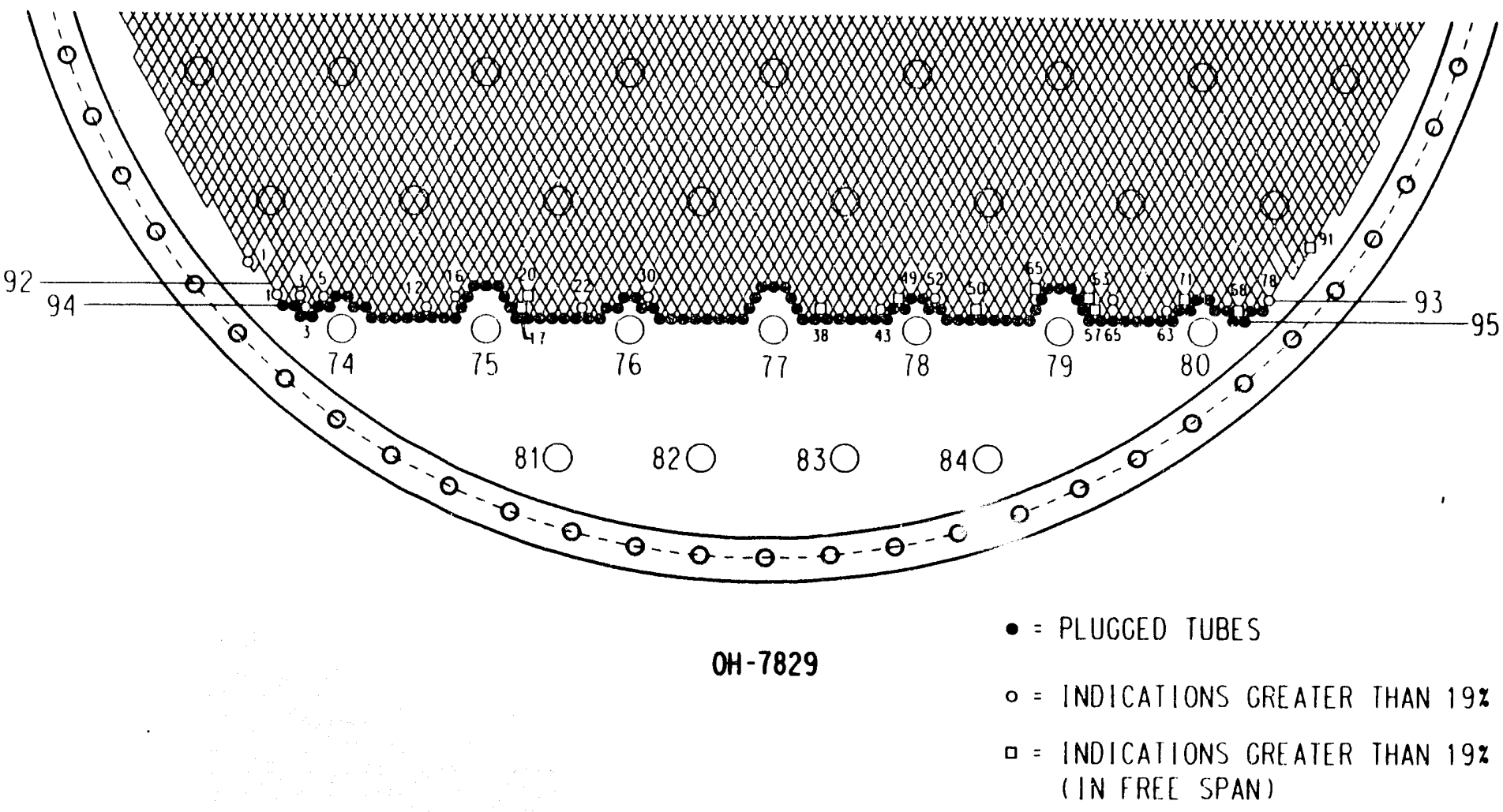




\section{APPENDIX 2 (Cont.)}

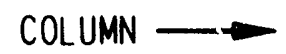

ROW

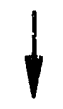

COLD END

TOP

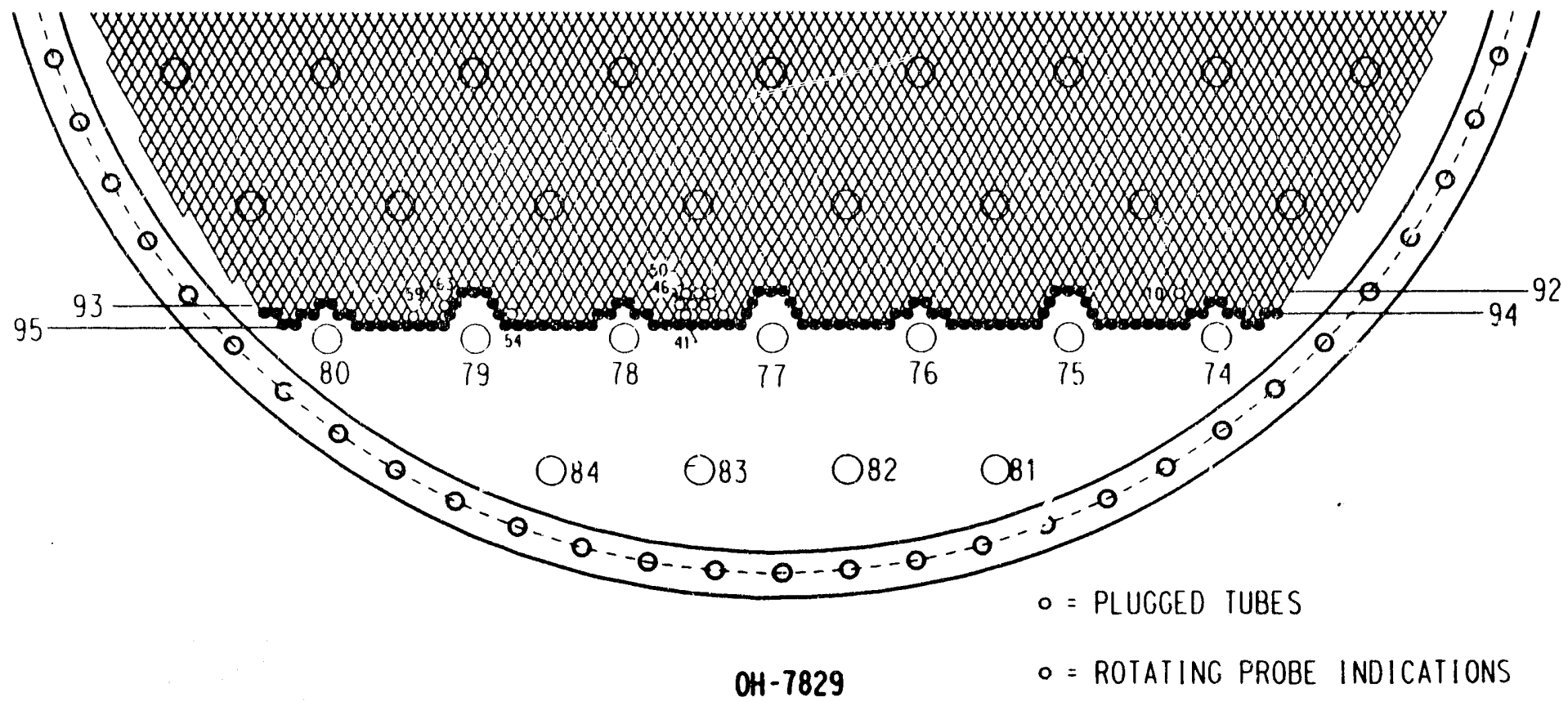




\section{APPENDIX 2 (Cont.)}

COLUMN

ROW

1

\section{COLD END}

TOP

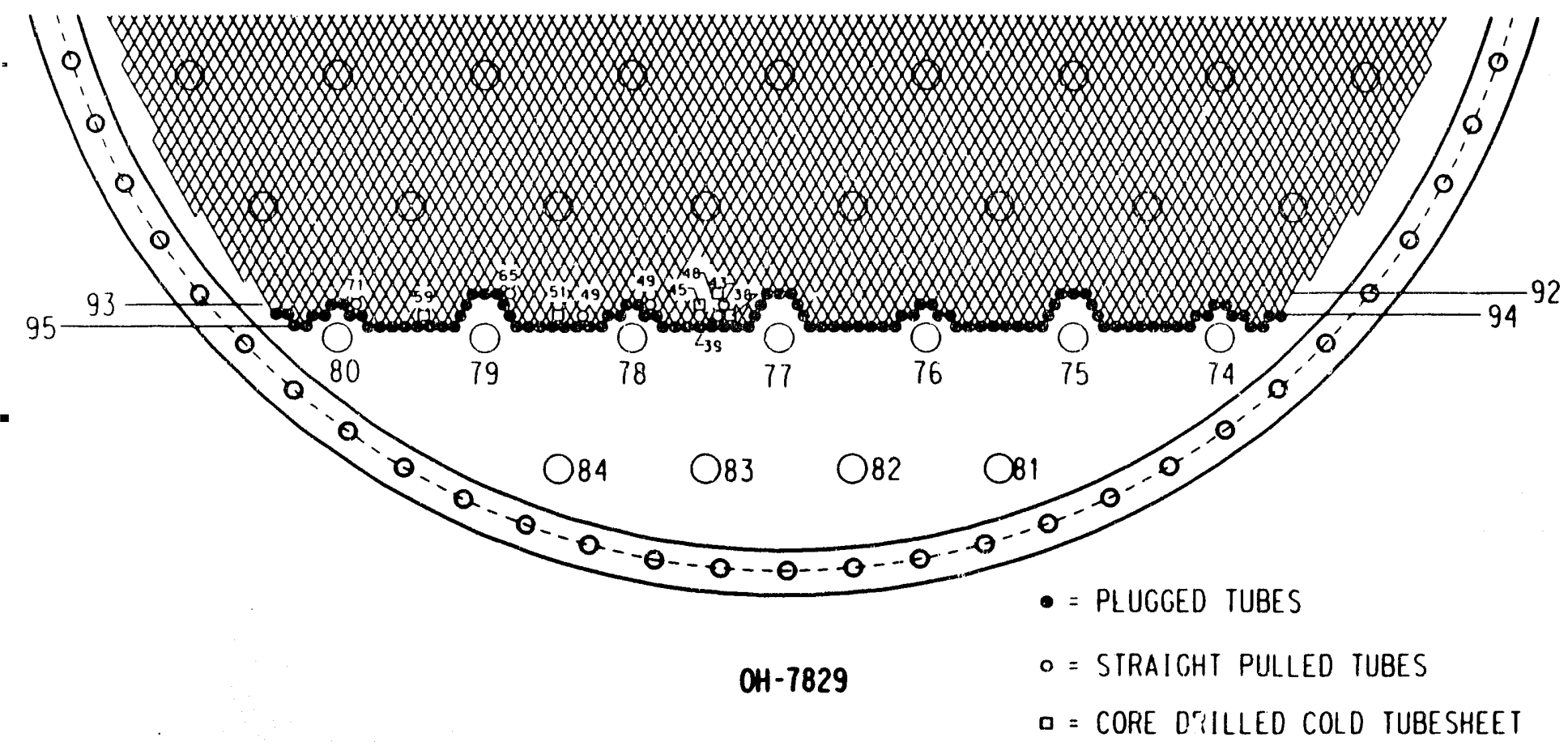




\section{APPENDIX 3}

\section{Westinghouse Savannah River Company \\ Inter-Office Memorandum}

SRL-MTS-920032

March 5, 1992

TO:

R. T. BEGLEY, 773-A

FROM:

D. Z. NELSON, 773-A

J. D. SCARBROUGH, 730-A

M. R. LOUTHAN, JR., 773-A

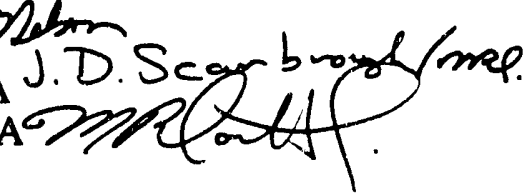

\section{METALLOGRAPHIC EVALUATION OF TUBES FROM K-REACTOR HEAT EXCHANGER 4A}

\section{SUMMARY}

This report summarizes metallographic data and analysis which demonstrate that the December 22, 1991, release of tritiated moderator from K-reactor heat exchanger 4A was caused by a single hole in tube 94-38 of that heat exchanger. The hole was formed by vibratory wear which initiated when a yet unidentified foreign object, in the secondary cooling water system, moved past the bottom row of tubes (these bottom row, or row 95, tubes are plugged), pressed against tube 94-38 and against the inner tube sheet and vibrated approximately perpendicular to the tube axis. The surface of the foreign object which was parallel to the tube axis was approximately 0.8 inches long. Vibration of this surface against the tube, reduced the wall thickness and produced a 0.8 by 0.3 inch wear scar which included a rectangular hole in the tube. This hole was approximately 0.02 by 0.085 inches with the 0.085 inch dimension parallel to the tube axis. The moderator that passed through this hole mixed with the secondary cooling water and caused the tritium release.

The metallurgical condition of other sections from this tube and sections from other tubes removed from this heat exchanger was excellent, except in areas of localized tube wear. No evidence of microbiologically influenced corrosion (MIC), intergranular attack, pitting, crevice corrosion or stress corrosion cracking were observed. The tube wear was typically induced by debris in the secondary cooling water side of the heat exchanger; however, limited tube wear and burnishing was seen in tube walls beneath certain baffles.

The metallurgical investigation has focused on tubes which were removed from the heat exchanger because of eddy current indications. Therefore, except for tube 93-43 which was selected as a baseline tube because of the lack of eddy current indications, the tubes characterized should represent worse case conditions in the heat exchanger. Furthermore, the eddy current inspection concentrated on tubes at, or near, the periphery of the tube bundle and immediately over the 


\section{APPENDIX 3}

secondary cooling water inlet. This area was selected for inspection because operating history has shown that the probability of foreign object wear is highest in that region of the heat exchangers.

The metallurgical characterizations determined specifically:

a) that recently active tube wear, induced by a foreign object on the shell side of the heat exchanger, was associated with the leak and leak area,

b) that baffle induced wear and surface burnishing were the cause of eddy current indications in tube regions immediately beneath baffles. (The tarnish films in these areas showed that the one case of baffle induced wear had been present for years and that surface burnishing processes had recently been active.),

c) that minor surface scratches and imperfections were the cause of eddy current indications at tube-to-tube sheet interfaces,

d) that recently active, localized, foreign object induced wear on the shell side of tubes 92-65 and 93-49 was the cause of eddy current indications remote from the baffles,

e) that wear induced by the core rod was the cause of inner surface eddy current indications on tube 93-71, and

f) that the eddy current inspections provided conservative estimates (over predictions) of the extent of tube wear and degradation.

These metallurgical evaluations revealed no evidence of stress corrosion cracking at tube-totube sheet interfaces. This observation is consistent with the lack of moderator leakage from the heat exchanger prior to the December 22, 1991, release. These results also demonstrate that stress corrosion cracking did not contribute to the December 22 incident.

Moderator leakage due to tube wear, induced by foreign objects on the shell side of the SRS heat exchangers, has been an infrequent event throughout the reactor operating history (eleven occurrences in over one thousand heat exchanger years of operation at SRS). However, until the December 22 event, wear induced leakage had not been noted since 1965. Because of this operating history and because non-leaking, recently active, foreign object induced wear was observed on several tubes from heat exchanger $4 \mathrm{~A}$, the occurrence of a wear induced leak in another K-reactor heat exchanger cannot be discounted and the timing for that postulated leak cannot be predicted. However, if such leakage were to reoccur, the recently revised monitoring programs and procedures are designed to assure early identification and should minimize the quantity of moderator released.

\section{BACKGROUND}

The leak in tube 94-38 in K-reactor heat exchanger 4A was located by leak checking the entire tube bundle and eddy current examination of selected tubes in the vicinity of the leak. Ten tubes, in a region adjacent to the leaking tube, Figure 1, did not contain core rods. (Core rods were inserted in tubes to reduce the inventory of heavy water required for reactor operations and to improve heat transfer.) This lack of core rods in a ten tube bundle adjacent to the leaking tube complicated the initial helium leak tests. 


\author{
WSRC-TR--92-097-Rev. 1 \\ DE93 004301
}

\title{
RRTD
}

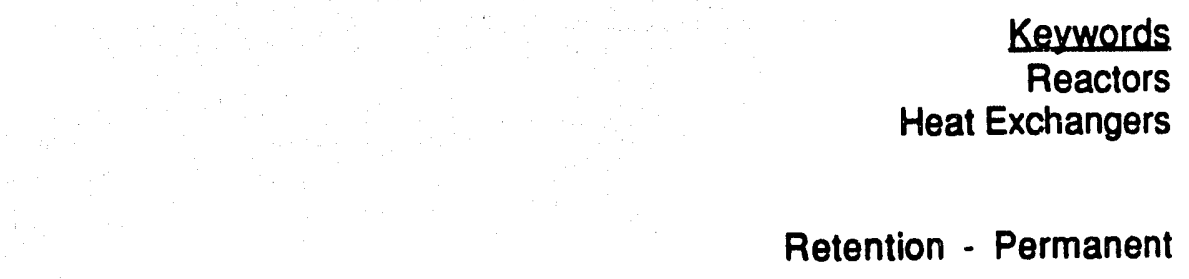

Heat Exchanger Restart Evaluation (U)

\author{
J. M. Morrison \\ C. W. Hirst \\ T. F. Lentz \\ Reactor Restart Technical Director Department
}

Issued: March 18, 1992 
DOCUMENT:

TULL:

DATE:

APPROVALS:
WSRC-TR-92-97, REVISION 1

HEAT EXCHANGER RESTART EVALUATION (U)

MARCH 18, 1992

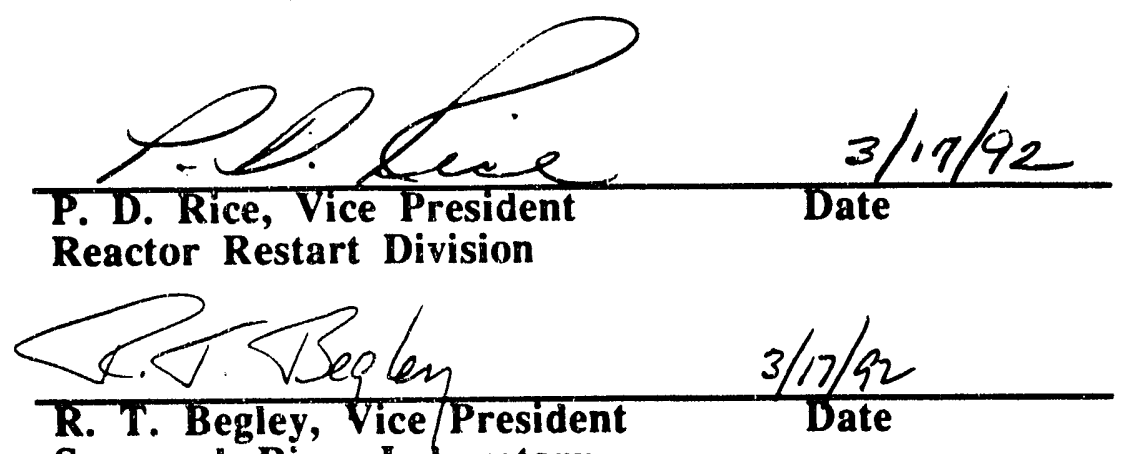

Savannah River Laboratory 
Document No.: WSRC-TR-92-97

Bevision

1

$\frac{\text { Page No. }}{3}$

1

1

14

1

1

1

6

40-73
Rev. No.: 1 Issue Date:

$3 / 18 / 92$

\section{Description of Revision}

Added paragraph beginning at bottom of page, noting a possible but unconfirmable increase in tendency for wear due to foreign objects. This possibility is a result of the lack of evidence of old wear scars, whereas three tubes showed evidence of recent wear.

Expanded third paragraph to provide additional detail concerning the $19 \%$ threshold for eddy current indications.

Added paragraph near the top discussing the lack of confirmation by the metallurgical examinations of a defect or leak near the middle of Tube 94-39, as had been indicated by the early helium leak tests.

Editorial correction in first paragraph.

Editorial corrections in first and third paragraphs in Section B.
Added Appendix 3, containing complete results of the metallurgical failure analysis program. 


\section{ACKNOWLEDGMENT}

This report in large measure reflects the efforts of a number of Westinghouse Savannah River Company technical personnel. The authors particularly wish to express their appreciation for the contributions provided by:
A. L. Boni
M. D. Brandyberry
G. L. Cauthen
C. D. Cowfer
J. F. Jordan
M. W. Loibl
M. R. Louthan
A. F. McFarlane
G. E. Mertz
J. D. Scarbrough

Additionally, expert consultation was provided by J. A. Begley, J. E. Esposito, and A. A. Raimondi of the Westinghouse Electric Corporation, Pittsburgh, PA. Finally, the efforts of P.S. Coffey in preparing the manuscript are gratefully acknowledged. 


\section{TABLE OF CONTENTS}

I. Introduction $\quad 3$

II. Executive Summary 3

III. Examination of Heat Exchanger 4A

A. Identification of Leaking Tube \& Subsequent Examination

B. Additional Examinations of Heat Exchanger 4A 6

IV. Metallurgical Examinations

A. Leaking Tube (94-38) 10

B. Non-Leaking Tubes 13

V. Tube Integrity Analysis

A. Analysis Per NRC Regulatory Guide 1.121 18

B. Wear Scar Parametric Study 19

VI. Heat Exchanger Tube Leakage History

$\begin{array}{llr}\text { A. } & \text { Overview of All Leaks } & 19 \\ \text { B. Significant Leaks and Corrective Actions } & 21 \\ \text { C. Leaks Caused by Wear Due to A Foreign Object } & 21 \\ \text { D. } & \text { Current Cooling Water Screening Process } & 21\end{array}$

VII. Compensatory Actions

A. Examinations of Installed K-Reactor Heat Exchangers 23

B. Sampling and Leakage Detection Program 24

C. Loose Parts Monitoring System 26

D. Procedures and Training 26

VIII. Safety Considerations

$\begin{array}{ll}\text { A. } & \text { Reactor Safety } \\ & 27\end{array}$

B. Potential Tritium Releases 27

$\begin{array}{ll}\text { IX. References } & 30\end{array}$

Appendix 1 Heat Exchanger 4A Examination Results 32

Appendix 2 Heat Exchanger 4A Tubesheet Inspection Maps 36

Appendix 3 SRL-MTS-920032, "Metallographic Evaluation of Tubes From K-Reactor 40 Heat Exchanger 4A" 


\section{INTRODUCTION}

On December 24, 1991, the K-Reactor was in the shutdown mode with full AC process water flow and full cooling water flow. Safety rod testing was being performed as part of the power ascension testing program. The results of cooling water samples indicated tritium concentrations higher than allowable. Further sampling and testing confirmed a Process Water System to Cooling Water System leak in heat exchanger 4A (HX 4A). The heat exchanger was isolated and the plant shutdown. Heat exchanger $4 \mathrm{~A}$ was removed from the plant and moved to C-Area prior to performing examinations and diagnostic testing. This included locating and identifying the leaking tube or tubes, eddy current examination of the leaking tube and a number of adjacent tubes, visually inspecting the leaking tube from both the inside as well as the area surrounding the identified tube. The leaking tube was removed and examined metallurgically to determine the failure mechanism. In addition ten other tubes that either exhibited eddy current indications or would represent a baseline condition were removed from heat exchanger 4A for metallurgical examination. Additional analysis and review of heat exchanger leakage history was performed to determine if there are any patterns which can be used for predictive purposes. Compensatory actions have been taken to improve the sensitivity and response time to any future events of this type. The results of these actions are summarized herein.

\section{EXECUTIVE SUMMARY}

The leak that occurred in heat exchanger 4A in K-Reactor released an estimated total of 5700 curies (Ci) of tritium, as tritiated water, to the Savannah River. The leak took place over a period of about 60 hours during December 22-25, 1991. A hypothetical individual located at the U. S. Highway 301 bridge over the river (about 20 miles south of the plant site), consuming 2 liters of river water per day for the duration of plume passage, would have received a dose from drinking the water of approximately $0.035 \mathrm{mrem}$ (Reference II.1). This is less than one one-hundredth of the EPA drinking water standard of $4 \mathrm{mrem} / \mathrm{yr}$. The leak in HX 4A posed no threat to the integrity and safety of the K-Reactor. The reactor was not operating, safety systems were not challenged, and the leak is well bounded by the current Safety Analysis Report.

An aggressive program was implemented immediately upon confirmation of the leak to determine its cause and significance to the integrity of the remaining heat exchangers in $\mathrm{K}$-Reactor. Heat exchanger $4 \mathrm{~A}$ was removed from the reactor system together with $\mathrm{HX} 4 \mathrm{~B}$ and $\mathrm{HX} 3 \mathrm{~B}$ which had shown slight indications of leakage throughout the last 2 years of plant operation but were well within acceptance criteria. All three heat exchangers, which were of the original SRS design, were replaced with new units of improved design and which passed leak testing criteria.

Heat exchanger 4A was staged to facilities in C-Area for investigation. The cause of the leak was determined to be wear of one of the 9000 stainless steel tubes (tube 94-38) located immediately adjacent to the inner tubesheet at the moderator outlet/cooling water inlet (cold) end of the heat exchanger. The wear had been caused by an unidentified foreign object rubbing against the outside (OD) of the tube, transverse to its axis. This wear had continued until a small rectangular hole 0.020 inches wide by 0.085 inches long opened up in the tube wall to cause the leak. An additional sample of 122 tubes near the bottom of the heat exchanger was examined with eddy current (ET) to determine their overall condition. Ten of these tutes were removed for further testing to quantify eddy current indications of wear and other modes of degradation. The damage site was localized and no indication of any contributing corrosion effects were found.

Wear scars were observed which were recently active and caused by the action of foreign objects against three tubes from HX $4 \mathrm{~A}$ tube bundle. No evidence of old, foreign object induced wear 
was noted. These observations suggest a possible increase in the tendency for wear in the peripheral tubes near the cooling water inlet. This suggestion is consistent with the fact that moderator leakage due to foreign object induced wear of heat exchanger tubing had not occurred since 1965. However, the data necessary to prove this suggestion are not available and neither the past or the present rate nor the frequency of foreign object induced wear can be predicated from the present observations.

Examination of the rectangular perforated flow distribution plate, which acts as a strainer in the cooling water inlet compartment of $\mathrm{HX} 4 \mathrm{~A}$, showed that some of the supports were significantly deformed. The cause of the deformation, which had no apparent physical connection to the tube leak, was investigated and is believed to have resulted from difficulties with its installation in 1965. The other K-Reactor heat exchanger distributor plate supports have been examined and none are deformed to any significant extent.

Only 10 leaks caused by a foreign object in the heat exchangers had occurred at SRS prior to the incident in December 1991. They occurred between 1956 and 1965. Six of them were caused by plastic bristles from brushes formerly used to clean the stationary screens in the cooling water basin. The brushes were eliminated long ago, hence, the type of tube wear that occlurred in HX 4A had actually been experienced only four times previously. Further, the SRS cooling water system is designed to minimize the likelihood of leaks caused by foreign objects entrained in the cooling water. The system includes three level of screens at the river pumphouses, traveling screens in the cooling water basin, stationary screens in the cooling water basin for emergency use, and the flow distributor plate in each heat exchanger. Nevertheless, some debris can still enter the heat exchanger as a result of screen damage, maintenance openings, etc. Further, a Loose Parts Monitoring System has been installed with sensors on each heat exchanger and is undergoing baselining to determine if additional early warning of impending leaks caused by foreign objects can be achieved.

Nonetheless, the possibility of future leaks from this or other causes cannot be eliminated. An aggressive program was therefore undertaken to upgrade the cooling water effluent monitoring capability to reduce the potential for release of tritiated water in the future. A new, state-of-the-art in-line tritium monitor was installed in the K-Reactor outfall. The frequency of effluent grab sampling was increased from once per 12-hour shift to once every 2 hours, and the tritium analysis instrumentation was relocated to the K-Reactor Building to reduce the time required to transport samples to the analytical laboratory. Corresponding changes were made to reactor operating procedures and operations personnel have been trained in their use. Overall, these upgrades should permit approximately a 20 fold reduction in tritium released should a similar size leak such as experienced in $\mathrm{HX} 4 \mathrm{~A}$ occur in the future.

Based on the above, the K-Reactor heat exchangers are considered in satisfactory condition for resumption of normal hydraulic operations. Briefly, this conclusion reflects:

- Reactor safety is not an issue because the December 1991 leak is much less than the design basis accident tube leak.

- The leak in HX 4A was within the envelope of SRS experience and was caused by a low probability event rather than by a generic, predictable mode of degradation.

- The cooling water system is designed to minimize the potential occurrence of leaks of this type. 
- The inlet flow distributor plates of the heat exchangers now installed in K-Reactor have been examined and are in satisfactory condition.

- $\quad$ All of the traveling screens in the cooling water basin have been examined and overhauled within the past two years. The cooling water basin is regularly drained and cleaned at extended outages.

- The tritium moniroring system in the cooling water effluent has been significantly upgraded, including installation of a state-of-the-art in-line tritium monitor, to improve sensitivity and response time to potential events. Corresponding improvements in procedures have been made and operators have been trained in their use.

- Except for the extent of wear in the tube that leaked and in two other tubes, the metallurgical condition of the rubing in $\mathrm{HX} 4 \mathrm{~A}$ is considered excellent.

\section{EXAMINATION OF HEAT EXCHANGER 4A}

\section{A. Identification of Leaking Tube \& Subsequent Examination}

The leaking tube was identified by combinations of helium and pneumatic testing using a bubble solution. Eddy current (ET) examination was the principal NDE method used to characterize the failure. The nature of the failure, its location and configuration were also characterized and recorded by remote visual means. Figure III- 1 is a picture of the hole taken by a video examination from the ID of the tube. The bobbin coil and rotating pancake coil (RPC) eddy current techniques were used. The bobbin coil identified an essentially throughwall indication and the RPC characterized the failure precisely in a three dimensional display. The location of the failure on the tube axis was correlated by further ET, helium leak test, and visual examination. This information was used to select a tube removal technique which would assure preservation of the failure for subsequent metallurgical evaluation.

\section{Figure III-1}

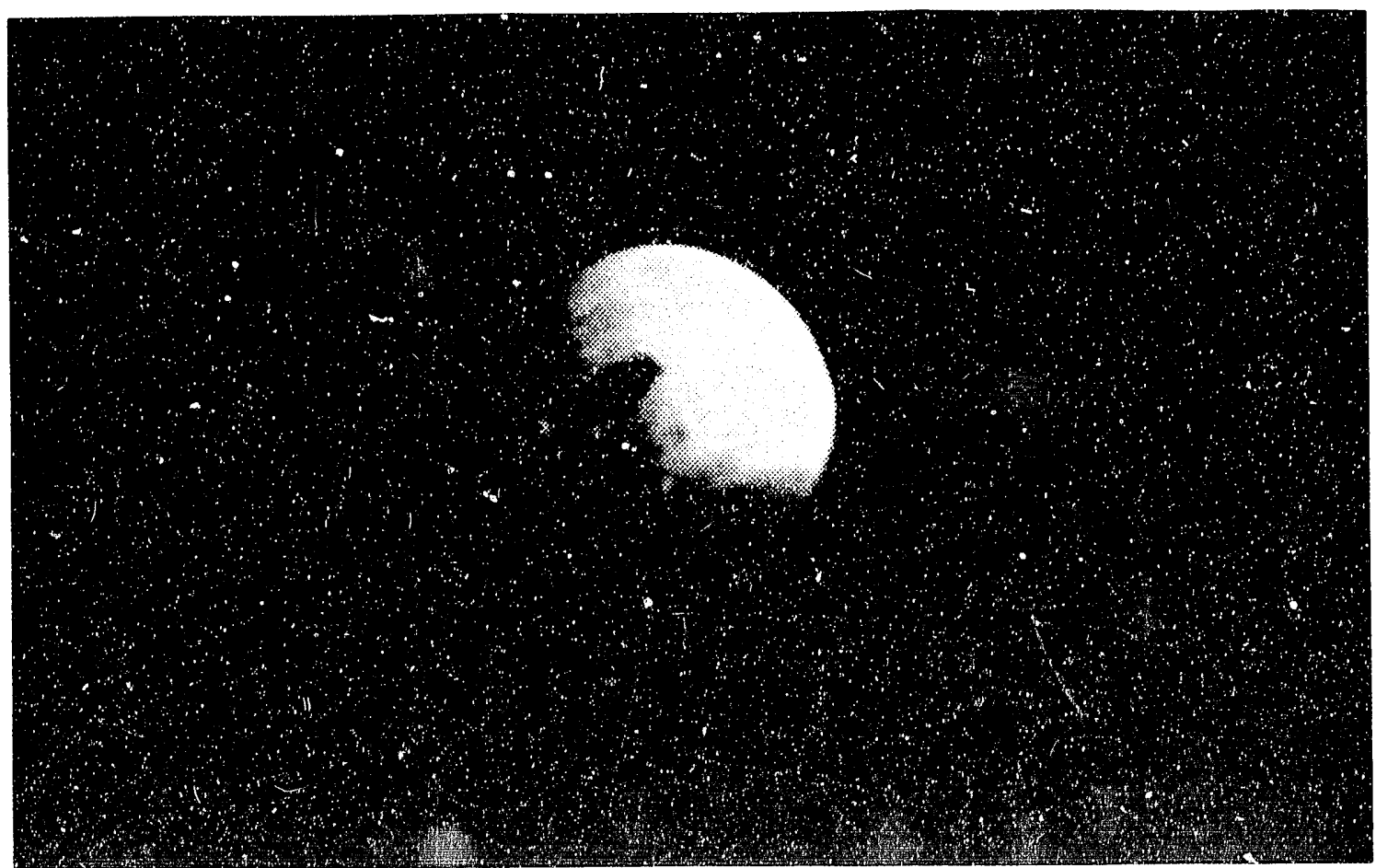




\section{B . Additional Examinations of Heat Exchanger 4A}

\section{Eddv Current Examinations of Additional Tubes}

An eddy current examination program was performed on 122 tubes in the leaking heat exchanger (Serial \# OH-7829). The purpose of the examination was to confirm the identification of the leaking tube. In addition the examinations were utilized to determine tube wear condition in the heat exchanger cooling water inlet region. The results of the examinations are annotated in Appendix 1.

The eddy current was accomplished utilizing three techniques, "bobbin," "6 by 1 ," and "rotating pancake coil (RPC)." The bobbin probe is most sensitive to axial indications. The " 6 by 1 " probe is used to locate and characterize circumferential indications. This is mainly a qualitative type of examination intended to flag indications of flaws. The "6 by 1" technique is not used to quantify the depth of the indication or its source. The rotating pancake coil is motor driven and rides along the ID surface of the tube. It is very sensitive to tube wall degradation and other anomalies and gives an excellent pictorial display of the examination results, Figure III-2. While the bobbin and "6 by 1" were utilized for the full tube length, the RPC technique was used to examine approximately 15 " into the hot or cold end of the tube bundle. In all cases calibration standards with simulated defects (wear, circumferential notches and drilled holes) were utilized to quantify indications of degradation.

Appendix 2 contains additional figures which show the location of the tubes examined by eddy current, tubes with bobbin probe indications greater than 19 percent, tubes with indications from the RPC probe, and a figure showing the tubes that were pulled for metallurgical examination. Indications greater than $19 \%$ (i.e., at least $20 \%$ ) are displayed because with only one exception, all eddy current indications less than $20 \%$ appeared to be caused by work hardening associated with surface burnishing rather than actual wear.

\section{Cooling Water Side Video Examination}

Remote visual examinations of heat exchanger $4 \mathrm{~A}$ shell side were conducted to assess debris and to locate the object(s) which caused wear observed on the leaking tube and two (2) other tubes with wear identified by ET. The foreign object which caused the leak has not been located. Efforts to locate this item included core drilling an access to the top of the cooling water flow distributor plate and subsequent removal of the distributor plate.

The video records document the fact that debris exists in the shell or $\mathrm{CW}$ side of heat exchangers. The video records also show that the bottom outer row of heat exchanger tubes (taken out of service by welded plugs) provides a backup filter to the flow distributor plate, because the $1 / 4$ inch spacing between tubes acts to limit large foreign object access to the outer rows of tubes.

Visual examination of the cooling water inlet nozzles on the heat exchanger cooling water inlet compartment revealed scale build up and other debris, which had partially plugged the perforated flow impingement plate and flow distributor plate. Thirty (30\%) to $40 \%$ of the flow impingement plate (not to be confused with the flow distributor plate) holes were plugged with debris. PVC pipe fragments and other debris trapped by the cooling water flow distributor plate were also present.

A thorough examination of the material removed from the heat exchanger revealed that it consisted of approximately one pound of loose debris that included scale, clams, rust, leaves, and small stones. Foreign objects also included two pieces of PVC pipe approximately 3 to 4 inches long, a 
Figure III-2

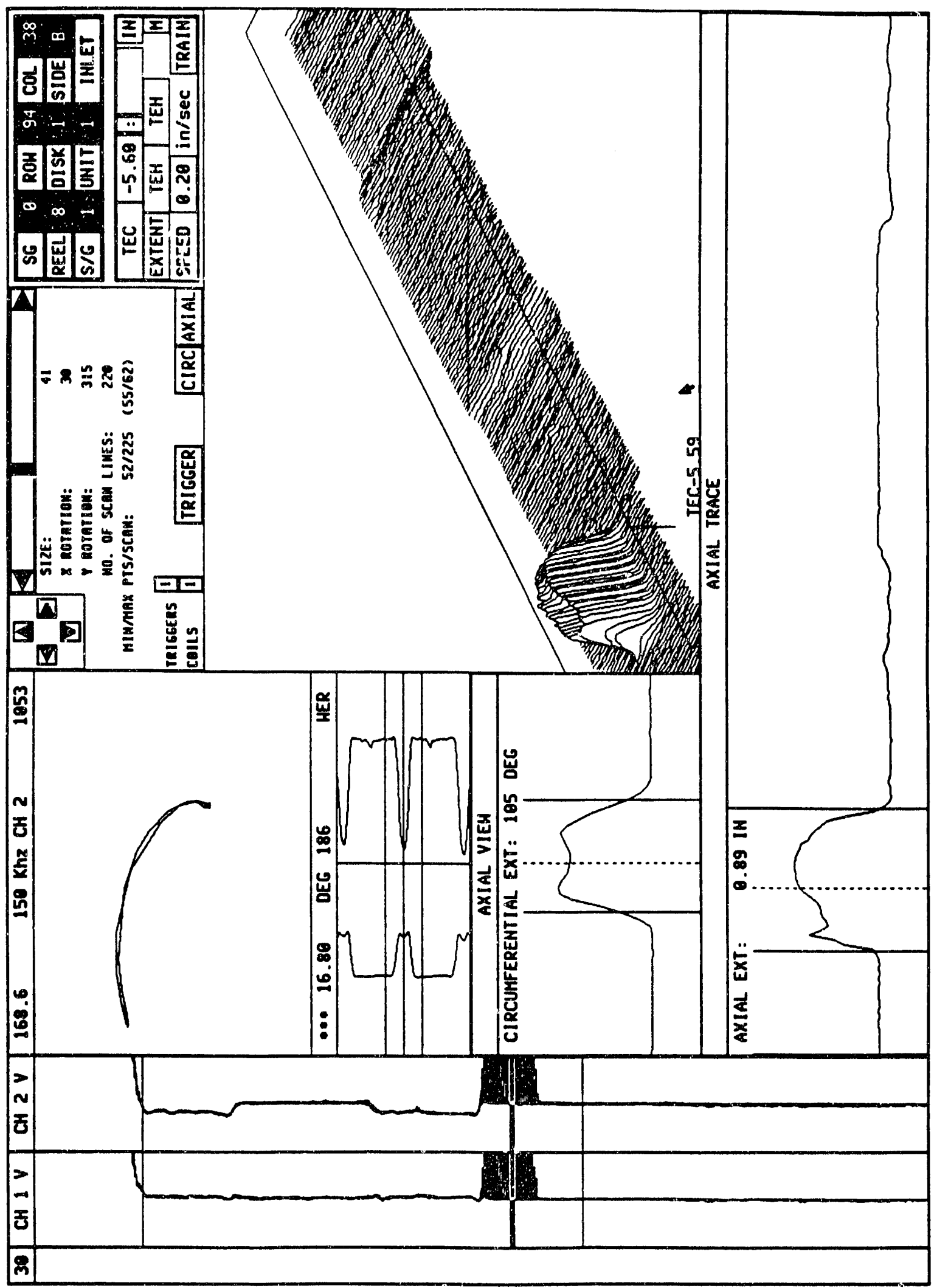


paint brush, safety glasses, plastic cigar tip, etc. The PVC pipe is presumed to be from a sodium hypochlorite (used to kill clam larvae and biological growth) injection line that failed in 1990.

\section{Cooling Water Elow Distributor Plate Examination}

Following confirmation of process water leakage from heat exchariger $4 \mathrm{~A}$, the heat exchanger was removed from service to investigate the cause of the leakage. Visual examination of the inlet cooling water compartment of HX 4A showed that many of the flow distributor plate supports were deformed (Reference III.1). Figure III-3 shows a typical heat exchanger cooling water flow distributor plate staged prior to installation during the 1964-1966 overhaul program.

Determination of the cause of the deformed flow distributor plate supports in HX $4 \mathrm{~A}$ is not conclusive for all deformed areas (Reference III.2). The deformation could be the result of either installation difficulties or hydraulic force such as from water hammer or flow distributor plate blockage. Some of the deformed areas clearly appear to be the result of improper installation. At the same time there is no record that this exchanger ever experienced a water hammer and very little pluggage of the flow distributor plate was found.

Previous analysis had been perforrned to determine the expected forces required to cause deformation of various heat exchanger components (References III.3 and III.4). These analyses indicated that the support straps are the weakest component in the cooling water flowpath. Additionai analyses indicate that a differential pressure of over 8 psi across the strainer would be required to cause the deformation observed (References III.5 and III.6). These analyses also showed that in order to cause a differential pressure of 8 psi across the strainer, the strainer would have to have a pluggage of $\sim 70 \%$. Blockage of this magnitude would have also reduced the flow sufficiently to pick up the safety computer flux tilt alarm on the heat exchanger, alerting the operators . the situation. Thus, there is little evidence to support the theory of blockage as the cause of defo, ation.

Structural evaluations indicate that the applied hydraulic force would cause plastic deformation of the flow distributor plate assembly which would be limited by the first baffle plate after a flow distributor plate movement of approximately two inches. In the unlikely event that the flow distributor plate assembly were to contact the bottom row of tubes (plugged in the old heat exchangers and solid rods in the new units), calculations indicate that the tubes would readily absorb the impact ( 56 psid is required to yield a tube) and prevent any further flow distributor plate movement. No plausible scenario has been identified $t$ connect the observed flow distributor plate deformation in $\mathrm{HX} 4 \mathrm{~A}$ directly with the tube leak. 
Figure III-3

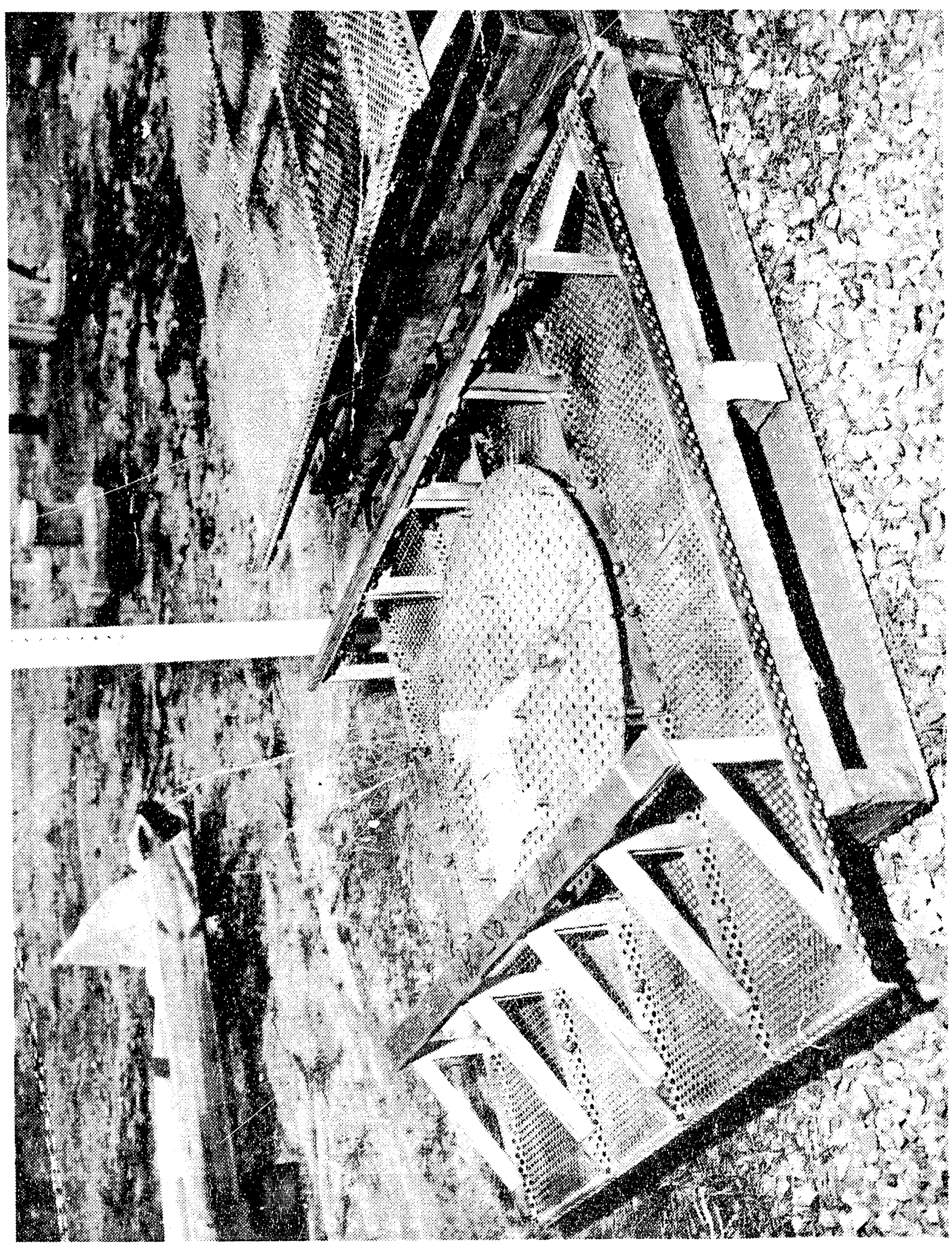




\section{METALLURGICAL EXAMINATIONS}

\section{A. Leaking Tube (94-38)}

Tube 94-38 was remuved from the heat exchanger by core drilling through the tube sheet. This procers was selected because tube wear had been identified in the region adjacent to the tube-toinner tube sheet interface at the moderator outlet end of the heat exchanger. Core drilling provided the maximum assurance that the tube removal operation would not cause additional damage to the worn portion of tube. The core drilling operation does cause damage to adjacent tubes, therefore, tube 93-43 which had been selected as a baseline tube because of the lack of eddy current indications, and tube 94-39 which contained several eddy current indications at tube-baffle interfaces were removed prior to core drilling. The wear section of tube 94-38 and the associated tube sheet are shown in Figure IV-1. The wear section of the tube was examined by scanning electron microscopy (SEM) and then mounted and serial sectioned for microscopic examination of the tube-wear area cross section.

Wear surfaces were apparent on both the tube (Figure IV-1) and tube sheet (Figure IV-2). The scanning electron microscopy of the tube wear surface revealed a very smooth, flat surface. Wear tracks, apparent at high magnifications, were approximately perpendicular to the tube axis and suggested that the relative motion of the two surfaces varied by as much as \pm 15 degrees.

\section{Figure IV-1}

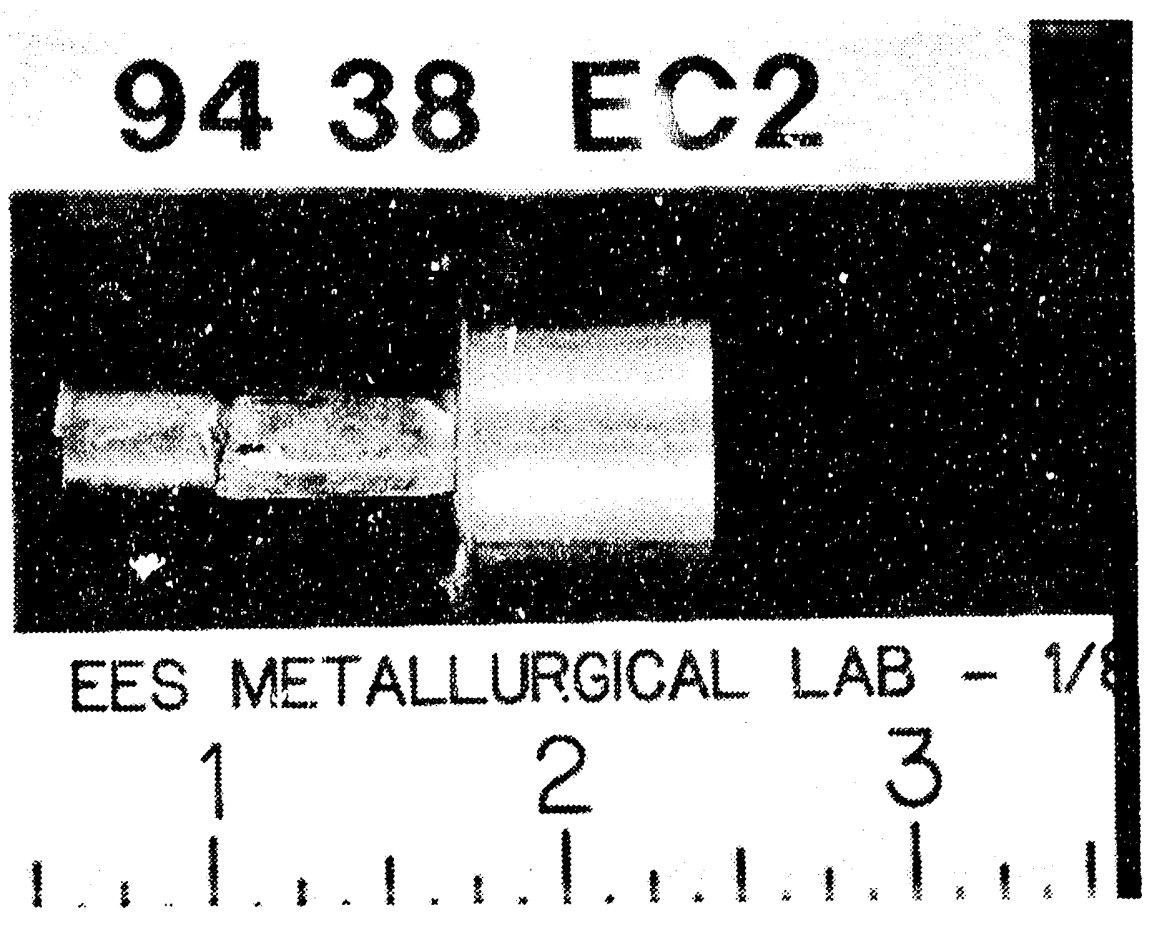


Figure IV-2

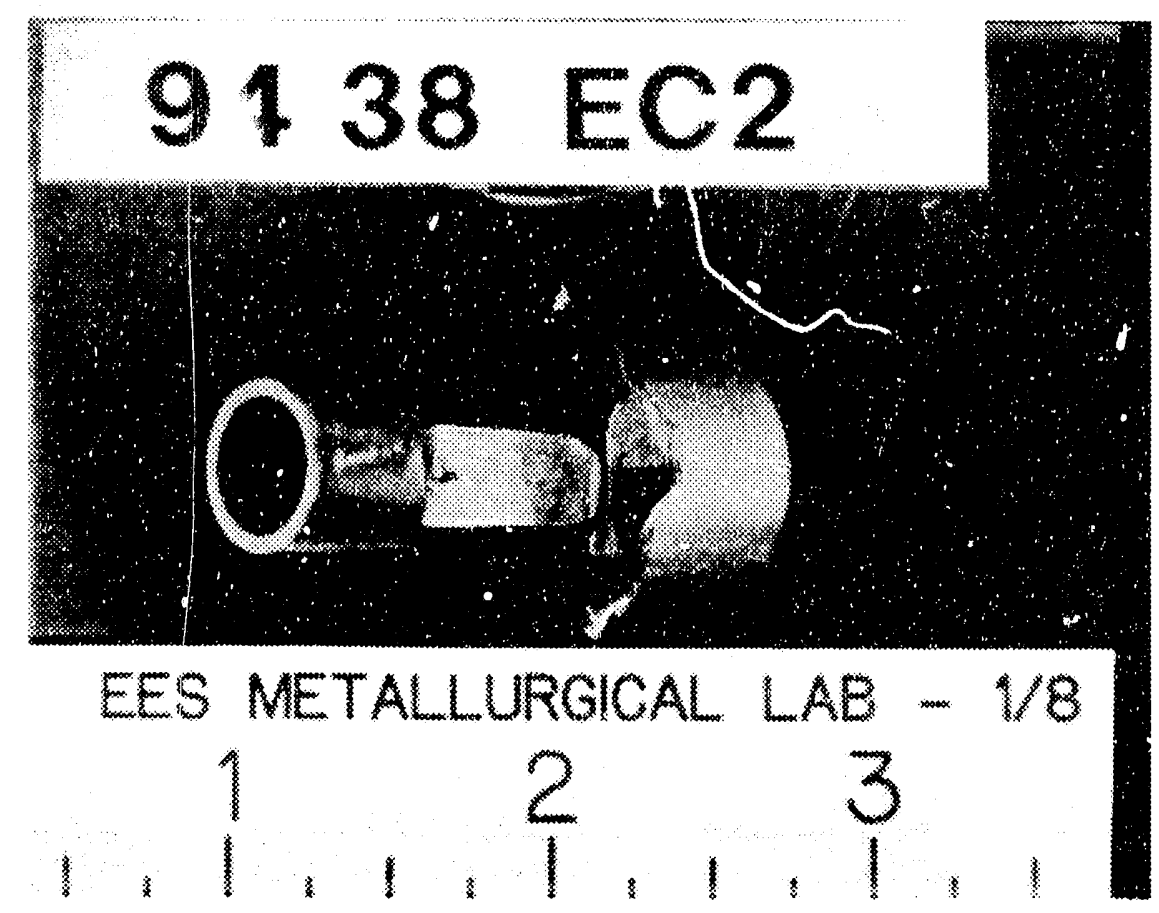

The foreign object that caused the wear on tube 94-38 has not been recovered; however, the shapes of the wear scars on both the tube and tube sheet have helped provide an indication of the size and shape of the foreign object, where it was in contact with the tube and tubesheet. This wear scar pattern suggests that tubes other than tube 94-38 were also in contact with the object. Evidence for that contact was provided by video tapes made during the pre-extraction examination of the wear area in tube 94-38.

The video tapes showed an area of apparent wear on one of the tubes in row 95 . This tube row is the lower periphery of the tube bundle. Because of previous operational experience, all tubes in row 95 are plugged; thus localized wear of these tubes is not significant to reactor operations. The wear indication was below and immediately to the right of tube 94-38. The foreign object may have been too large to pass through the $3 / 8$ inch diameter holes in the flow distributor plate, and in that case would either have had to enter the tube bundle through gaps between the flow distributor plate and the heat exchanger shell, or have been present before installation of the distributor plate.

The wear surface on tube 94.38 was polished to a finish of at least 600 grit. This very fine surface finish, the flatness of the wisar scar, and the observation of wear tracks perpendicular to the tube length suggest that the 0.8 inch long wear scar on the tube was made by an object of similar length. If the foreign object had been significantly shorter than 0.8 inches, the probability of a flat, smooth wear scar across the entire worn region of the tube would have been very low. 
The leak site had apparently been damaged from the $\mathrm{ID}$, probably during the eddy current examination of the tube. The very thin, wom flaps of metal extending above the wear surfaces on the right side of the hole (Arrow A, Figure IV-3) possibly were forced up when a RPC eddy current probe examined the leak site. The bubble, barely apparent on the left side of the leak site (Arrow B in Figure IV-3) and the apparent deformation of much of the thinned section of the tube are also attributed to the passage of the RPC eddy current probe (rotating at $300 \mathrm{rpm}$ ).

The actual leak path was a rectangular hole approximately 0.020 inches wide and 0.085 inches long. Any metal that was above the wear surface during the incident should have been forced down by the continuing wear process. The protrusion of the metal flaps allowed the thickness of the remaining section to be estimated during the initial SEM examination. The sample was too large to permit its rotation (in the electron microscope chamber) so that the flap was perpendicular to the scanning beam, but the thickness could be estimated at ten to fif. zen microns. Serial sectioning through the worn area of the tube confirmed the ligament thickness and demonstrated that the wear surface on the foreign object was sufficiently smooth to wear the tube surface to a thickness of less than one grain diameter before the tube was penetrated. These observations demonstrate that the ligament required to contain the $\mathrm{D}_{2} \mathrm{O}$ moderator in the tube under these wear conditions is less than ten microns. Hydraulics estimates indicate that the actual area of the hole in tube 94-38 is greater than would be expected based on the amount of tritium released. Possibly, this could be accounted for by changes in the hole size during the leak, by pressure exerted by the foreign object still in contact with the tube, and/or enlargement due to passage of the RPC eddy current probe through the tube.

\section{Figure IV-3}

\section{B}

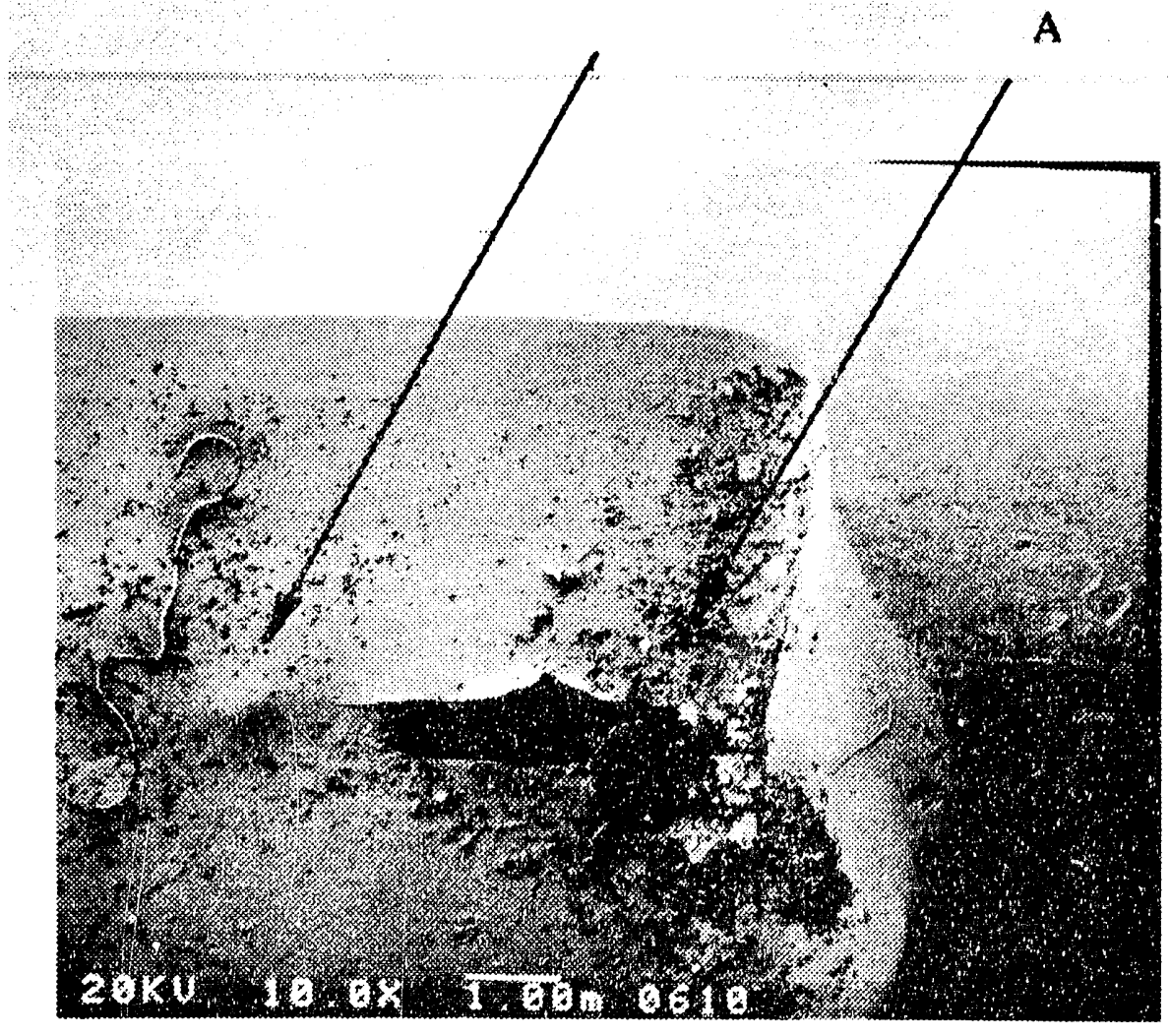


The metallurgical evaluation of the leak site in tube 94-38 demonstrates that the leak was caused by wear which was induced by the presence of a foreign object in the secondary cooling water. The offending object has not been identified, however, size and shape estimates based on the wear scars suggest that the object may have been too large to have passed through the $3 / 8$ inch diameter holes in the flow distributor plate plate immediately beneath the tube bundle and above the cooling water inlet. The smooth, flat wear surface suggests that the wear process removed very little material with each cycle. However, in the absence of identification of the offending object, there is no technical basis for estimation of the wear rate.

\section{B . Non-Leaking Tubes}

\section{Corrosion Induced Degradation}

The metallurgical evaluations of selected sections of 10 additional tubes removed for examination provided no evidence of intergranular attack, stress corrosion cracking, crevice corrosion, pitting or microbiologically influenced corrosion. Penetrant testing and macroscopic examination revealed no indications of corrosion induced degradation on either the outer or inner surfaces of any of the tube sections examined. Microscopic examination of both longitudinal and transverse cross sections also confirmed the absence of corrosion degradation. The focus of these examinations for corrosion induced effects was tube sections associated with tube sheets and baffles because the crevices in these areas should increase the potential for corrosion in those areas compared to other portions of the tubes. Operational history of other heat exchangers also indicated that these areas were the most likely areas to experience corrosion induced degradation.

The eddy current examinations had provided indications of possible degradation near the tube sheet interface of tubes 94-59 and 93-45. Visual and macroscopic examination of these areas in these two tubes revealed no evidence of stress corrosion cracking or any other significant metallurgical defects. Penetrant testing of both inner and outer tube surfaces also provided no evidence of crack like defects. The metallurgical quality of these two tubes was further confirmed by serial sectioning the tube-to-tube sheet regions. The only defect found during this detailed examination was a smäll groove, approximately 0.001 inches deep on the outer surface and near the tube-totube sheet crivice of tube 94-59.

Similar metallurgical examinations, except for the serial sectioning through the tube-to-tube sheet regions were conducted on tubes 94-49, 93-43, 95-51, 94-38 and 92-48. No evidence of cracking, pitting, crevice corrosion or other metallurgical defects was found in any of these tubes. The lack of corrosion induced degradation in the tube-to-tube sheet region is consistent with the very low levels of leakage that this heat exchanger had experienced throughout its operational history. These observations suggest that, except for the few foreign object induced wear sites identified, the tubes in this heat exchanger were in excellent condition.

\section{Baffle Wear}

The baffle positions on most of tube sections removed from this heat exchanger were apparent because of differences in the surface films in the baffle-to-tube crevice and because of minor artifacts in the surface films. Two tubes, 94-39 and 93-71, were removed because eddy current examination indicated baffle wear. The eddy current examinations had indicated a possibility of minor wear on tube 94-39 at baffles 5,6 and 9, and of significant wear on tube 93-71 at baffle 9 . Penetrant testing of the outer surfaces of sections of 94-39 that contained these three baffle areas showed no indications and wall thickness measurements showed no significant wall thinning. 
Metallurgical examination of these sections from tube 94-39 confirmed the wall thickness measurements and provided no indications of corrosion damage.

The leak check of specific tubes in the tube bundie (see 'HE AXIAL FLOW REAC' column in Appendix 1) indicated a very low level helium leak near the fifteen foot position of Tube 94-39. This tube was the only tube other than the leaker (Tube 94-38) that had such an indication and because of this and indications of baffle wear, the tube was extracted from the tube bundle. However, this leak was not confirmed during the metallurgical evaluation of the extracted tube. Visual examination of the outer and inner tube surfaces revealed no evidence of wear in that area. Subsequent laboratory attempts to confirm the presence of either a leak or a tube defect included edảy current inspection and leak testing. Neither examination found any evidence of tube degradation. These results suggest that the original helium leak indication was probably a false signal, although there is a very small chance that the defect, if real, either was too small to be detected by the laboratory tests or was masked by the tube extraction process, which included sectioning the tube at two locations approximately six inches from the fifteen foot position.

The visusl examination of tube 93-71 confirmed the presence of baffle wear at baffle 9. Much of the circumtcrence of the baffle wear surface was covered with the dark film that is typical of type 304 stainless sieel surfaces exposed to river water for significant periods of time. The most significant circumtercitial wear was approximately $46 \%$ of the tube wall. The wear surfaces in this area were totally cove-ed with the river water induced film, demonstrating that the wear process was inactive during the recent hydraulic operations. Portions of the tube in the circumferential baffle region had the shiny and burnished appearance of active wear. The maximum wear in these active regions was $30 \%$ of the tube wall, with most of the region showing only $5 \%$ wear. The $30 \%$ wear regions were extensions of deeper, old circumferential wear scars and probably resulted from wear during previous operations.

The physical measurements of baffle wear demionstrated that the eddy current indications were very conservative, probably because of martensite transformations induced in the tube walls during the burnishing operations. Throughout the metallurgical evaluations, no evidence was found for any degradation not detected by the eddy current examinations. The actual depth of defects which were identified by the eddy current examinations for baffle wear was consistently less than suggested as summarized in Table IV-1.

\section{Eoreign Object Wear in Other Tubes}

\section{Outer Surface Wear}

Two tubes, 92-65 and 93-49, were removed because eddy current indicated significant outer surface wall thinning, not associated with baffles or tube sheets. Physical measurement of the wear depth in both of these tubes confirmed the eddy current indications, Table IV-2. The wear depth in tube $92-65$ was $40 \%$. The measured depth in $93-49$ was $62 \%, 10 \%, 38 \%$, and $12 \%$. The wear scars in these two tubes appeared recent, and other areas of tube burnishing by foreign objects were apparent. The topological characteristics of the wear tracks in tube 93-49 suggested that although the wear appeared recent, the process was probably inactive at the time of the December incident. The shape of the wear scars on tube 93-49 suggests that the offending object was long and thin, similar to a wire. The four wear scars could have resulted from a single object moving down the tube during hydraulic operation. The tarnish films on the wear scars support this hypothesis by suggesting that the four scars were formed one after another, the oldest scar having the darkest tarnish film. However, proof of this hypothesis is virtually impossible. 
The two scars from tube 92-65 had tarnish films on the scar surfaces which suggest that these wear processes may also have been inactive by the time of the December incident. Contamination on this tube has prevented the scanning electron microscopy of the wear tracks.

\section{Inner Surface Wear}

The only inner surface eddy current indications on any of the tubes examined were two indications on tube 93-71. These two indications were both inner surface wear associated with the "point" contact between the core rod and the inner surface of the tube. The depth of wear at both locations was approxim ly 0.017 inches or $34 \%$ of the tube wall. Due to the purity of the process water, it is not possible to determine the age of the wear activity based on surface film. No evidence was found for pitting, stress corrosion or intergranular attack by the moderator.

The report containing the detailed results of the metallurgical investigations in their entirely is included herein as Appendix 3. 


\section{Table IV-1}

\section{Measured Depths of Baffle Wear}

$\begin{array}{lccc}\begin{array}{c}\text { Tube } \\ \text { Number }\end{array} & \begin{array}{c}\text { Baffle } \\ \text { Number }\end{array} & \begin{array}{c}\text { Eddy Current } \\ \text { Indication }\end{array} & \begin{array}{c}\text { Actual Physica } \\ \text { Measurement }\end{array} \\ 92-48 & & \begin{array}{c}\text { no wear noted } \\ 8 \%\end{array} & \\ 92-65 & 7 & \text { no wear noted } & \text { burnishing } \\ 93-43 & 1 & 20 \% & \text { not measured } \\ 93-45 & 5 & 18 \% & \text { not measured } \\ & 6 & 21 \% & \text { not measured } \\ 93-49 & 1 & 20 \% & \text { not measured } \\ & 2 & 11 \% & \text { not measured } \\ & 3 & 7 \% & \text { not measured } \\ & 5 & 5 \% & \text { not measured } \\ & 9 & 17 \% & \text { not measured } \\ & 10 & 17 \% & \text { not measured } \\ & 11 & 21 \% & \text { burnishing } \\ & 13 & 10 \% & \text { burnishing } \\ 93-71 & 8 & 13 \% & \text { burnishing } \\ & 9 & 66 \% & 46 \% \text { (filmed) }\end{array}$

(The deepest wear under baffle 9 was old and had filmed over. The shiny or burnished regions, indicative of recent wear, were $30 \%$ of the wall on one side of the tube and $5 \%$ of the wall on the other side.)

$\begin{array}{lccl}94-38 & 5 & 11 \% & \text { not measured } \\ 94-39 & 5 & 23 \% & \text { burnishing } \\ & 0 & 15 \% & \text { burnishing } \\ \text { burnishing } \\ 94-49 & 9 & 15 \% & \text { not examined for baffle wear } \\ 94-51 & & 5 \% & \text { not measured } \\ 94-59 & 7 & & \text { no wear noted }\end{array}$




\section{Table IV-2}

\section{Measured Depths of Foreign Object}

Induced Tube Wear

Tube

Number

92-48

92-65

93-43

93-45

93-49

93-71

94-38

94-39

94-49

94-51

94-59

\section{Eddy Current Indications}

no foreign object wear noted $40 \%$

$15 \%$

no foreign object wear noted no foreign object wear noted

$$
50 \%
$$$$
23 \%
$$

$$
\begin{gathered}
\text { inner surface wear } \\
\text { two locations, } 27 \% \text { and } 34 \% \\
98 \% \text { (the leaker) } \\
19 \% \\
\text { no foreign object wear noted } \\
\text { no foreign object wear noted } \\
\text { no foreign object wear noted }
\end{gathered}
$$

\section{Actual Phroical Measurement}

$40 \%$

$10 \%$

$62 \% \& 10 \%$

$38 \%$

$12 \%$

$34 \%$, both locations

(wear cause by core rod)

$100 \%$

no wear detected 


\section{TUBE INTEGRITY ANALYSIS}

Each process water heat exchanger has approximately 9000 tubes of 0.5 inch diameter and 0.049 inch wall thickness. Minimum structural tubing requirements are consistent with commercial practice with PWR steam generator tubing. Postulated tubing defects with $0.5 \mathrm{lb} /$ day calculated leakage were compared to the structural requirements, demonstrating adequate structural margins against gross tube rupture. A parametric wear scar study, based on national codes and standards, determined the minimum structural requirements for highly localized wall thinning.

\section{A. Analysis Per NRC Regulatory Guide 1.121, "Basis for Plugging Degraded PWR Steam Generator Tubes"}

Commercial nuclear practice with FWR stean generator tube plugging criteria was used for guidance in performing this analysis (Reference V.1). It is important to note that the SRS reactors are low energy systems with normal operating pressures of 203 psig at $130^{\circ} \mathrm{F}$, while a PWR is a high energy system with operating pressures near 2200 psig at $600^{\circ} \mathrm{F}$. Clearly, PWR steam generators have loadings which are more severe than the SRS heat exchangers.

The commercial basis for plugging PWR steam generator tubing is defined by Regulatory Guide 1.121 which is explicitly limited to PWRs. However, where applicable, this guideline was applied to the current evaluation of the SRS heat exchanger tubing integrity.

Consistent with the Regulatory Guide 1.121 criteria, both wastage (wall thinning) and cracking were addressed. Structural limits on wall thinning and crack size were developed to preclude gross rupture. The wall thinning criteria are based on ASME Section VIII, which is the design code for the SRS heat exchanger. ASME Section XI criteria, with the loadings and factors of safety recommended by Regulatory Guide 1.121 were applied to develop the allowable crack size criteria. Allowances for corrosion or crack growth were not included in this analysis.

Normal operating loads consist of internal pressure, dead weight, hydraulic drag and thermal forces. Accident conditions consist of seismic and water hammer loadings. These loadings were conservatively combined and bound the loadings specified in Regulatory Guide 1.121.

Structurally, the heat exchanger tubing is over designed. The allowable normal operating pressure for the tubing is $3600 \mathrm{psig}$. Normal uperating pressure is approximately $200 \mathrm{psig}$ and the system design pressure is 300 psig. The minimum wall thickness for the design pressure, using minimum material properties, is 0.0037 inches.

The ASME Section XI limit load criteria in Appendix C-3320 and C-3340 were used with Regulatory Guide 1.121 factors of safety (3 for normal operation and 1.5 for accident conditions) to determine the allowable sizes of postulated circumferential and axial flaws. Allowable flaw sizes were calculated for: 1) the nominal wall thickness of 0.049 inches, and 2) a region previously thinned by wastage with a postulated wall thickness of 0.025 inches. The non-mechanistic combination of wastage and cracking is used to determine the sensitivity of the allowable flaw length to variations in wall thickness.

The critical flaw size of circumferential throughwall flaws is greater than $50 \%$ of the tubing circumference $(\approx 0.8 \mathrm{inch})$, for tubing 0.025 inches and thicker. The critical flaw depth for a circumferential part-throughwall flaw is $90 \%$ of the remaining tubing thickness, for tubing 0.025 
inches and thicker. The allowable size of circumferential flaws is relatively insensitive to variations in the wall thicknesses between 0.049 and 0.025 inches.

The critical flaw length of a throughwall axial flaw is 2.0 inches for 0.049 inch thick tubing and 0.74 inches for 0.025 inch thick tubing. Interpolation can be used to determine the critical flaw lengths for intermediate tubing thicknesses. The critical flaw depth of part-throughwall axial flaws is $85 \%$ of the remaining tubing thickness for tubing between 0.049 and 0.025 inches thick.

The IGSCC Leak Rate Model was used to calculate the tube leakage with various assumed throughwall crack sizes. For the 0.049 inch thick tubing, the crack lengths required to obtain $0.5 \mathrm{lb} /$ day leakage (the criteria for heat exchanger replacement) are between 0.3 and 0.6 inches. Since the critical flaw size is larger than the leakage flaw size, the tubing has adequate structural margins and will leak without breaking. This calculation is supported by the past 37 years of reactor operating experience in which 63 leaks were detected in the heat exchanger tubing without a double ended guillotine break.

\section{B . Wear Scar Parametric Study}

A parametric study of the critical flaw size of a wear scar was performed using ASME Code Case N-480 criteria for local wall thinning. This study demonstrates that the minimum thickness of a very small area is 0.0011 inches for normal and accident conditions (300 psig) and that the allowable thickness for a 0.02 inch transverse by 0.085 inch axial wear scar is 0.0032 inches. These calculated local thicknesses are less than the minimum thickness for gross wall thinning which is 0.0037 inches. (See V.A above)

The allowable wear scar for normal operating conditions of a tube on the cold end of the heat exchanger with a differential pressure of 110 psi was also examined. The critical thickness for a very small wear scar is 0.00065 inches and the allowable thickness for a 0.02 inch transverse by 0.085 inch axial wear scar is 0.0017 inches; whereas, the minimum thickness for gross wall thinning is 0.0022 inches.

These analyses demonstrate that for small wear scars even less tube wall thickness is required to maintain integrity than for normal design or accident conditions.

\section{HEAT EXCHANGER TUBE LEAKAGE HISTORY}

\section{A. Overview of All Leaks}

Prior to the leak in HX 4A that occurred in K-Reactor in December 1991, there had been 63 recorded instances of heat exchanger leakage since startup of the five SRS reactors in 1954-55. In most of these instances, including all of those prior to 1974, the moderator leakage rates were typically measured in $\mathrm{lbs} / \mathrm{hr}$ and are considered significant. For purposes of this report, a leakage rate is classified as "significant" if it is sufficient to cause the reactor to be shutdown immediately for isolation and repair or replacement of the leaking heat exchanger. Various measures outlined herein were implemented to eliminate these recurring problems, with the result that beginning in 1974 the predominant mode of heat exchanger tube degradation has been long-term stress corrosion cracking (SCC) of the tubes. Leakage is trended over periods of months and years and the current practice is to replace any heat exchanger at the next scheduled outage when such leakage 
reaches $0.5 \mathrm{lb} /$ day. Stress corrosion cracking is an environmental and life limiting mechanism rather than a safety problem.

\section{B . Significant Leaks and Corrective Actions}

Forty-six (46) of the 63 heat exchanger leakage incidents are classified as significant. All but one involved tube leaks and were due to a variety of causes:

Vibration against baffle plate

Structural failure (crack in 3-in. drain nozzle, Nov. 1956)

Vibration fatigue

Vibration by core rod

Wear by foreign object

Pitting corrosion

Chloride stress corrosion from neoprene seals

Unknown

As shown, most of the significant leaks were caused either by vibration of a tube against a baffle plate or by wear due to a foreign object in contact with a tube. The remaining causes were primarily isolated occurrences, for example:

- an improperly installed core rod in a tube vibrated and caused a leak in the leak collection space in 1972;

- three instances of pitting corrosion occurred in the 1976-77 time period in K and C Areas;

- a drain nozzle weld developed a crack shortly after initial startup in P Area;

- chloride from neoprene seals caused numerous tube leaks in the leak collection space on three occasions in R, P, and C Areas within a 6-month period beginning in May 1960;

- two instances of vibration fatigue occurred in 1961 and 1964.

Beginning with the first instance of tube leakage in June 1955, various corrective actions were implemented to eliminare these problems, including:

- $\quad$ plugging tubes vulnerable to vibration wear (total of 210 tubes per heat exchanger);

- reversing flow direction to extend life by retarding corrosion limitations;

- eliminating chloride-bearing elastomer seals by material substitution and design modifications;

- circulating inhibitor solution between tube sheets to retard corrosion;

- installing a cooling water inlet flow distributor plate to reduce vibration wear at the baffle plates and to capture foreign objects entrained in the cooling water;

- installing improved screens in the cooling water basin to remove foreign objects. 
The above improvements were completed by late 1966 and essentially eliminated nearly all significant leaks, the only exceptions being the improperly installed core rod in 1972 and the three cases of pitting corrosion in 1976-77. No other significant leaks occurred until the recent leak in K-Reactor in December 1991, which was caused by wear due to a foreign object.

\section{Leaks Caused by Wear Due to a Foreign Object}

As summarized above, prior to the December 1991 leak in HX 4A, there had been ten significant heat exchanger tube leaks attributed to a foreign object in contact with a tube. Six of the foreign objects were plastic bristles from brushes used to clean the screens in the cooling water basin. Other foreign objects included a welding electrode, tie rod spacer, insulated wire, and a small stone. Data for each of the ten cases are summarized in Table VI-1.

The potential for further failures due to plastic bristles was eliminated by redesigning the screen cleaning mechanism and by dissolving any bristles possibly remaining in the heat exchangers with dimethylformamide (DMF). Thus only four significant leaks caused by other foreign objects occurred over the entire SRS reactor service life until the December 1991 leak.

\section{Current Cooling Water Screening Process}

The cooling water system is designed to minimize the entry of foreign objects into the process water heat exchangers. Screens of various types are located at various points.

- River pumphouses: Three levels of screens are installed to minimize entrainment of foreign objects. A chain link fence across the mouth of the intake canal guards against very large objects. A bar screen consisting of $1 / 4$-inch rods on 3 -inch centers is located in the pumphouse intake. The bar screen in turn is backed up by traveling screens that have a 3/16-inch mesh.

- Cooling water basin: The 25 million gallon cooling water basin itself provides some capability for the settling of any heavy objects entering the basin. Sluice gates containing traveling screens with a $1 / 8$-inch mesh connect the three basin compartments to the two cooling water pumpwells. Other sluice gates contain stationary screens also with a $1 / 8$-inch mesh, but these are normally closed and are only for emergency use.

- Heat exchangers: Each of the 12 heat exchangers has a rectangular flow distributor assembly positioned inside the cooling water inlet compartment. It is located between the inner tube sheet and baffle 12,2 inches below baffle 13. This assembly consists of a circular 28-inch diameter perforated impingement plate facing the CW inlet, which is bolted in turn to a rectangular perforated flow distributor plate (Figure III-3). All perforations are 3/8-inch in diameter. This assembly is designed to spread the inlet CW flow evenly across the tube bank as well as to provide screening capability for the bulk of the CW flow. In practice, there is a clearance gap ranging up to as much as about one-inch between the rectangular distributor plate and the HX structure (shell, baffle, and tube sheet), therefore, its effectiveness as a strainer is less than ideal. The tube bank itself, with $1 / 4$-inch spacing between tubes, is even more effective as a strainer for foreign objects.

The flow distributor assemblies were first installed in the original heat exchangers during the major overhaul program during 1964-66. Since this overhaul included inverting the heat exchangers and reversing the direction of flow, the distributor assembly was installed 
in what was formerly the CW outlet compartment, therefore, it is highly unlikely that foreign objects were initially present in the new inlet. No leaks from foreign object wear subsequently occurred until the December 1991 event in K-Reactor. The object causing the wear has not been identified and it is not possible to determine when it entered HX 4A following the installation of the flow distributor assembly.

Table VI-1

Heat Exchanger Leaks Caused By A Foreign Object

\begin{tabular}{lcclcr}
$\begin{array}{l}\text { Failure } \\
\text { No. }\end{array}$ & Reactor & $\begin{array}{c}\text { Date of } \\
\text { Failure }\end{array}$ & \multicolumn{1}{c}{ Object } & $\begin{array}{c}\text { Max. Leak Rate } \\
\text { (Lbs/Hour) }\end{array}$ & $\begin{array}{c}\text { D 20 Loss } \\
\text { Total Lbs }\end{array}$ \\
\hline $2 \mathrm{P} 1$ & $\mathrm{P}$ & $2 / 17 / 56$ & Welding Electrode & 18.0 & 1500 \\
$24 \mathrm{C} 3$ & $\mathrm{C}$ & $7 / 31 / 61$ & Tie Rod Spacer & 1.8 & 32 \\
$29 \mathrm{R} 7$ & $\mathrm{R}$ & $8 / 31 / 63$ & Insulated Wire & 1.1 & 60 \\
$30 \mathrm{~K} 6$ & $\mathrm{~K}$ & $11 / 19 / 63$ & Plastic Bristle & 6.1 & 47 \\
$32 \mathrm{~L} 9$ & $\mathrm{~L}$ & $4 / 25 / 64$ & Plastic Bristle & 3.3 & 8 \\
$33 \mathrm{C} 5$ & $\mathrm{C}$ & $6 / 13 / 64$ & Plastic Bristle & 5.6 & 240 \\
$35 \mathrm{~L} 10$ & $\mathrm{~L}$ & $8 / 11 / 64$ & Plastic Bristle & 16.2 & 125 \\
$36 \mathrm{C} 7$ & $\mathrm{C}$ & $9 / 13 / 64$ & Plastic Bristle & 5.6 & 288 \\
$40 \mathrm{~K} 10$ & $\mathrm{~K}$ & $12 / 18 / 64$ & Plastic Bristle & 3.4 & 48 \\
$42 \mathrm{C} 10$ & $\mathrm{C}$ & $11 / 14 / 65$ & Stone & 6.0 & 19
\end{tabular}




\section{COMPENSATORY ACTIONS}

\section{A. Examinations of Installed K-Reactor Heat Exchangers}

\section{Examination of Cooling Water Inlets}

Subsequent to the discovery of flow distributor plate support deformation in $\mathrm{HX} \mathrm{4A}$, visual examinations of the other K-Reactor heat exchangers (References VII.1, VII.2 and VII.3) of the same manufacture and service were performed in-place in K-Reactor. These examinations revealed little or no deformation of flow distributor plate supports in those heat exchangers. The interior condition of these heat exchangers was clean with a slight to solid slime coating on the shell surfaces. Various small debris consisting of plastic pieces, PVC chunks, small steel parts, pieces of wood and rubber, leaves, clams and small rocks were also seen in the inlet of the heat exchangers.

\section{Examination of Replacement Heat Exchangers}

Five replacement heat exchangers were examined externally and internally and then leak tested. The external examinations were performed to determine if exposure to the environment during onsite storage for the last five years had initiated any adverse effects. No problems were found.

Internal examinations were performed on both the process water side and cooling water side. All of the heat exchangers contained a residue on the cooling water side that at first was described only as a thick black sticky substance. Investigation and subsequent analysis confirmed that the substance was dehydrated deionized soap. The soap was used by the vendor as a lubricant when sliding the tube bundle into the heat exchanger shell. The residue was removed and the heat exchanger wiped clean with alcohol.

In one instance a mechanical jack was found in the cooling water outlet end (below the tube bundle where an inspection port is located) of a new heat exchanger. The vendor was brought in to discuss both the soap and the jack. The jack had been inadvertently left in the heat exchanger after it was used to align the tube bundle (already attached to one tube sheet) with the other tube sheet. The shell, tubes, tube sheets, and baffles were examined for dents or other evidence of impact by the jack in the event it had bounced or slid during transportation of the heat exchanger. No evidence of damage was found.

The heat exchangers were vacuum dried prior to being leak tested using a helium leak test technique. All three of the replacement heat exchangers installed in K-Reactor passed the helium leak test acceptance criteria of $1 \times 10^{-4} \mathrm{Std}-\mathrm{cc} / \mathrm{sec}$ as indicated below:

$\begin{array}{ll}\text { Serial No. } & \text { Leakage Rate } \\ \text { D-1689-5 } & 3 \times 10^{-7} \text { Std-cc/sec } \\ \text { D-1689-3 } & 8 \times 10^{-5} \mathrm{Std}-\mathrm{cc} / \mathrm{sec} \\ \text { D-1689-7 } & 5 \times 10^{-5} \mathrm{Std}-\mathrm{cc} / \mathrm{sec}\end{array}$




\section{B. Sampling and Leakage Detection Program}

The K-Reactor sampling and leakage detection program has been upgraded to provide improved sensitivity and response to a heat exchanger tube leak. These improved requirements have been incorporated in the Plant Operating Specification (POS), as well as in revised training for the plant operators and support personnel.

The regulations and guidelines which govern the operation of the site include requirements for aqueous releases to the Savannah River. These come in several levels with respect to the severity of the event and the consequential release.

\section{Bequirements}

The following standards are used to judge the impact of a heat exchanger leak to the effluent cooling water.

\section{1) DOE Order 5480.6}

For design basis events, DOE Order 5480.6 leads to the application of Nuclear Regulatory Commission criteria. For infrequent incidents (ANS 51.1, Condition III), the criteria of 10CFR100 apply.

Heat exchanger tube rupture is an ANS Condition III design basis event discussed in the SAR. Reactor scram and AC motor trip reduces the amount of heavy water lost to well within the 10CFR 100 iimits.

\section{2) DOE Order 5400.5}

DOE Order 5400.5 limits the liquid release at the site boundary to a dose of $100 \mathrm{mrem} / \mathrm{yr}$. Experience at the Savannah River Plant has shown that this limit is much less restrictive than the EPA regulation for liquid releases directly into the Savannah River.

3) 40CFR141 - Water Pollution Control; National Primary Drinking Water Regulation; Radionuclides.

The EPA regulation on radiological contamination of drinking water limits the dose to water users to $4 \mathrm{mrem} / \mathrm{yr}$. Since two communities about 100 miles downstream from SRS use the Savannah River for drinking water, this limi: is applicable and in fact is limiting for liquid releases.

4) SRS Annual Guides.

SRS Annual Guides, ar: ALARA-driven release guides established by SRS staff based on historical data. The release guides are normally very demanding goais with very low limits on allowable release.

\section{Old Monitoring and Sampling Program}

The sampling and detection program which was in place at the time of the December 1991 heat exchanger leak consisted of the following elements and processes:

1) Cooling water sample and analysis program 
2) Cooling Water Gamma Monitor

The cooling water sample and analysis program which took samples every 12 hours, with sample analysis being completed within the next 8 hours, could detect leaks as low as $0.5 \mathrm{lb} / \mathrm{hr}$. A 0.5 $\mathrm{lb} / \mathrm{hr}$ leak could be identified and isolated in 22.5 hours.

The Cooling Water Gamma Monitor, which is only effective during reactor operation at power levels above $250 \mathrm{MW}$, can detect leaks of about $20 \mathrm{lb} / \mathrm{hr}$. A $20 \mathrm{lb} / \mathrm{hr}$ leak can be identified and isolated in 1.5 hours.

\section{Present Monitoring and Sampling Program}

With the addition of the new in-line monitor, there are three ways in which heat exchanger tube leaks are detectable:

1) The In-line Tritium Monitor

2) Cooling water sample and analysis program

3) Cooling Water Gamma Monitor

1) The In-line Tritium Monitor has a minimum reliable detectable level of about $2 \times 10^{-3}$ microCi/ml (about $20 \mathrm{lb} / \mathrm{hr}$ ) for a counting instrument setting which has an integration period of one hour. System flow delays lead to an instrument response time of 1.5 to 2 hours.

If the In-line Tritium Monitor indicates a required action, the time to isolate a leak is 3.5 hours, made up as follows:

\section{$0 \quad$ leak initiates}

$2 \mathrm{hr} \quad$ alarm from In-line Tritium Monitor

$2.5 \mathrm{hr}$ samples taken from reacior building $\mathrm{CW}$ effluent to provide redundant indication and earh CW header to locate the leak

$3 \mathrm{hr} \quad$ analysis of samples available in CCR

$3.5 \mathrm{hr} \quad$ reactor shutdown and leaking CW header isolated

A more rapid response for the In-line Tritium Monitor is available for larger leaks with a ten-minute integration. With this setting a sensitivity of about $40 \mathrm{lb} / \mathrm{hr}\left(3.6 \times 10^{-3} \mathrm{microCi} / \mathrm{ml}\right)$ is available with corresponding time to isolation of 2.5 hours.

The POS action level is set at any alarm from the In-line Tritium Monitor.

2) The cooling water sample and analysis program which takes samples every 2 hours, has a reliable sensitivity of $5 \times 10^{-5} \mathrm{microCi} / \mathrm{ml}$, corresponding to about $0.5 \mathrm{lb} / \mathrm{hr}$. This frequency was selected to ensure that more probable leaks, those with leak rates less than 10 pounds per hour, would be detected and isolated before leaking even as much total radioactivity as the larger leaks detected earlier by the in-line tritiun monitor. A $0.5 \mathrm{lb} / \mathrm{hr}$ leak can be identified and isolated in 4.5 hours. The isolation time is composed of the following actions:
$0 \quad$ leak initiates
$2 \mathrm{hr}$
$3 \mathrm{hr}$ next sample taken (per procedure to meet $3 \mathrm{hr}$ interval)
$3.5 \mathrm{hr}$ analysis of sample available in CCR samples taken from reactor building $\mathrm{CW}$ effluent and each $\mathrm{CW}$ header to provide redu dant indication and location information 
$4 \mathrm{hr} \quad$ analysis of samples available in CCR

$4.5 \mathrm{hr} \quad$ reactor shutdown and leaking CW header isolated

In the event that there is a failure to meet the specified surveillance requirements for effluent water sampling, an additional 1 hour for obtaining and analyzing a sample is permitted by the POS. This is acceptable because the grab sample system including the 1 hour delay is still equivalent to the In-line Tritium Monitor. The grab sample will catch a leak too small for the In-line Tritium Monitor to detect before 110 pounds have escaped.

By procedure, if the In-line Tritium Monitor is out of service, the frequency of effluent sampling is increased to every hour. This provides the same isolation time ( $3.5 \mathrm{hr})$ as for the In-line Tritium Monitor for leaks below $40 \mathrm{lb} / \mathrm{hr}$, with the better sensitivity of sampling analysis. Leaks above 40 $\mathrm{lb} / \mathrm{hr}$, which would be isolated an hour earlier with the In-line Tritium Monitor, are very unlikely to occur.

3) As stated earlier, the Cooling Water Gamma Monitor can detect leaks of about $20 \mathrm{lb} / \mathrm{hr}$, such that identification and isolation can be completed in 1.5 hours.

\section{Loose Parts Monitoring System}

The Loose Parts Monitor (LPM) was determined to be necessary prior to continuing power ascension testing. It is designed to monitor each of 12 heat exchangers (PW and CW inlet on each one) as well as the reactor tank (each of 6 pump suction inlet pipes) for a total of 30 monitoring points. Spare sensors and signal conditioners used by the existing VAM (Vibration Acoustic Monitor) were connected to a new computerized data acquisition system designed by SRL's Equipment Engineering Section (EES). The system has been installed since January 25, 1992. At present, "baselining" is continuing, i.e., monitoring the equipment as the reactor goes through power ascension and steady-state operation. This process will take several months before alarm thresholds can be set for voltage and frequency responses.

\section{Procedures and Training}

WSRC has aggressively pursued the review of procedures, personnel, and equipment in relationship to environmental sensitivity. Two main groups were established to review these areas and provide solutions. A Chemistry Task Group was formed to assess samples taken from effluent streams for sample frequency, sample equipment, sample basis, responsibilities, and notifications. A second team, headed by the K-Reactor Plant Manager, reviewed all routine procedures, administrative procedures, and abnormal condition control procedures. This team provided lists of procedures and recommended changes to these procedures to provide enhanced communications and sensitivity to environmental considerations. These improvements have been implemented.

Training programs have been developed and implemented for the In-line Tritium Monitoring System, a review of the Critiques and Lessons Learned, and a procedure overview for tritium sampling and leak detection. This training was given to the Reactor Shift Crew, Health Protection Department, and Laboratory Analysis personnel. Additionally, in-plant drill scenarios were written and conducted to assure that the environmental sampling program has been implemented satisfactorily. All shift personnel were trained. 
WSRC has reviewed the notification responsibilities from the initial time an event is discovered until the appropriate regulatory notifications are made. WSRC has strengthened programs associated with the Reactor Restart Division and Environmental Protection Department interface. In addition, administrative notification procedures were upgraded to ensure proper communication during the exchange of information at this interface. Training was conducted for the Environmental Spill Coordinators on the lessons learned from this event and on regulatory reportable trip points.

\section{SAFETY CONSIDERATIONS}

\section{A. Reactor Safety}

The safety margin of the K-Reactor as analyzed and detailed in the "K-Reactor Safety Analysis Report" is valid. The leak in heat exchanger $4 \mathrm{~A}$ posed no threat to the safety of the $\mathrm{K}$-Reactor, nor posed any challenge to any of the safety systems in the plant. This conclusion is supported by the tube integrity analysis, the detailed metallurgical examinations of the leaking and non-leaking tubes and the observed condition of the remainder of heat exchanger 4A.

The tube integrity analysis indicates the heat exchanger tubes can still perform their function of providing a barrier to contain the process water for all postulated transients identified in the Safety Analysis Report with a wall thickness as low as 0.0037 inch, compared to the nominal wall thickness of 0.049 inches.

The metallurgical examination of the leaking tube demonstrates the inherent strength of these tubes under these operating conditions. The tube wall was mechanically being removed by the foreign object being excited during cooling water flow. As the process proceeded, the tube wall in the area of the foreign object became thinner, and ultimately, the foreign object wore a hole in the tube and the leak occurred. The hole in the tube wall as examined did not indicate any increase in hole size due to internal pressure, which would have been evident if the tube was very highly stressed due to the reduced wall just prior to the hole emerging.

These analyses and metallurgical examinations demonstrate the inherent robustness of the heat exchangers to provide the reactor with a margin of safety that is equivalent to a commercial nuclear power reactor.

\section{B . Potential Tritium Releases}

The real consequence of this heat exchanger tube leak was the amount of tritiated water which was released to the K-Reactor outfall and eventually to the Savannah River. The operating history of the SRS reactors over the past thirty-five years of operation has shown that there have been occasional leaks from the heat exchangers which vary from small leaks to leaks in excess of $40 \mathrm{lb} / \mathrm{hr}$. To date, only 64 leakage events have occurred in over 1000 heat exchanger-years of operation.

\section{Safety Analysis Report}

The K-Reactor Safety Analysis Report (SAR) (Reference VIII.1) addresses heat exchanger leaks in Section 15.6.1. The postulated leak is a five-hour duration, $100 \mathrm{gpm}$ leak from a double-ended 
break of a single heat exchanger tube. Ultimately, this accident, as analyzed, is found not to exceed the SAR offsite dose acceptance criteria.

This scenario is acknowledged in the SAR to be very conservative since:

1) No breaks of this type or magnitude have occurred in the history of SRS operation.

2) The leak is caused by a double-ended guillotine break of an unrodded heat exchanger tube. Only 10 of the 9000 tubes in a heat exchanger are unrodded.

3) Automatic shutdown systems would scram the reactor within 5 minutes (versus the hour assumed) and the operators would then trip the $\mathrm{AC}$ motors as part of the automatic scram response. This would terminate the outflow of primary coolant to the secondary side, although isolation of the heat exchanger would still need to be accomplished.

4) No credit is given to the Cooling Water Gamma Monitors (non-safety grade), or the reactor tank level scram (limiting single failure).

The December 1991 leak would not have caused the Cooling Water Gamma Monitors to alarm or have required a reactor trip since the reactor was not operating at power. Nevertheless, it was identified and corrected with a release of primary coolant (containing approximately $5700 \mathrm{Ci}$ of tritium) which was well under the assumed $2.4 \mathrm{MCi}$ release in the SAR. Furthermore, procedures have been tightened to identify future leaks with less delay. Thus, the leak which occurred is well bounded by the current K-Reactor safety case as described in the SAR.

A very low frequency of occurrence for the SAR scenario as analyzed has been assessed and vrill be discussed in the PRA seztion below.

\section{Environmental Impact Statement}

The SRS Reactor Environmental Impact Statement (EIS) (Reference VIII.2) discusses heat exchanger leaks in Section 4.1.3.1.4. The predicted consequences of a heat exchanger leak are not explicitly calculated because this event is considered to be bounded by a DEGB LOCA of the primary system. The DEGB LOCA releases the entire coolant inventory from the primary system. The activity in this released inventory may follow several pathways out of the reactor building (stack, holding tanks, retention basin). Both the December 1991 heat exchanger leak and the postulated scenario in the SAR release much less of the reactor primary coolant inventory than the DEGB LOCA analyzed in the EIS. Thus, the safety case for operation of K-Reactor as presented in the EIS is not impacted.

\section{Probabilistic Risk Analysis}

The Probabilistic Risk Analysis (PRA) (References VIII.3 and VIII.4) for the K-Reactor discussed large heat exchanger tube leaks $(>5000 \mathrm{gpm})$. Based on site experience and information from the Reactor Materials Program, leaks of this magnitude were judged to be incredible events $\left(<<10^{-6}\right.$ per reactor year). A recent assessment of the frequency of heat exchanger leaks of approximately $50 \mathrm{gpm}$ concluded that the frequency of a leak of this magnitude (based on site experience) was also negligible ( $<10^{-6}$ per reactor year) (Reference VIII.5). Thus, the initiator frequency for the $100 \mathrm{gpm}$ leak postulated in the SAR analysis is also $<10^{-6}$ per reactor year. This is the initiating 
frequency only and does not credit subsequent shutdown and isolation activities. A heat exchanger leak of the magnitude analyzed in the SAR is therefore a very rare event.

A recent analysis of credible leak sizes (considering compound causes and multiple simultaneous tube leaks) and their probabilistic distribution of occurrence frequencies has concluded the following (Reference VIII.6):

$\begin{array}{ll}\text { HX leak size } & \text { frequency (per reactor year) } \\ >0.036 \mathrm{gpm} & 0.013 \\ >0.072 \mathrm{gpm} & 0.004 \\ >0.160 \mathrm{gpm} & 0.0005\end{array}$

The PRA is concerned with initiators which lead to accidents which may cause reactor core damage. Small leaks such as those listed above are not considered to be accident initiators. This is primarily due to the amount of time which would be necessary to allow the leak to degrade the reactor state to a point at which some automatic or manual action would be required to prevent core damage. At a $0.16 \mathrm{gpm}$ leak rate, it would be days before any action would be required to prevent core damage. Coupled with the many manual and automatic systems which would have to fail to detect the leak (Cooling Water Gamma Monitors, In-line Tritium Monitor, effluent sampling program, tank level and blanket gas scram systems, etc.), the $5 \times 10^{-4}$ per year initiating frequency for this level of leakage would cause a negligible increase in the overall K-Reactor core melt frequency. Also, as discussed previously, larger leaks from the system which would require quicker response have occurrence frequencies which make them negligible contributors to core melt frequency.

Thus, neither the December heat exchanger leak nor any subsequent analysis results change the risk analysis results for $\mathrm{K}$-Reactor.

\section{Conclusions}

It is evident from the above discussions that the December heat exchanger leak at K-Reactor falls well within the bounds set by the current safety documentation for the reactor. The scenarios postulated in the SAR and the EIS are still considered to be conservative or bounding, and there is no perceptible effect on the core melt frequencies calculated in the PRA. 


\section{REFERENCES}

II.1 WSRC-RP-92-186, "Emergency Response Monitoring Activities and Environmental Impacts of The K-Reactor Aqueous Tritium Release of December 1991," February 7, 1992.

III.1. SSD-QCM-920072, "Heat Exchangt 4 A Cooling Water Inlet Nozzle Hardware," W. S. Ehrhart, January 28, 1992.

III.2. RRD-PSI-920005, "Safety Considerations Relevant to Deformation of Strainer Supports in Cooling Water Inlet of Process Heat Exchangers," J. M. Morrison, et al., January 17, 1992.

III.3. Memorandum, "Reactor Heat Exchanger - Relative Strength of Internal Components Subjected to Differential Pressure Loading (U)," J. P. Veldman, March 13, 1989.

III.4. SRL-MTS-921021, "Load Capacity of the PWS Heat Exchanger Inlet Strainer Supports (U)," G. E. Mertz, January 24, 1992.

III.5. SRL-MTS-921026, "A Comparison of the 4A Heat Exchanger Inlet Strainer Deformadion to Finite Element Results (U)," R. F. Miller, January 31, 1992.

III.6. NES-ETH-920012, Revision 1, "Pressure Drop Across the Shell Side HX Inlet Distributor (U)," M. R. Duignan, February 18, 1992.

V.1. WSRC-TR-92-72, "Savannah River Reactor Process Water Heat Exchanger Tube Structural Integrity Margin," G. E. Mertz, D. M. Barnes and R. L. Sindelar, February 1992.

VII.1. SSD-QCM-920071, "Heat Exchanger 4B Cooling Water Inlet Nozzle Hardware," W. S. Ehrhart, January 28, 1992.

VII.2. SSD-QCM-920074, "Heat Exchanger 3B Cooling Water Inlet Nozzle Hardware," W. S. Ehrhart, January 28, 1992.

VII.3. SSD-QCM-920081, "Heat Exchangers 1A, 2A, 2B, 3A, 5A and 5B Cooling Water Inlet Nozzle Hardware," W. S. Ehrhart, January 30, 1992.

VIII.1. Savannah River Site K-Reactor Safety Analysis Report, Westinghouse Savannah River Co., Aiken, SC, Amendment 2, November, 1991.

VIII.2. DOE/EIS-0147, Final Environmental Impact Statement; Continued Operation of K-, L-, and P-Reactors, U. S. Department of Energy, December, 1990.

VIII.3. WSRC-RP-89-570, Savannah River Site Probabilistic Risk Analysis of Reactor Operation, Level 1 Internal Events, Westinghouse Savannah River Co., June, 1990.

VIII.4. WSRC-RP-89-570, Savannah River Site Probabilistic Risk Analysis of Reactor Operation, Level 1 External Events, Westinghouse Savannah River Co., June, 1990. 
VIII.5. SRL-PRA-910054, "Estimates of the Frequency of Leaks in the Heat Exchanger Tubes Using a Lognormal Distribution Fit to Site Data for Small Leaks," D. S. Cramer, February 28, 1991.

VIII.6. WSRC-TR-92-96, "Probability of Heat Exchanger Leaks", D. S. Cramer, E. P. Shine, W. J. Copeland, February 28, 1992. 


\section{APPENDIX 1}

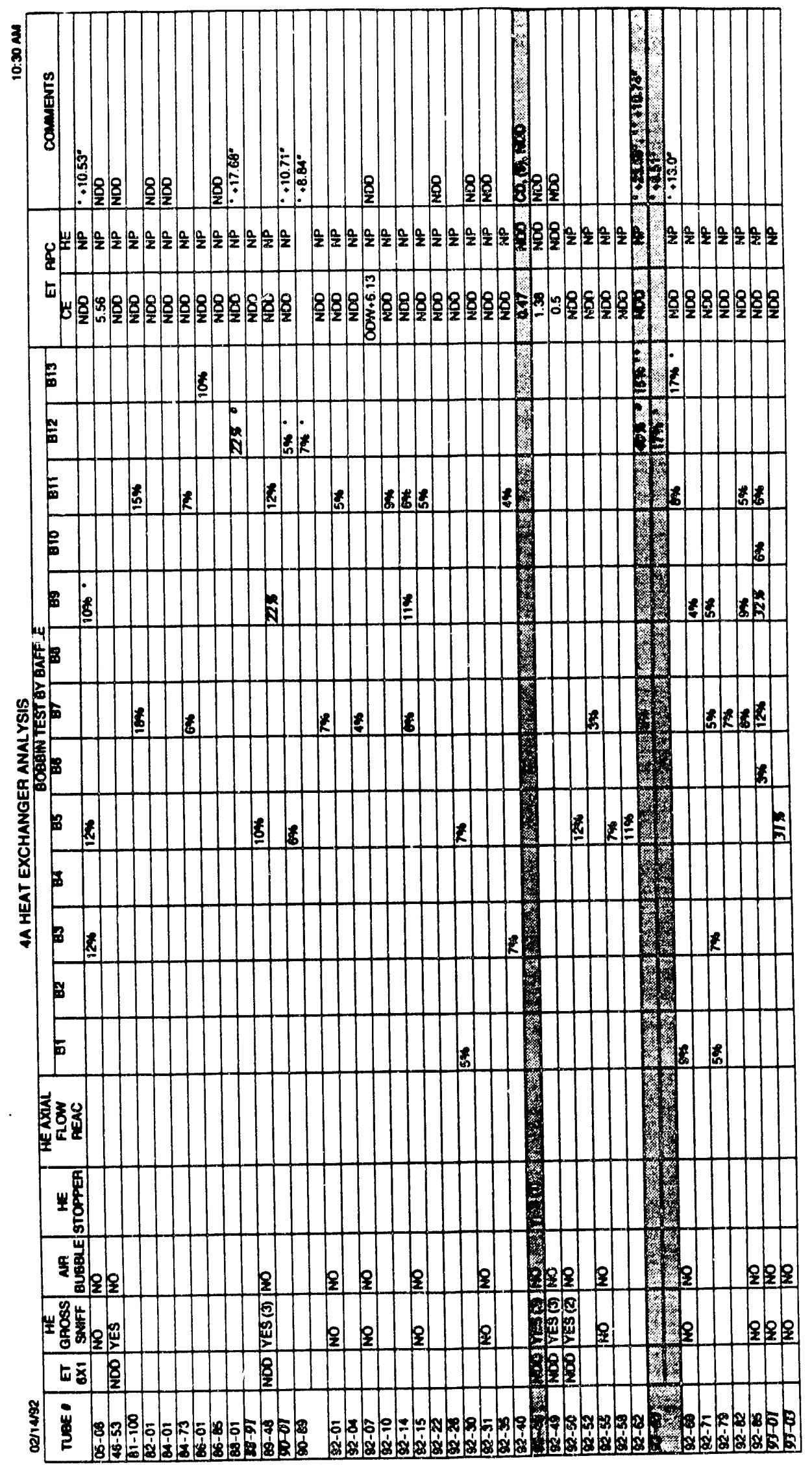


APPENDIX 1 (Cont.)

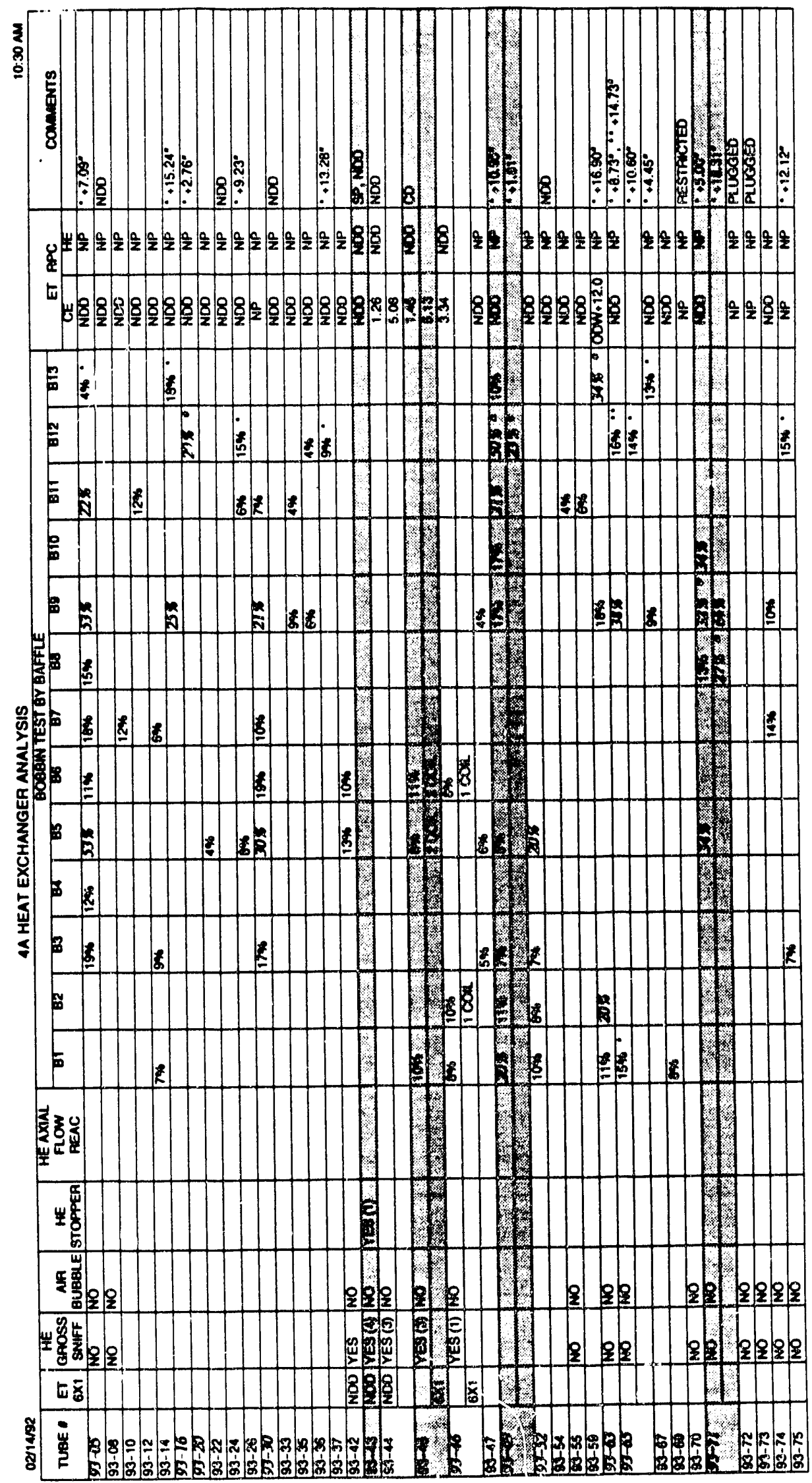




\section{APPENDIX 1 (Cont.)}

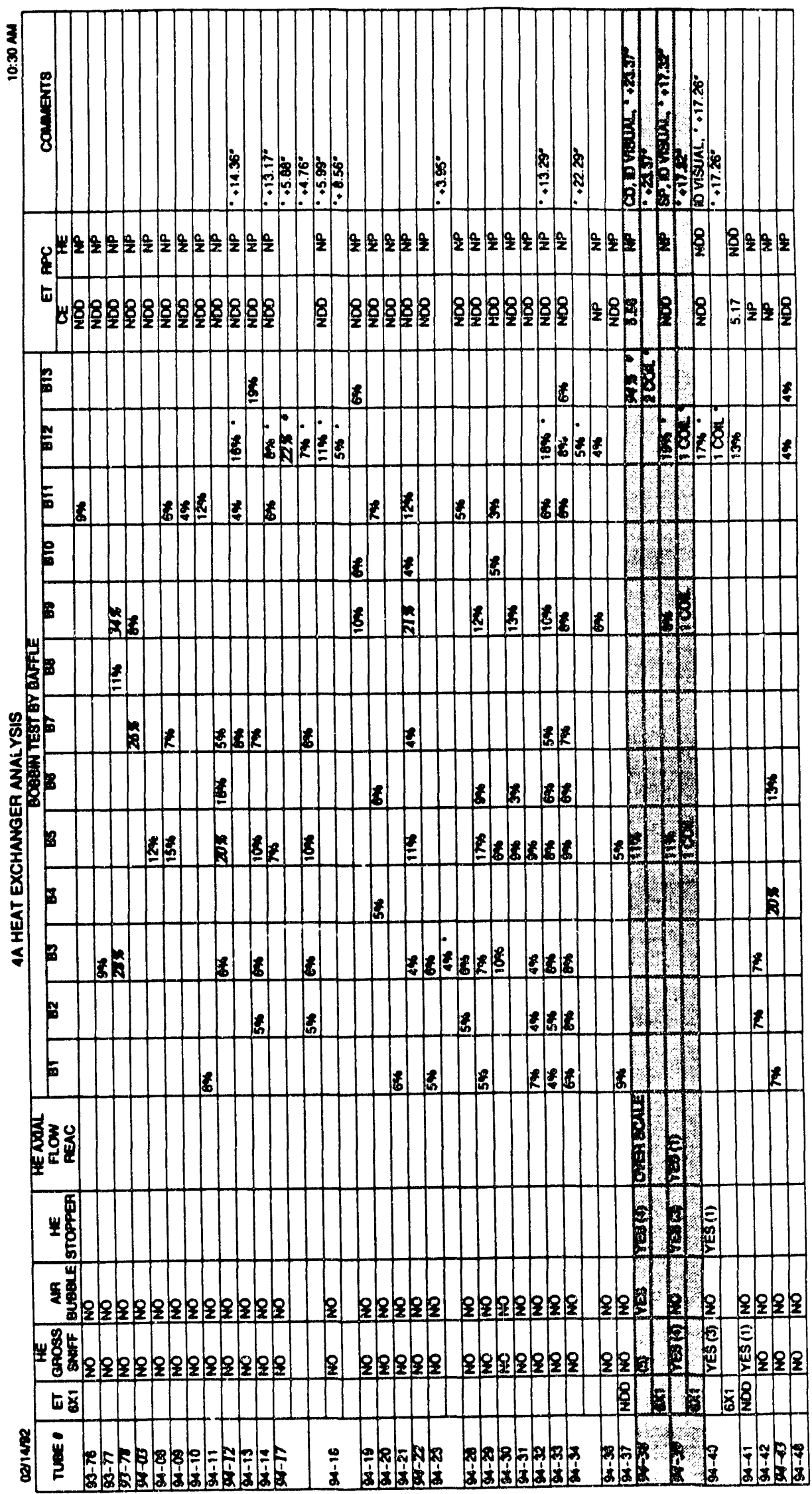


APPENDIX 1 (Cont.)

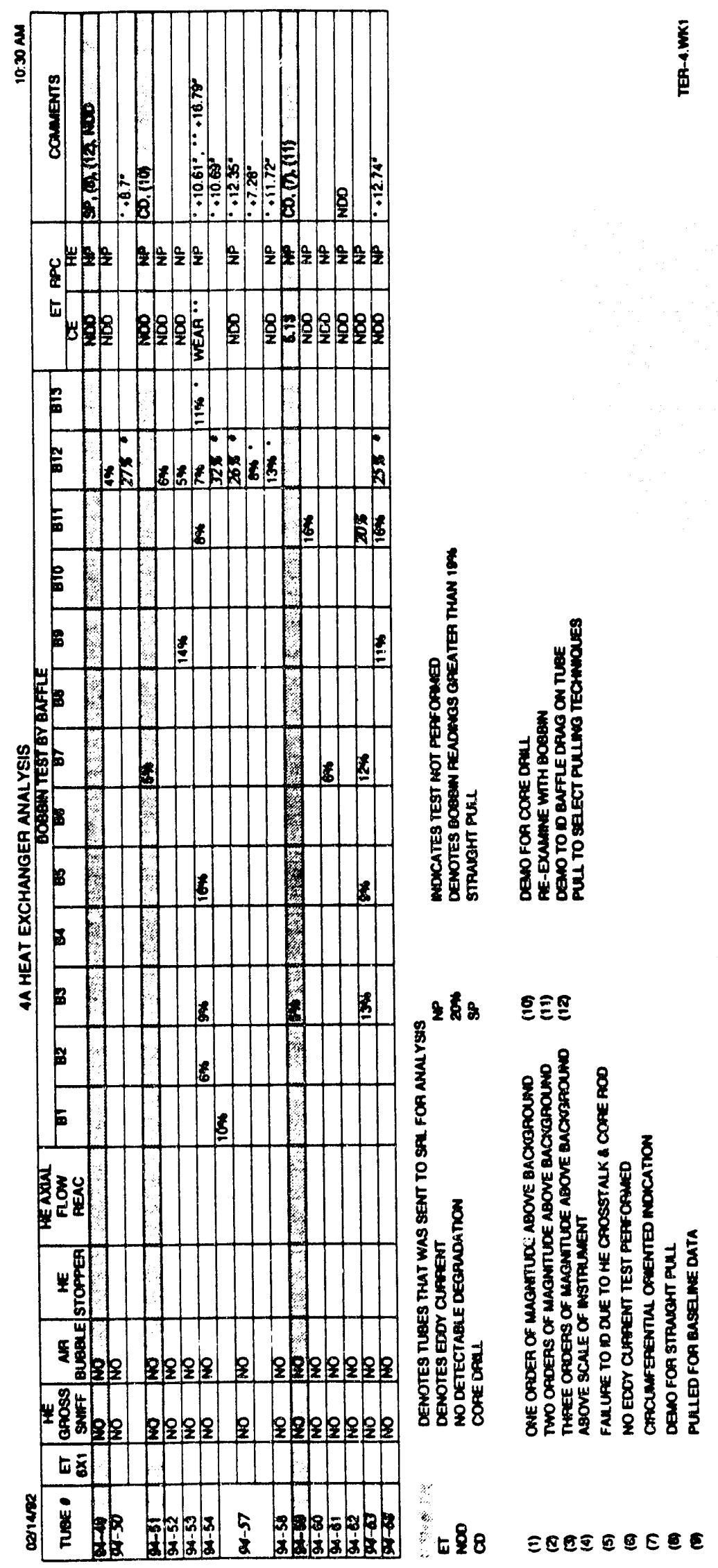




\section{APPENDIX 2}

COLUMN $\longrightarrow$
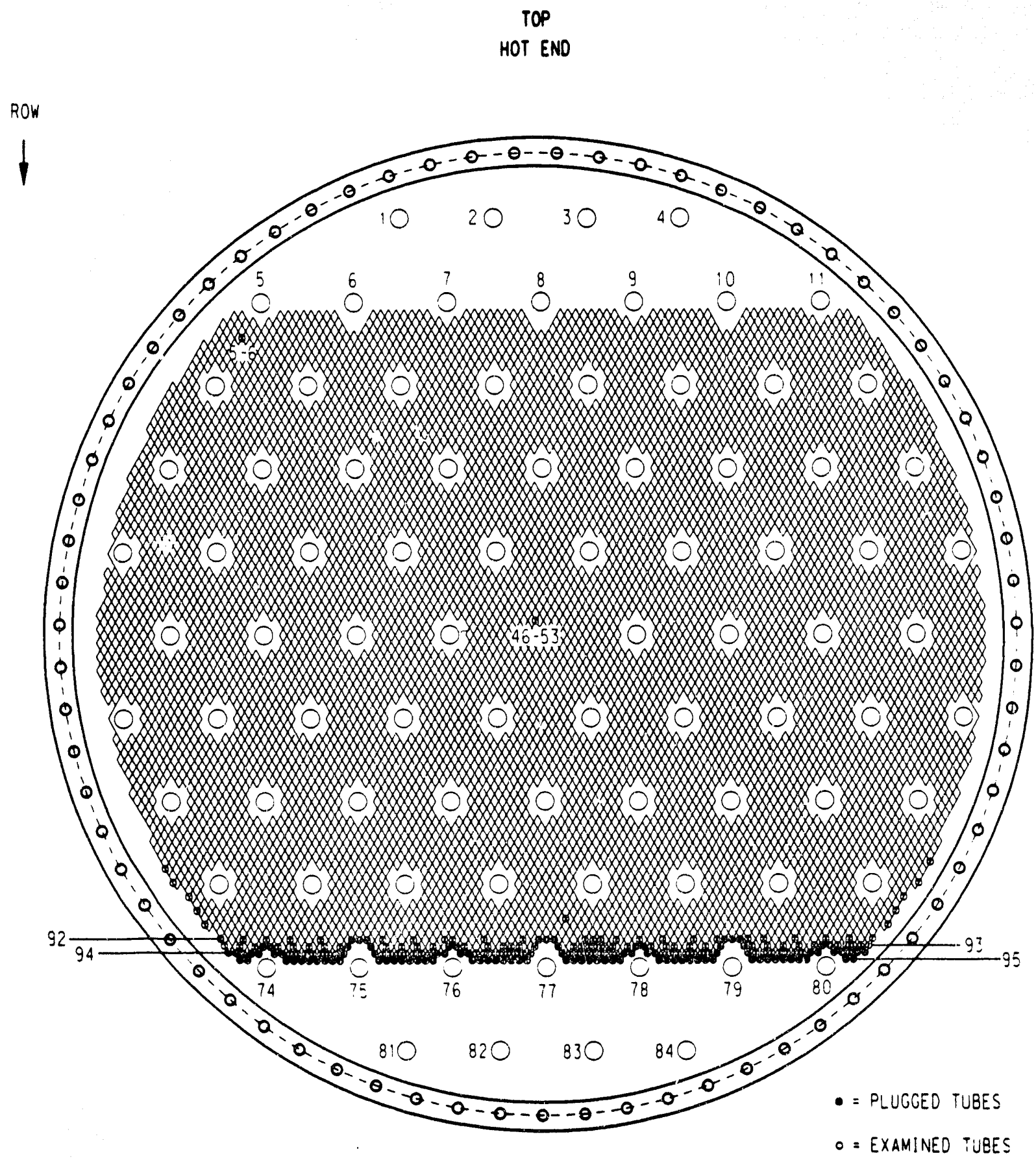


\section{APPENDIX 2 (Cont.)}

COLUMN

ROW

1

HOT END

TOP

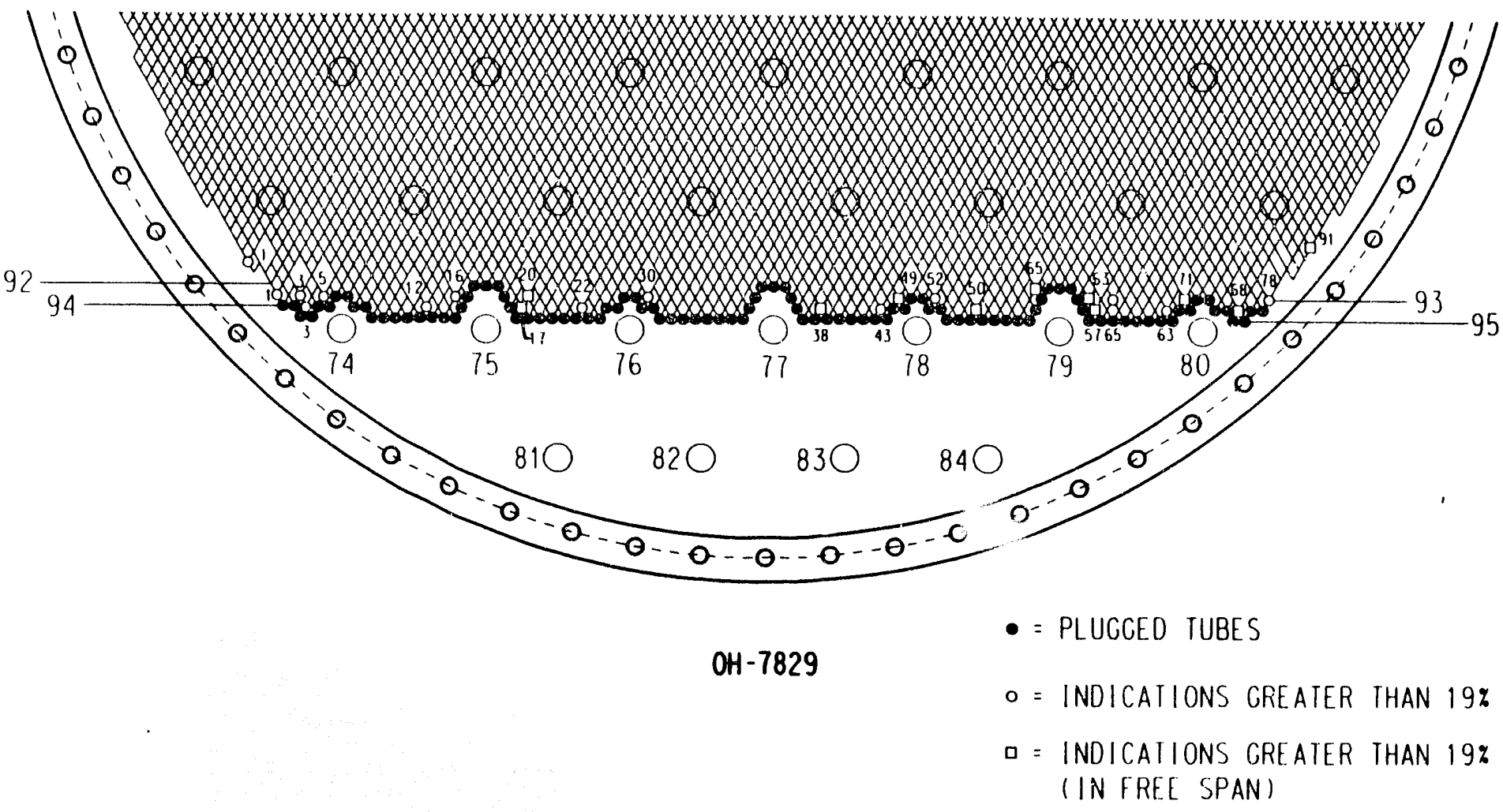




\section{APPENDIX 2 (Cont.)}

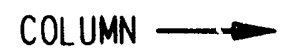

ROW

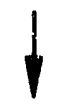

COLD END

TOP

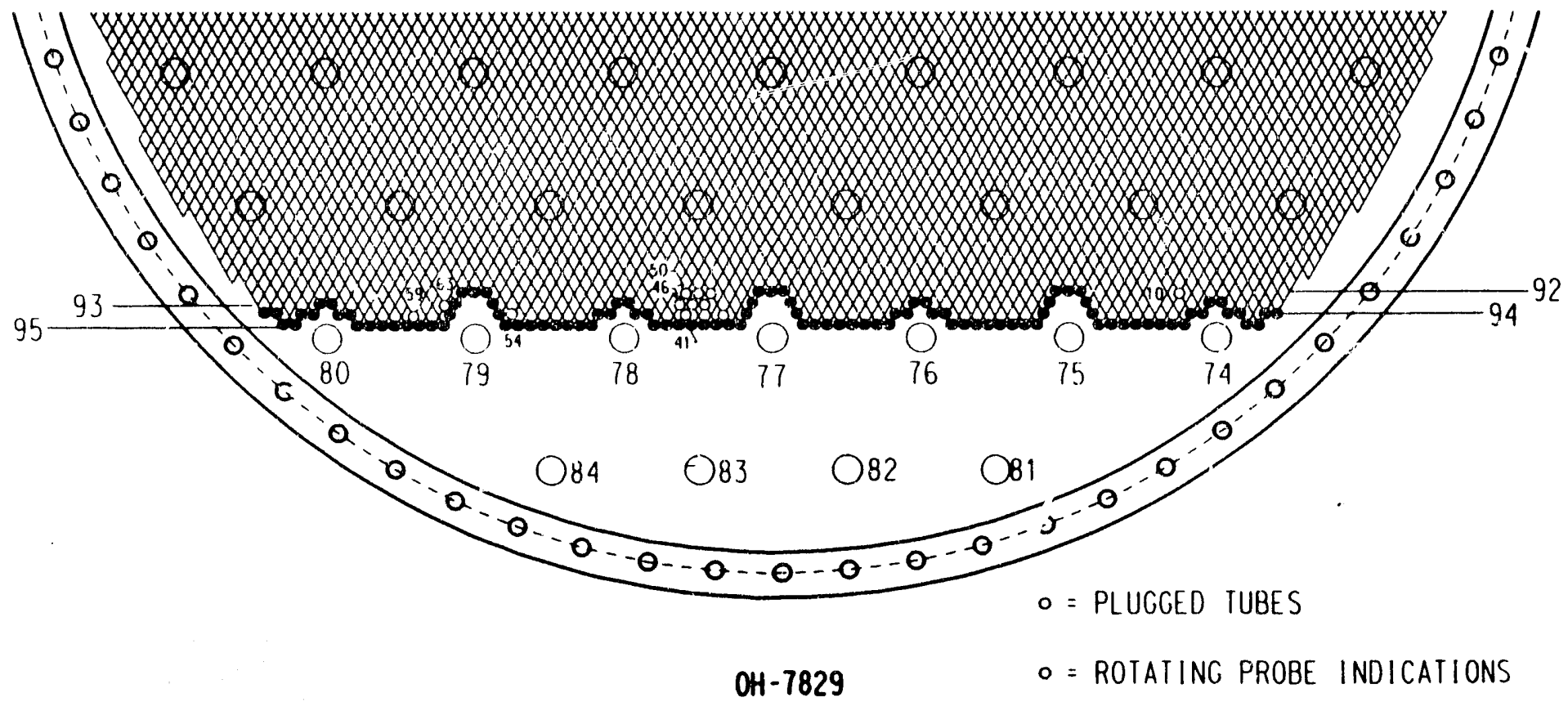




\section{APPENDIX 2 (Cont.)}

COLUMN

ROW

1

\section{COLD END}

TOP

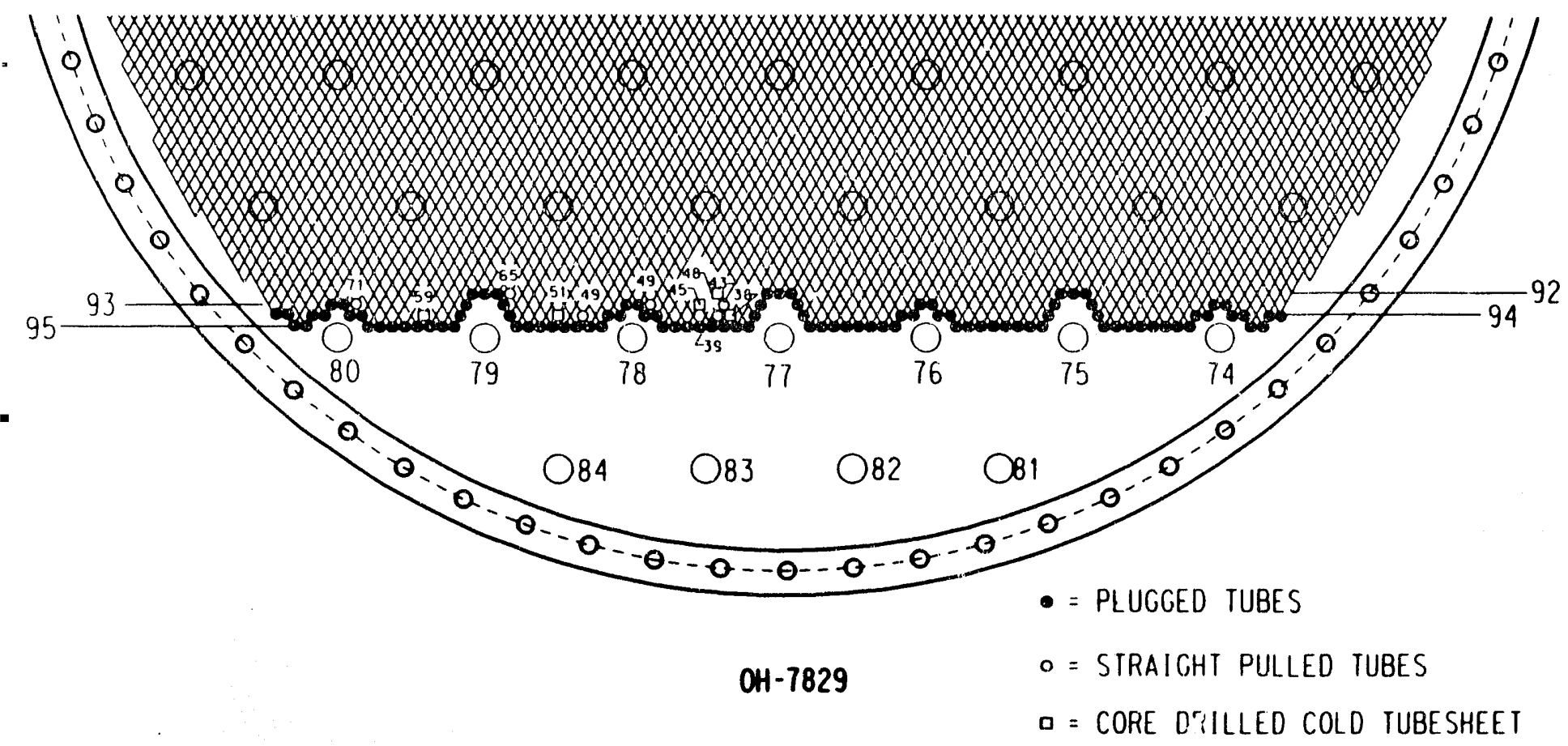




\section{APPENDIX 3}

\section{Westinghouse Savannah River Company \\ Inter-Office Memorandum}

SRL-MTS-920032

March 5, 1992

TO:

R. T. BEGLEY, 773-A

FROM:

D. Z. NELSON, 773-A

J. D. SCARBROUGH, 730-A

M. R. LOUTHAN, JR., 773-A

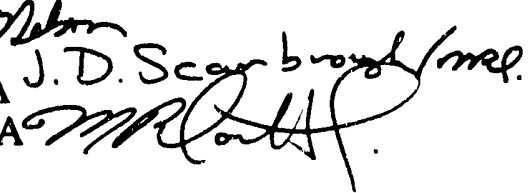

\section{METALLOGRAPHIC EVALUATION OF TUBES FROM K-REACTOR HEAT EXCHANGER 4A}

\section{SUMMARY}

This report summarizes metallographic data and analysis which demonstrate that the December 22, 1991, release of tritiated moderator from K-reactor heat exchanger 4A was caused by a single hole in tube 94-38 of that heat exchanger. The hole was formed by vibratory wear which initiated when a yet unidentified foreign object, in the secondary cooling water system, moved past the bottom row of tubes (these bottom row, or row 95, tubes are plugged), pressed against tube 94-38 and against the inner tube sheet and vibrated approximately perpendicular to the tube axis. The surface of the foreign object which was parallel to the tube axis was approximately 0.8 inches long. Vibration of this surface against the tube, reduced the wall thickness and produced a 0.8 by 0.3 inch wear scar which included a rectangular hole in the tube. This hole was approximately 0.02 by 0.085 inches with the 0.085 inch dimension parallel to the tube axis. The moderator that passed through this hole mixed with the secondary cooling water and caused the tritium release.

The metallurgical condition of other sections from this tube and sections from other tubes removed from this heat exchanger was excellent, except in areas of localized tube wear. No evidence of microbiologically influenced corrosion (MIC), intergranular attack, pitting, crevice corrosion or stress corrosion cracking were observed. The tube wear was typically induced by debris in the secondary cooling water side of the heat exchanger; however, limited tube wear and burnishing was seen in tube walls beneath certain baffles.

The metallurgical investigation has focused on tubes which were removed from the heat exchanger because of eddy current indications. Therefore, except for tube 93-43 which was selected as a baseline tube because of the lack of eddy current indications, the tubes characterized should represent worse case conditions in the heat exchanger. Furthermore, the eddy current inspection concentrated on tubes at, or near, the periphery of the tube bundle and immediately over the 


\section{APPENDIX 3}

secondary cooling water inlet. This area was selected for inspection because operating history has shown that the probability of foreign object wear is highest in that region of the heat exchangers.

The metallurgical characterizations determined specifically:

a) that recently active tube wear, induced by a foreign object on the shell side of the heat exchanger, was associated with the leak and leak area,

b) that baffle induced wear and surface burnishing were the cause of eddy current indications in tube regions immediately beneath baffles. (The tarnish films in these areas showed that the one case of baffle induced wear had been present for years and that surface burnishing processes had recently been active.),

c) that minor surface scratches and imperfections were the cause of eddy current indications at tube-to-tube sheet interfaces,

d) that recently active, localized, foreign object induced wear on the shell side of tubes 92-65 and 93-49 was the cause of eddy current indications remote from the baffles,

e) that wear induced by the core rod was the cause of inner surface eddy current indications on tube 93-71, and

f) that the eddy current inspections provided conservative estimates (over predictions) of the extent of tube wear and degradation.

These metallurgical evaluations revealed no evidence of stress corrosion cracking at tube-totube sheet interfaces. This observation is consistent with the lack of moderator leakage from the heat exchanger prior to the December 22, 1991, release. These results also demonstrate that stress corrosion cracking did not contribute to the December 22 incident.

Moderator leakage due to tube wear, induced by foreign objects on the shell side of the SRS heat exchangers, has been an infrequent event throughout the reactor operating history (eleven occurrences in over one thousand heat exchanger years of operation at SRS). However, until the December 22 event, wear induced leakage had not been noted since 1965. Because of this operating history and because non-leaking, recently active, foreign object induced wear was observed on several tubes from heat exchanger $4 \mathrm{~A}$, the occurrence of a wear induced leak in another K-reactor heat exchanger cannot be discounted and the timing for that postulated leak cannot be predicted. However, if such leakage were to reoccur, the recently revised monitoring programs and procedures are designed to assure early identification and should minimize the quantity of moderator released.

\section{BACKGROUND}

The leak in tube 94-38 in K-reactor heat exchanger 4A was located by leak checking the entire tube bundle and eddy current examination of selected tubes in the vicinity of the leak. Ten tubes, in a region adjacent to the leaking tube, Figure 1, did not contain core rods. (Core rods were inserted in tubes to reduce the inventory of heavy water required for reactor operations and to improve heat transfer.) This lack of core rods in a ten tube bundle adjacent to the leaking tube complicated the initial helium leak tests. 


\section{APPENDIX 3}

The initial leak tests were made by removing the head from the moderator inlet end of the heat exchanger and pressurizing the moderator outlet end to establish nitrogen flow through the tubes. The shell or secondary cooling water side of the heat exchanger was than pressurized with helium and the moderator inlet side examined for the presence of that helium. Because the tube leak was at the moderator outlet end and because the leaking tube contained a core rod, some of the helium that passed through the hole in tube 94-38 migrated counter to the nitrogen flow, exited the tube and was transported to the moderator inlet end of the heat exchanger by the nitrogen flowing through the unrodded tubes. The helium test thus provided leak indications in several of the unrodded tubes, especially tubes 94-39 and 93-43, which were adjacent to the leaking tube. The initial examination was thus focussed on this bundle of unrodded tubes and, even after the leak in tube 94-38 was identified, characterization of several of these unrodded tubes was included in the metallurgical evaluations.

The evaluations also included other tubes which were removed because eddy current inspections had provided indications which were considered worthy of further evaluation. The tubes selected for removal included those tubes which had the strongest eddy current indications at baffles, at tube-to-tube sheet interfaces and at regions remote from either the tube sheets and/or baffles. The eleven tubes removed from this heat exchanger were:
a) the tube identified, through the leak test program and eddy current evaluations, as the leaker (tube 94-38),
b) seven tubes which had eddy current indications of significant interest (tubes 93-45, 94-39, 92-48, 94-59, 92-65, 93-49 and 93-71),
c) one base-line tube which was selected because it was free of eddy current indications (tube 93-43), and
d) two tubes removed as part of an evaluation program for the tube extraction process (tubes 94-49 and 94-51).

The metallurgical evaluations, made on selected portions of the eleven removed tubes, included: visual and dye penetrant examinations, optical macroscopy and microscopy, scanning electron microscopy, and $\mathrm{X}$-ray spectroscopy.

\section{TUBE EXTRACTUON PROCEDURES}

Tubes were removed from the heat exchanger by either a tube pulling operation or a core drilling process. With the exception of one tube which was removed as part of the process for selection of techniques for subsequent tube extractions, each tube was inspected by eddy current techniques prior to removal. The tube pulling process required that the tube be freed from the outer and inner tube sheets and than pulled through the tube sheets in a step wise process. Steps in that process that included:

1) sectioning, between the between the inner and outer tube sheet, near the inner tube sheet surface,

2) tapping the inside end of the tube to provide a technique for tube withdrawal, 


\section{APPENDIX 3}

3) insertion of the tube draw device and removal the tube section by the application of a tensile load,

4) reaming to enlarge the hole in the outer tube sheet and decrease the restriction for subsequent steps in the tube pulling operation,

5) a repeat of steps two, three and four for the section contained within the inner tube sheet, and

6) cutting and extraction of tube sections between the two inner tube sheets.

All tubes were withdrawn from the moderator outlet end of the heat exchanger. The long section of tube between the two inner tubes sheets was sectioned during the withdrawal process. Appropriate care was taken to assure that no cuts were made at baffle positions or areas associated with eddy current indications of possible defects.

The tube pulling operation was not used to extract any tube that had eddy current indications beneath, or adjacent to, either the inner or outer tube sheet. These tubes were extracted by a core, or hole, drilling operation that also removed the section of tube sheet surrounding the tube of interest. This process left the tube-to-tube sheet interface relatively undisturbed. The steps involved in core drilling included:

1) sectioning between the between the inner and outer tube sheet at a position significantly remote from the inner tube sheet surface to preserve the area of interest,

2) core drilling through the outer tube sheet,

3) withdrawal of the tube-tube sheet section,

4) a repeat of steps two and three for the section contained within the inner tube sheet, and

5) cutting and extraction of tube sections between the two inner tube sheets.

Tubes 94-49 was not eddy current inspected because it was removed as part of the process to confirm and select tube extraction techniques for use on this particular heat exchanger. After tube 94-49 was removed, a decision was made to provide metallurgical evaluations of sections from all tubes extracted from the heat exchanger, thus tube 94-51 (the other tube used in the confirmation and selection process) was eddy current inspected before removal.

\section{EDDY CURRENT INDICATIONS}

A hole or leak in tube 94-38 was identified during the leak testing of the tube bundle in K-reactor heat exchanger 4A. The core rod was therefore withdrawn for this tube and eddy current inspection was initiated. The eddy current inspection indicated a significant defect in the tube wall adjacent to the inner tube sheet on the moderator outlet end of the heat exchanger, Figure 2. Subsequent visual inspection confirmed the eddy current indication and suggested that tube wear, induced by the presence of a foreign object on the shell side of the heat exchanger, had caused defect. Tube wear induced by foreign objects on the shell side had, during the history of SRS 


\section{APPENDIX 3}

reactor operations, caused ten other tube leaks, Table 1 . In each previous case, the wear was on a tube in the periphery of the tube bundle, Figure 3, and the wear location was near the inlet for the secondary cooling water. The observations on tube $94-38$ were consistent with the history of wear induced moderator leakage, thus, the emphasis for the eddy current test program was placed on evaluation of the peripheral tubes near the cooling water inlet.

One hundred thirteen tubes were examined by eddy current test techniques. These examinations provided eddy current indications from three general areas of the tubes:

1) beneath baffle plates,

2) beneath the tube sheet and/or adjacent to the tube-to-tube sheet interface, and

3 ) in isolated regions remote from either the tube sheets or baffle plates.

These eddy current indications were used to select tubes for extraction from the tube bundle. The extracted tube sections were decontaminated prior to the metallurgical evaluations. The eddy current indications from the eleven tubes selected for metallurgical evaluation are summarized in Table 2. As will be apparent from details in subsequent sections of this report, the eddy current indications were called in a conservative manner. In no case was uncalled damage observed and in most cases the measured tube damage was less than that indicated by the eddy current signal. This over prediction of damage was particularly true for the indications of baffle induced wear and defects beneath and/or adjacent to the tube sheets.

\section{METALLURGICAL EXAMINATION}

\section{Tube 94-38 (The Leaker)}

Tube 94-38 was removed from the heat exchanger by core drilling through the tube sheet. This process was selected because tube wear had been identified in the region adjacent to the tube-toinner tube sheet interface at the moderator outlet end of the hear exchanger. Core drilling provided the maximum assurance that the tube removal operation would not cause additional damage to the worn portion of tube. However, the core drilling operation does cause damage to adjacent tubes, therefore, tube 93-43 which had been selected as a base line tube because of the lack of eddy current indications and 94-39 which contained severil eddy current indications of significant interest, were removed prior to core drilling. The wear patterns on tube 94-38 and on the associated tube sheet are shown in Figure 4. The wear section on the tube was examined by scanning electron microscopy (SEM). The tube and tube sheet section was than mounted and serial sectioned for microscopic examinations of the tube wear area.

The scanning electron microscopy of the tube wear surface revealed a very smooth, flat topography (Figure 5). The wear tracks were only apparent at high magnifications and were approximately perpendicular to the tube axis, (Figure 6). Several sets of tracks were observed and the relative orientation of these tracks suggested that the relative motion of the tube surface and the surface of the foreign object varied by as much as thirty degrees.

The foreign object that caused the wear on, and moderator leakage from, tube 94-38 has not been identified. However, the shapes of the wear scars on both the tube and tube sheet have helped provide an indication of the size and shape of the foreign object, Figure 7 . This prediction of foreign object shape is consistent with the pre-extraction video observation that one of the plugged 


\section{APPENDIX 3}

tubes in row 95 of the tube bundle was also worn by the object. The video observations did not provide any direct evidence of the foreign object.

The video observation of wear on a tube in row 95 is not significant to reactor operations because all tubes in this lowest row on the periphery of the tube bundle had been previously plugged because of operational concerns. Localized wear of these plugged tubes would not cause moderator leakage or any of the attendant problems. The wear indication on the row 95 tube was below and immediately to the right of tube 94-38. If the shape of the foreign uiject is similar to that predicted in Figure 7, the object would have been too large to pass through the three eights inch diameter holes in the strainer plate and, in that case, would have entered the tube bundi: through gaps between the strainer plate and the heat exchanger shell.

The wear surface on tube 94-38 was polished to a finish of at least 600 grit. This can be seen by comparison of the surface topography of a 600 grit polish on type 304 stainless steel (Figure 8) with the wear surface previously shown in Figure 6. This very fine surface finish, the flatness of the wear scar, and the observation of wear tracks perpendicular to the tube length suggest that the 0.8 inch long wear scar on the tube was made by an object of similar length. If the foreign object had been significantly shorter than 0.8 inches, the probability of a flat, smooth wear scar across the majority of the worn region of the tube would have been very low. These observations provide the basis for the hypothesis that the long wear surface on the foreign object shown in Figure 7 was approximately 0.8 inches.

The leak site had apparently been damaged (Figure 9), probably during the eddy current inspection of the tube. The very thin, worn flaps of metal extending above the wear surfaces on the right side of the hole (Arrow A in Figure 9) are thought to have been forced up when the eddy current probe became lodged at the leak site. The bubble-like feature, barely apparent on the left side of the leak site (Arrow B in Figure 9), and the apparent deformation of the much of the thinned section of the tube (shown at slightly higher magnification in Figure 10) are also attributed to the lodging and removal of the eddy current probe.

The actual leak path was a rectangular hole approximately 0.02 inches wide and 0.085 inches long. (It is important to recognize that any metal that was above the wear surface during the incident should have been forced down by the continuing wear process.) The postulated rectangular hole is fit to the observed hole in tube 94-38 as illustrated in Figure 10. The protrusion of the metal flaps allowed the thickness of the remaining section to be estimated during the initial SEM examination. The sample was too large to permit its rotation (in the electron microscope chamber) so that the flap was perpendicular to the scanning beam, but the thickness could be estimated at ten to fifteen microns from nearly perpendicular rotations such as shown in Figure 11. Serial sectioning through the worn area of the tube confirmed the ligament thickness (Figure 12) and demonstrated that the wear surface on the foreign object was sufficiently smooth to wear the tube surface to a thickness of less than one grain diameter before the tube was penetrated. These observations indicate that the remaining ligament required to contain the $\mathrm{D}_{2} \mathrm{O}$ moderator in the tube under these wear conditions is less than ten microns.

Energy dispersive analysis of X-rays created during the scanning electron microsropy examination of the wear tracks failed to provide any identification of the wear debris except for silicon, oxygen, sulfur and aluminum. The sulfur on the wear surface was probably from the cutting oils used in core drilling the tube from the tube sheet and the oxygen, aluminum and silicon are typical elements in clay and sand. The absence of well defined wear debris is not surprising considering the water 


\section{APPENDIX 3}

flow during the wear process and the use of a decontamination procedure that included ultrasonic cleaning of the sample.

The fact that the wear process produced a very flat, very smooth surface may have enhanced the size of the leak path. Approximately 150 gallons or 1380 pounds of moderator passed through this hole during the 60 hour period of leakage. Therefore the rate of moderator leakage from tube 9438 was approximately twenty to twenty-five pounds per hour. This leak rate is significantly larger than the one to eighteen pounds per hour leak rates observed in previous foreign object wear incidents. None of the wear areas from the previous incidents were as consistently smooth and flat as the wear scar on tube 94-38.

The metallurgical evaluation of the leak site in tube 94-38 demonstrates that the leak was caused by wear which was induced by the presence of a foreign object in the secondary cooling water. The offending object has not been identified, however, size and shape estimates based on the wear scars suggest that the object may have been too large to have passed through the three eights diameter holes in the strainer plate immediately beneath the tube bundle and above the cooling water inlet. The smooth, flat wear surface suggests that the wear process was relatively slow. However, in the absence of any identification of the offending object, there is no technical basis for estimation of the progression rate of the wear process. The offending object, therefore may have been in place for a long period of time (years) or may have been introduced to the system only days, weeks or months before the December incident.

\section{Corrosion Induced Degradation}

The metallurgical evaluations of the selected tubes provided no evidence of intergranular attack, stress corrosion cracking, crevice corrosion, pitting or microbiologically influenced corrosion. Penetrant testing and macroscopic examination revealed no indications of corrosion induced degradation on either the outer or inner surfaces of any of the tube sections examined. Microscopic examination of both longitudinal and transverse cross sections also confirmed the absence of corrosion induced degradation. The focus of the examinations for corrosion induced effects was tube sections associated with tube sheets and baffles. This region was selected because crevices between the tube and tube sheets should increase the potential for corrosion in those areas compared to other portions of the heat exchanger tubes. Operational history of other heat exchangers also indicated that these creviced areas were the most likely areas to experience corrosion induced degradation.

The eddy current inspections had provided indications of possible degradation near the tube sheet interface of tubes 94-59 and 93-45 (Figures 13 and 14). Visual and macroscopic examination of these areas in these two tubes revealed no evidence of stress corrosion cracking or any other significant metallurgical defects. Penetrant testing of both inner and outer tube surfaces also provided no evidence of crack like defects. The metallurgical quality of these two tubes was further confirmed by serial sectioning and microscopic examination of the the tube-to-tube sheet regions. The only defect found during this detailed examination was a small groove, approximately 0.001 inches deep on the outer surface and near the tube-to-tube sheet crevice of tube 94-59 (Figure 15).

Similar metallurgical examinations, except for the serial sectioning, were conducted on the tube-totube sheet regions of rubes 94-49,93-43, 95-51, 94-38, and 92-48. No evidence of cracking, pitting, crevice corrosion or other metallurgical defects was found in any of these tubes. The lack of corrosion induced degradation in the tube-to-tube sheet region is consistent with the low levels of leakage that this heat exchanger had experienced throughout its operations history (Figure 16). 


\section{APPENDIX 3}

These observations suggest that, except for foreign object induced wear, the tubes in this heat exchanger were in excellent condition.

\section{Baffle Wear}

The baffle positions on most of the tube sections from this heat exchanger were apparent during visual examination because differences in the surface films in the baffle-to-tule crevice and because of minor, localized discontinuities in the surface films. Two tubcs, 94-39 and 93-71, were removed because of eddy current indications of baffle wear. The eddy current examinations had indicated a possibility of minor wear on tube $94-39$ at baffles 5, 6, and 9 and of significant wear on tube 93-71 at baffle 9. Penetrant test of the outer surfaces of sections that contained these baffle areas showed no indications of cracking or pitting. Furthermore, wall thickness measurements on tube 94-39 showed no significant wall thinning. Metallographic examination of these tubes provided no indications of corrosion damage. Measurable baffle induced wear was only cbserved in tube 93-71.

The visual examination of tube 93-71 had confirmed the presence of baffle wear and showed that much of the wear surface was covered with the dark film. Such filming is typical of the type 304 stainless steel surfaces exposed to river water for significant periods of time. The deepest, baffle induced wear measured on tube 93-71 was approximately $46 \%$ of the tube wall. The wear surfaces in this area were totally covered with the river water induced film, demonstrating that the wear process in this area had not been active during the recent reactor operations. Other portions of this baffle wear region had the shiny and burnished appearance of active wear; the maximum wear in these regions was $30 \%$ of the tube wall and most of the active wear region showing only $5 \%$ wear. Furthermore, the active areas which showed $30 \%$ wear were adjacent to the old wear, filmed wear scars and probably represent active burnishing of wear scars which had developed during previous operations.

The physical measurements of baffle wear demonstrated that the eddy current indications were very conservative, probably because of martensite transformations induced in the tube walls during the burnishing operations (Figure 17). Throughout the metallurgical evaluations, the actual depth of defects identified by the eddy current inspections as baffle wear was consistently less than predicted during evaluation of the eddy current indication, Table 3 . In no case was wear observed in regions not called by the eddy current inspections.

\section{Eoreign Object Wear in Other Tubes}

\section{Quter Surface Wear}

Two tubes, 92-65 and 93-49, were removed because the eddy current inspection had identified significant outer surface wall thinning, not associated with baffles or tube sheets. Measurement of the wear depth in both of these tubes, confirmed the eddy current indications, Table 4 . The wear process in these two tubes had recently been active, Figures 18-21, and other areas of tube burnishing by foreign objects were apparent. The topological characteristics of the wear tracks in tube 93-49 (Figures 22 and 23) suggested that although the wear was recently active, the process was probably inactive by the time of the December 22 incident .

The shape of the wear scars on tube 93-49 suggests that the offending object was long and thin, similar to a wire, thread or bristle. The four wear scars, shown in Figures 18 and 19, could have resulted from a single object moving down the tube during the hydraulic testing of the reactor. The 


\section{APPENDIX 3}

tarnish films on the wear scars support this hypothesis by suggesting that the four scars were formed one after another; the oldest scar having the darkest tarnish film. However, proof of this hypothesis is virtually impossible, and the four scars may had been caused by four different objects. Additionally, even though some wear, in each scar, had clearly developed during recent hydraulic testing, the observed wear may have taken years to develop.

The two scars from tube 92-65 were also recently active even though the tarnish films on the scar surfaces suggest that these "ar was inactive by the time of the December 22 incident. Contamination on this tube has prevented the scanning electron microscopy of the wear tracks. The shape of the scars on tube 92-65 suggest that the offending object was not similar to the object(s) that wore either tube $94-38$ or tube $93-49$. These observations suggest that at least three types of debris were responsible for the wear detected.

The metallurgical evaluations of tubes from this heat exchanger revealed no evidence of old, film covered, foreign object induced wear. This observation, coupled with the observations of recently active foreign object induced wear in tubes 94-38,93-49 and 92-65 (three of the one hundred twenty two tubes inspected by eddy current techniques), suggest that recent hydraulic testing of the reactor increased the tendency for wear in the peripheral tubes near the cooling water inlet. This suggestion is further supported by the fact that moderator leakage due to foreign object induced wear of heat exchanger tubing had not occurred since 1965. This analysis thus suggests that the probability for foreign object induced tube wear in heat exchanger tubing may be increasing. However, these evaluations cannot discount the possibility that the observed wear was due to objects which had been causing wear in the heat exchanger for years. Additionally, the fact that many of the wear scars were apparently inactive by the time of the December 22 incident suggests that the activity of the wear processes was decreasing at the time of the incident, probably because the objects which were inducing tube wear were being removed from the tube bundle.

\section{Inner Surface Wear.}

The only inner surface eddy current indications on any of the tubes examined were two indications on tube 93-71. These two indications were both inner surface wear associated with the "point" contact between the core rod and the inner surface of the tube (Figure 24). The depth of wear at both locations was approximately 0.017 inches or $34 \%$ of the tube wall. The eddy current evaluations had not provided estimated depths of these inner surface indications.

The metallurgical evaluation of the inner surfaces of this and several other tubes provided no evidence for pitting, stress corrosion or intergranular attack by the moderator. These observations are consistent with the lack of significant corrosion in the tubing in this heat exchanger.

\section{CONCLUSION}

The metallurgical evaluations demonstrate that wear, by a foreign object, of tube $94-38$ in $\mathrm{K}$ reactor heat exchanger $4 A$ caused the December 22,1991, tritium release. No evidence of corrosion induced degradation processes was found and the metallurgical condition of the tubing, except for isolated regions of foreign object wear was excellent.

Wear scars, which were recently active and caused by the action of foreign objects against three tubes in the $4 \mathrm{~A}$ heat exchanger tube bundle, were observed. No evidence for old, foreign object induced wear was noted. These observations suggest a possible increase in the tendency for wear in the peripheral tubes near the cooling water inlet. This suggestion is consistent with the fact that 


\section{APPENDIX 3}

moderator leakage due to foreign object induced wear of heat exchanger tubing had not occurred since 1965 . However, the data necessary to prove this suggestion are not available and neither the past, nor the present, rate or frequency of foreign object induced wear can be predicted from the present observations. 


\section{APPENDIX 3}

\section{LIST OF TABLES}

Table 1. Heat Exchanger Failures Caused by a Foreign Object

Table 2. Eddy Current Indications in the Eleven Tubes Selected for Metallurgical Evaluations

Table 3. Measured Depths of Baffle Wear

Table 4. Measured Depths of Foreign Object Induced Tube Wear 


\section{APPENDIX 3 \\ LIST OF FIGURES}

Figure 1. Tube Sheet Map of Area of Interest

Figure 2. Eddy Current Indication in Tube 94-38 from K-Reactor Heat Exchanger 4A. (Inspection used rotating pancake coil technique)

Figure 3. Tube Sheet Map Showing Locations of Previous Foreign Object Induced Wear Failures

Figure 4. Photographs Showing Wear Pattern on Tube 94-38 and on Inner Tube Sheet Containing Tube $94-38$

Figure 5. Scanning Electron Micrograph of wear Surface on Tube 94-38

Figure 6. Wear Tracks on the Wear Surface of Tube 94-38

Figure 7. Postulated Shape of Foreign Object that Caused Wear of and Moderator Leakage from Tube 9438

Figure 8. Topographical Appearance of 600 Grit Polish on Stainless Steel Plate

Figure 9. Scanning Electron Micrograph of Leak Site in Tube 94-38

Figure 10. Damage to Leak Site in Tube 94-38

Figure 11. Scanning Electron Micrograph Ilustrating Thinness of Wear Region

Figure 12. Metallographic Cross Section of Wear Region in Tube 94-38

Figure 13. Eddy Current Indication beneath Tube Sheet in Tube 93-45

Figure 14. Eddy Current Indication at Tube-to-Tube Sheet Interface in Tube 94-59

Figure 15. Small Groove in Tube 94-59. This was the only defect identified through extensive metallurgical characterization of the tube-to-tube sheet region of the tube

Figure 16. Graph Ilustration Leak History of K-reactor 4A Heat Exchanger

Figure 17. Surface Deformation and Martensite Associated with Burnishing Process

Figure 18. Wear Scars on Tube 93-49 Portion A

Figure 19. Wear Scars on Tube 93-49 Portion B

Figure 20. Wear Scar on Tube 92-65 Portion A

Figure 21. Wear Scar on Tube 92-65 Portion B

Figure 22. Wear Tracks on Portion A of Tube 93-49 


\section{APPENDIX 3}

Figure 23. Wear Track on Portion B of Tube 93-49

Figure 24. Inner Surface Wear Scar on Tube 93-71 and Photograph of Typical Core Rod 


\section{APPENDIX 3}

TABLE 1

HEAT EXCHANGER FALLURES CAUSED BY A FOREIGN OB.IECT

Eailure Number

$2 \mathrm{P} 1$

$24 \mathrm{C} 3$

29R7

$30 \mathrm{~K} 6$

$32 \mathrm{~L} 9$

$33 \mathrm{C5}$

$35 \mathrm{~L} 10$

$36 \mathrm{C7}$

$40 \mathrm{~K} 10$

$42 \mathrm{C} 10$
Date of Eailure

$2 / 17 / 56$

$7 / 31 / 61$

$8 / 31 / 63$

$11 / 19 / 63$

$4 / 25 / 64$

$6 / 13 / 64$

$8 / 11 / 64$

$9 / 13 / 64$

$12 / 18 / 64$

$11 / 14 / 65$

\section{Eoreign_ Object}

weld electrode

tie rod spacer

insulated wire

plastic bristle

plastic bristle

plastic bristle

plastic bristle

plastic bristle

plastic bristle

stone
Leak Rate

$18.0 \mathrm{lbs} / \mathrm{hr}$

$1.8 \mathrm{lbs} / \mathrm{hr}$

$1.1 \mathrm{lbs} / \mathrm{hr}$

$6.1 \mathrm{lbs} / \mathrm{hr}$

$3.3 \mathrm{lbs} / \mathrm{hr}$

$5.6 \mathrm{lbs} / \mathrm{hr}$

$16.2 \mathrm{lbs} / \mathrm{hr}$

$5.6 \mathrm{lbs} / \mathrm{hr}$

$3.4 \mathrm{lbs} / \mathrm{hr}$

$6.0 \mathrm{lbs} / \mathrm{hr}$

TABLE 2

\section{EDDY CURRENT INDICATIONS IN THE ELEVEN TUBES SELECTED FOR METALLURGICAL EVALUATIONS}

Tube

Number

$92-48$

$92-65$

93-43

93-45

93-49

93-71

94-38

94-39

94-49

94-51

94-59
Eddy Current Indication

Tube-to-Tube Sheet

Yes

No

No

Yes

No

No

No

No

Not evaluated by eddy current inspection

Yes

No
No

Yes
Bemote from Bafiles

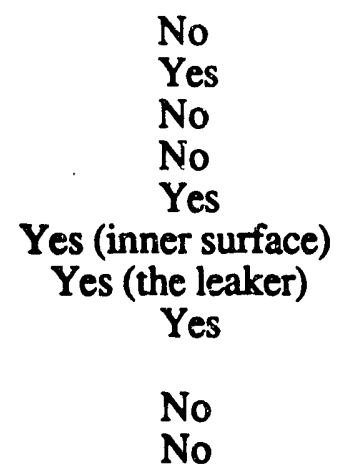




\section{APPENDIX 3}

TABLE 3

\section{MEASURED DEPTLS OF BAFFLE WEAR}

Tube

Number

92-48

92-65

93-43

93-45

93-49

93-71
Baffle Number

no wear noted

7

no wear noted

1

5

6

2

3

5

9

10

11

13

9
Eddy Current_Indication

$8 \%$

$20 \%$

$18 \%$

$21 \%$

$20 \%$

$11 \%$

$7 \%$

$5 \%$

$17 \%$

$17 \%$

$21 \%$

$10 \%$

$13 \%$

$66 \%$
Actual

Physical Measurement

(The deepest wear under baffle 9 was old and had filmed over, the shiny, or burnished regions indicative of recent wear were $30 \%$ of the wall on one side of the tube and $5 \%$ of the wall on the other side.)

94-38

94-39

94-49

94-51

94-59

$\begin{array}{ll}5 & 11 \% \\ 5 & 23 \% \\ 6 & 15 \% \\ 9 & 15 \%\end{array}$

not examined for baffle wear 7 no wear noted
$5 \%$ not measured

burnishing

burnishing

burnishing

not measured 


\section{APPENDIX 3}

TABLE 4

\section{MEASURED DEPTHS OF FOREIGN OBJECT} INDUCED TUBE WEAR

Tube

Number Eddy Current_Indications

$92-48$

$92-65$

93-43

93-45

93-49

93-71

94-38

94-39

94-49

94-51

94-59 no foreign object wear noted

$40 \%$

$15 \%$

no foreign object wear noted

no foreign object wear noted $50 \%$

$23 \%$

inner surface wear

two locations, no depth estimates

$98 \%$, the leaker $19 \%$

no foreign object wear noted no foreign object wear noted

no foreign object wear noted

\section{Actual_Physical_Measurement}

$40 \%$

$10 \%$

two nearly adjacent scars, $62 \%, 10 \%$ two nearly adjacent scars, $38 \%, 12 \%$ $34 \%$, both locations (wear caused by core rod) $100 \%$ no wear detected 
APPENDIX 3

Figure 1 Tube Sheet Map of Area of Interest

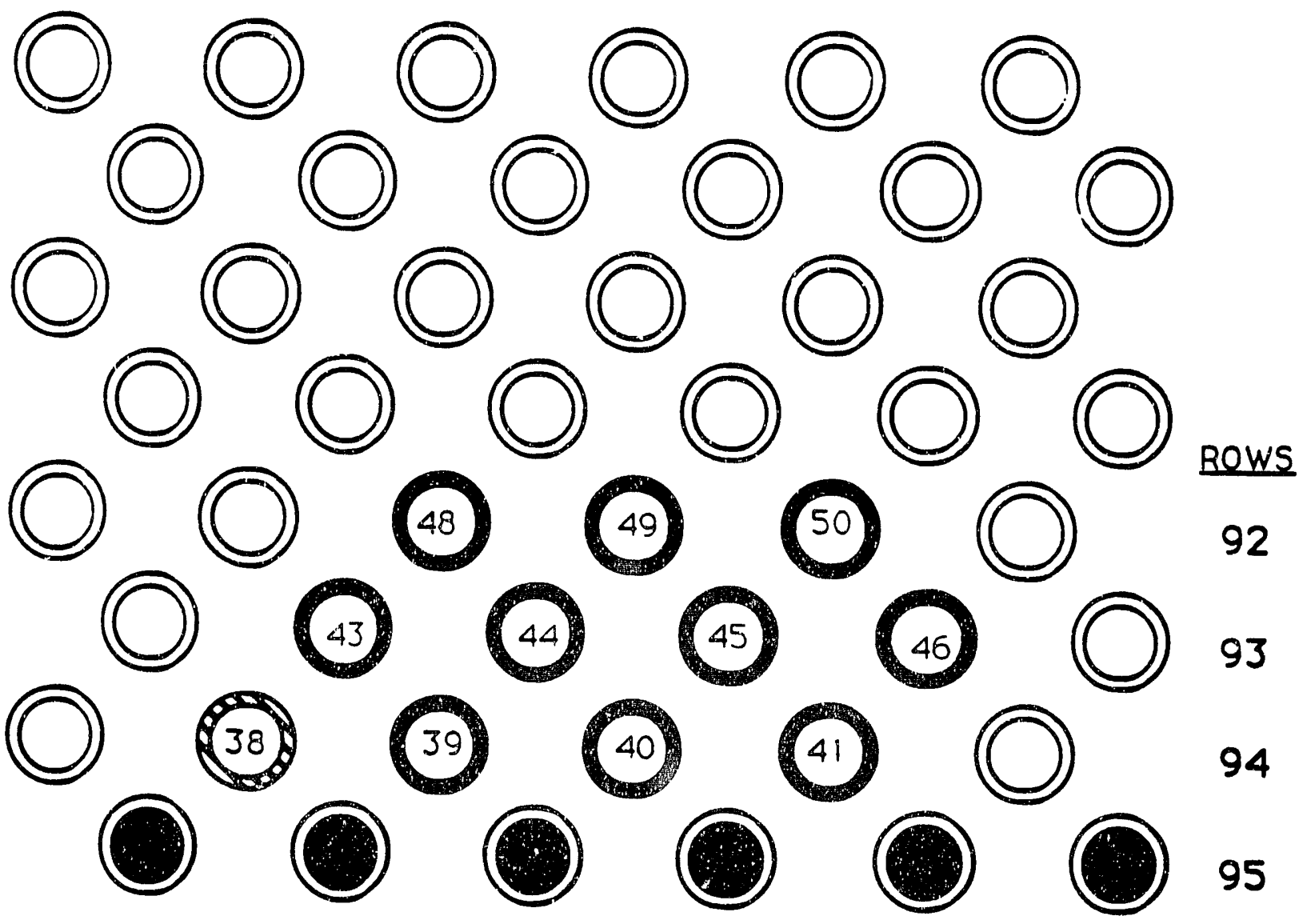

Plugged Tubes in Row 95

Original 10 Tubes of interest (without core rods)

8 Leaking Tube 


\section{APPENDIX 3}

Figure 2 Eddy Current Indication in Tube 94-38 from K-Reactor Heat Exchanger 4A. (Inspection used rotating pancake coil technique)

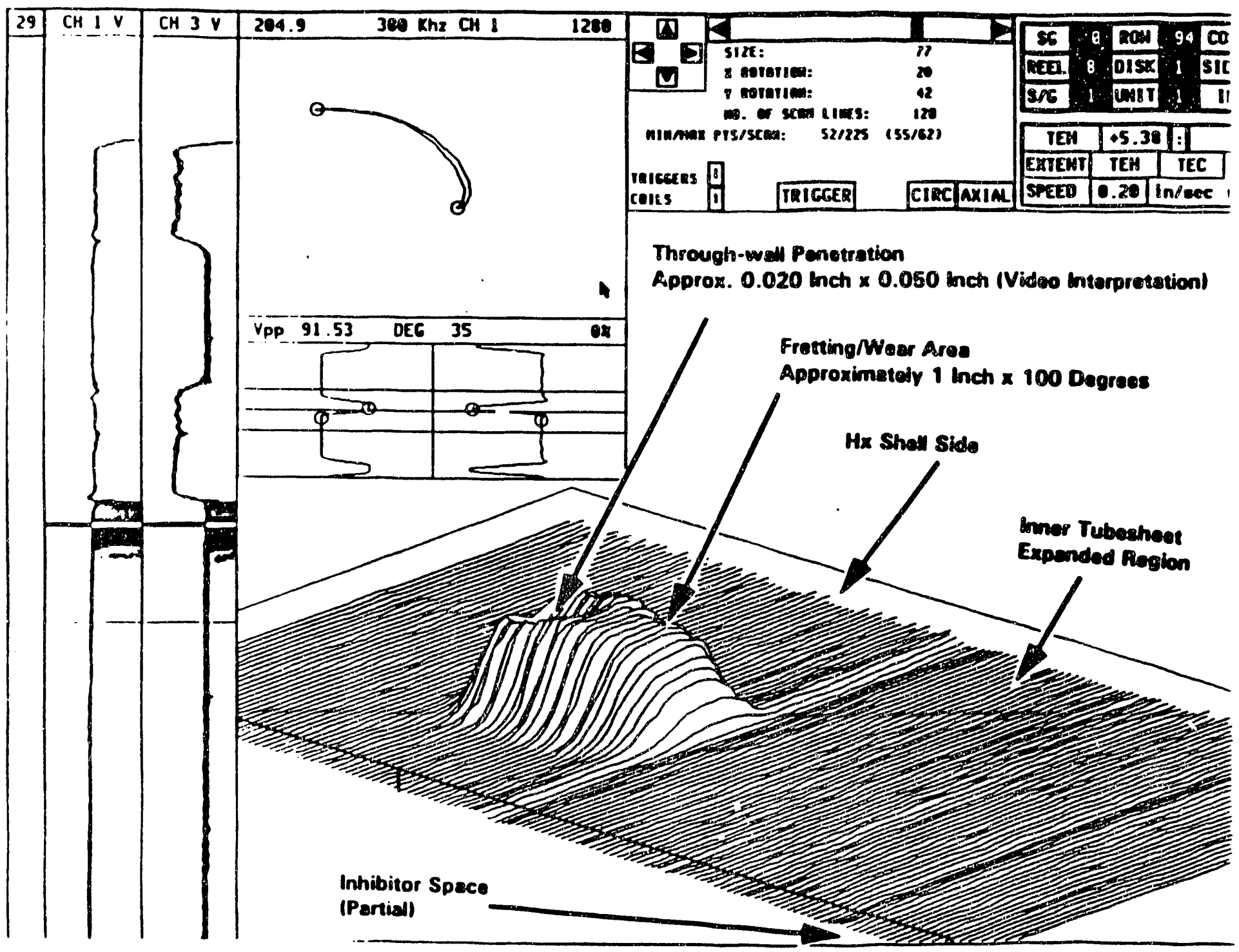




\section{APPENDIX 3}

Figure 3 Tube Sheet Map Showing Locations of Previous Foreign Object Induced Wear Failures

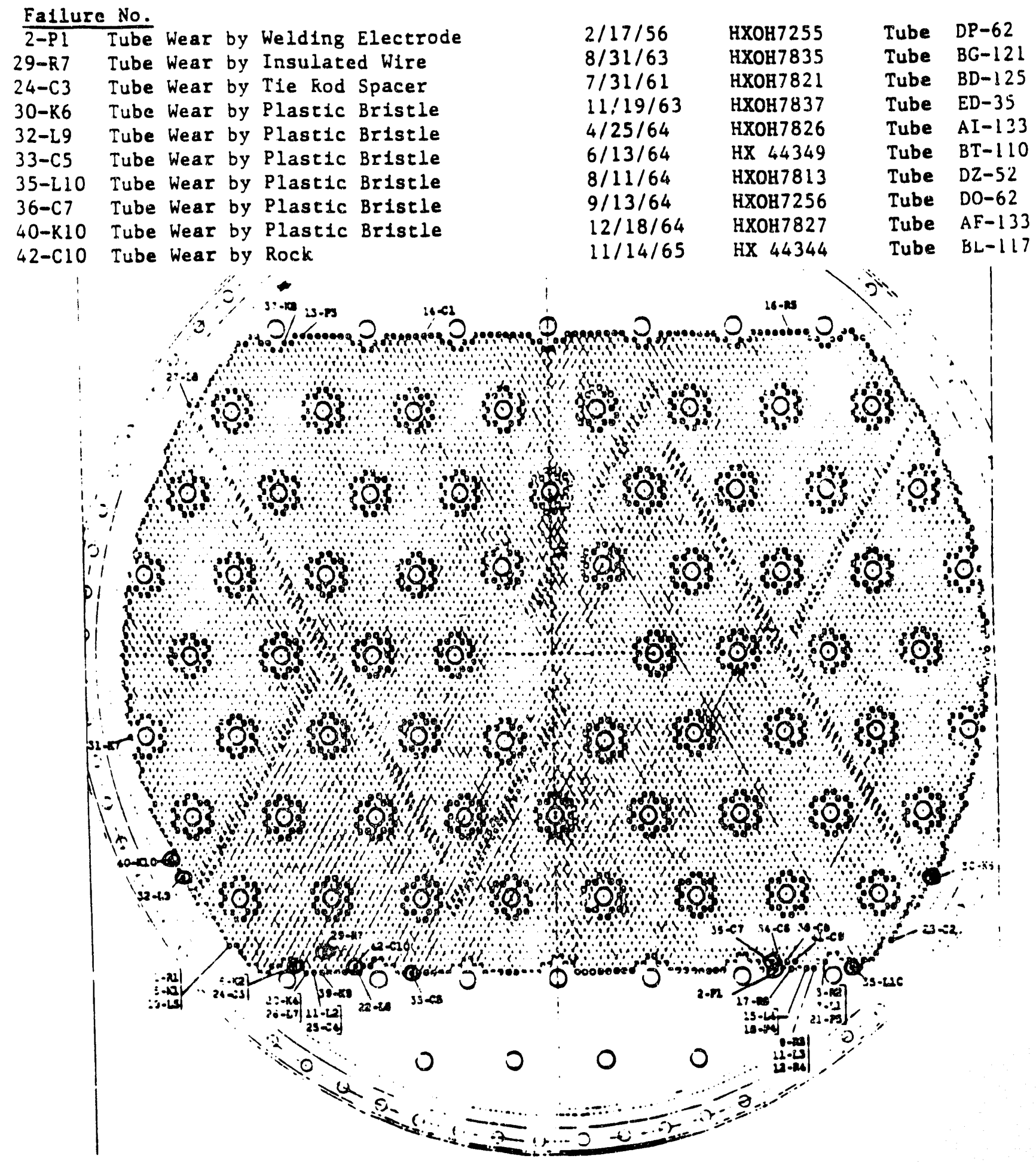


APPENDIX 3
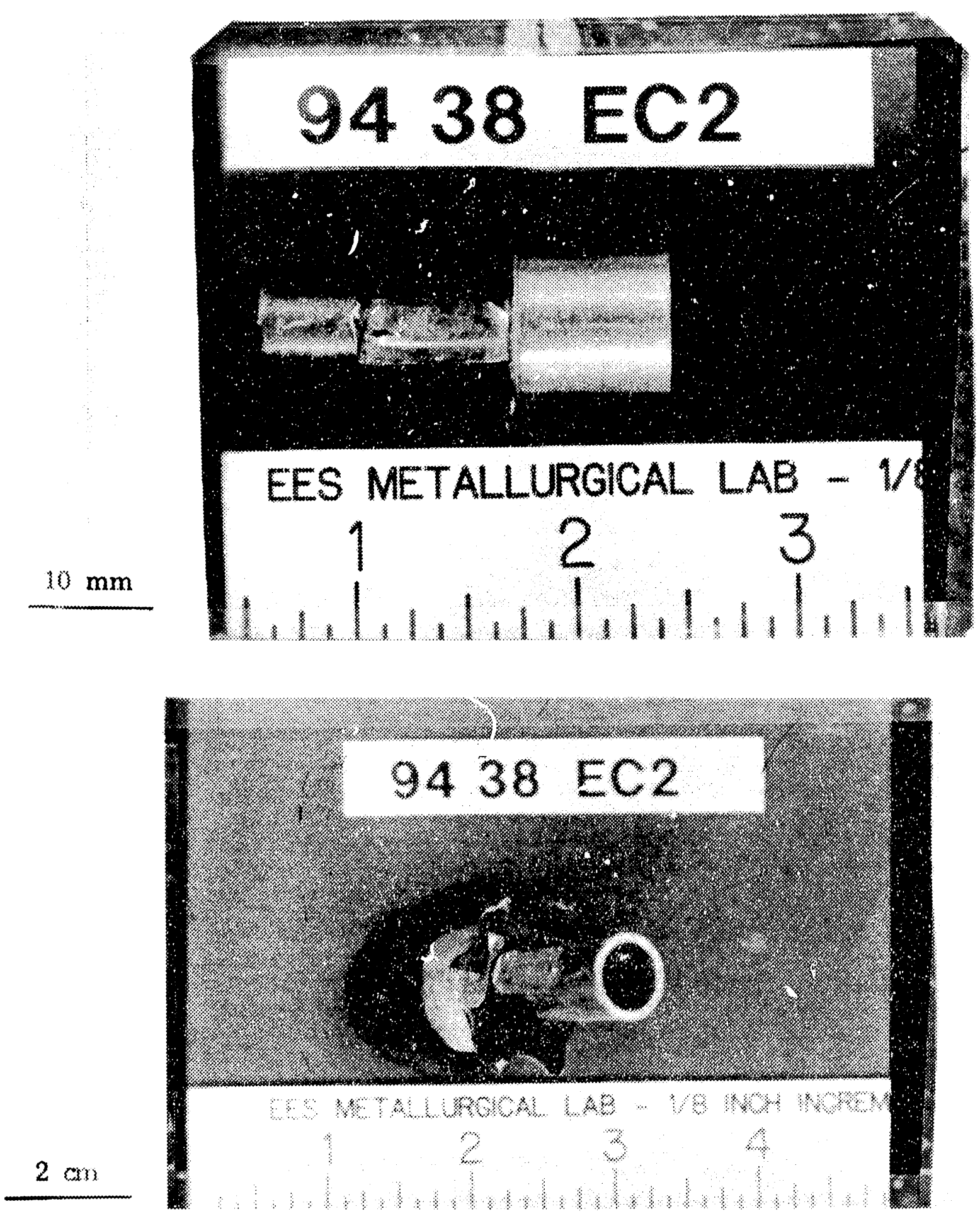

Figure 4 Photographs Showing Wear Pattern on Tube 94-38 and on Inner Tube Sheet Containing Tube 94-38 
APPENDIX 3

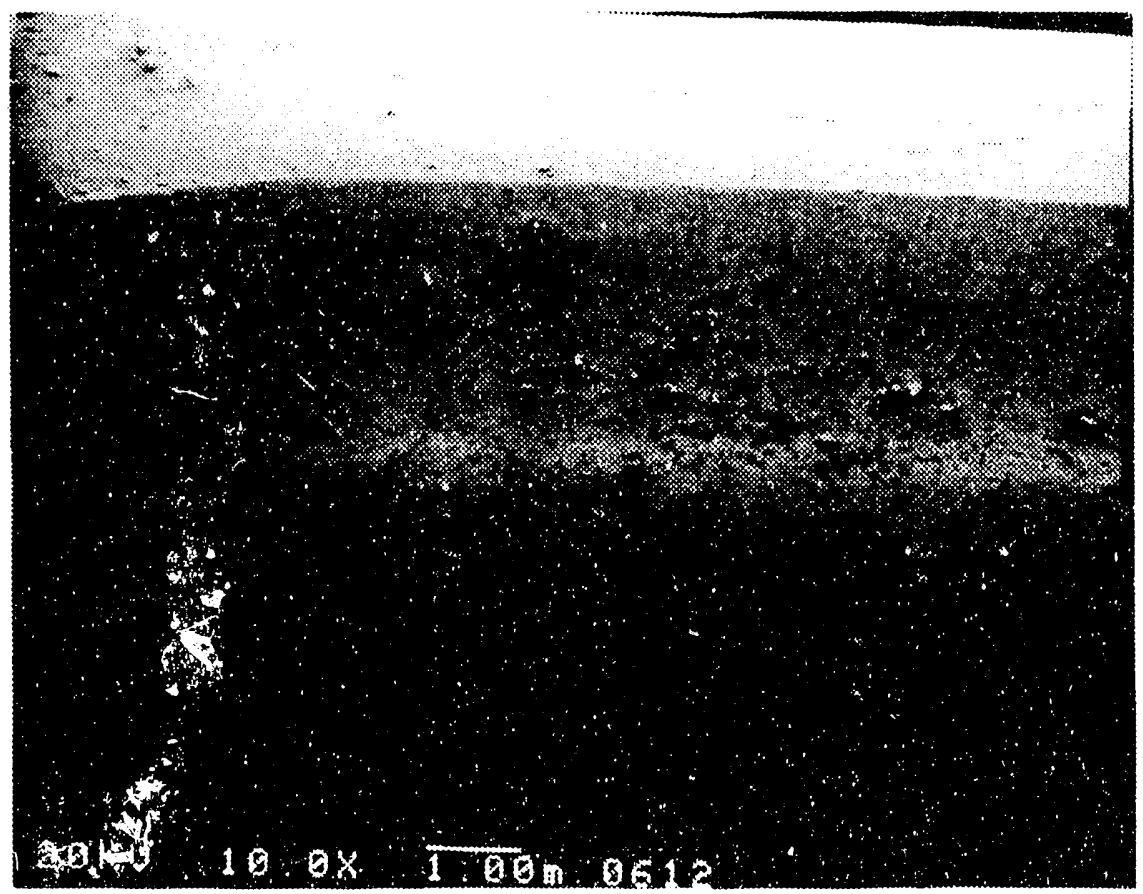

Figure 5 3̇canning Electron Micrograph of wear Surface on Tube 94-38

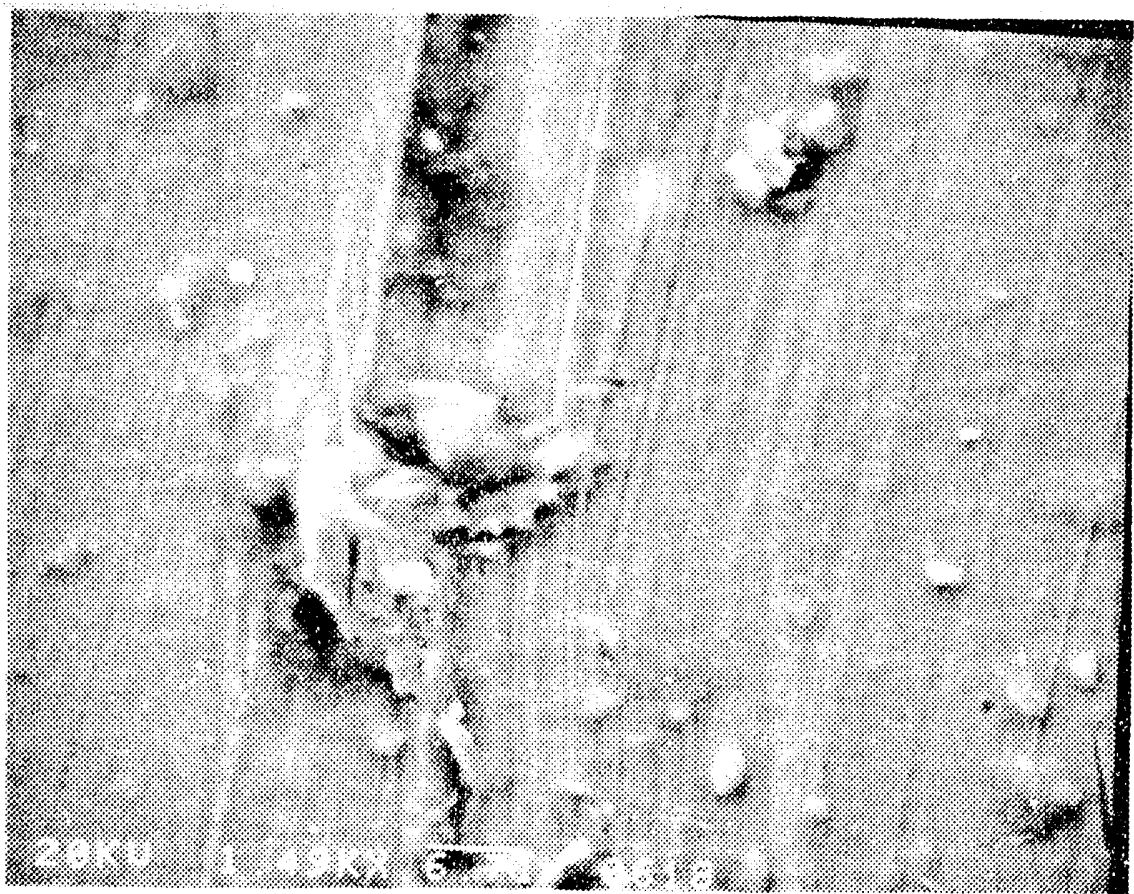

Figure 6 Wear Tracks on the Wear Surface of Tube 94-38 


\section{APPENDIX 3}

Figure 7 Postulated Shape of Foreign Object that Caused Wear of and Moderator Leakage from Tube 94-38
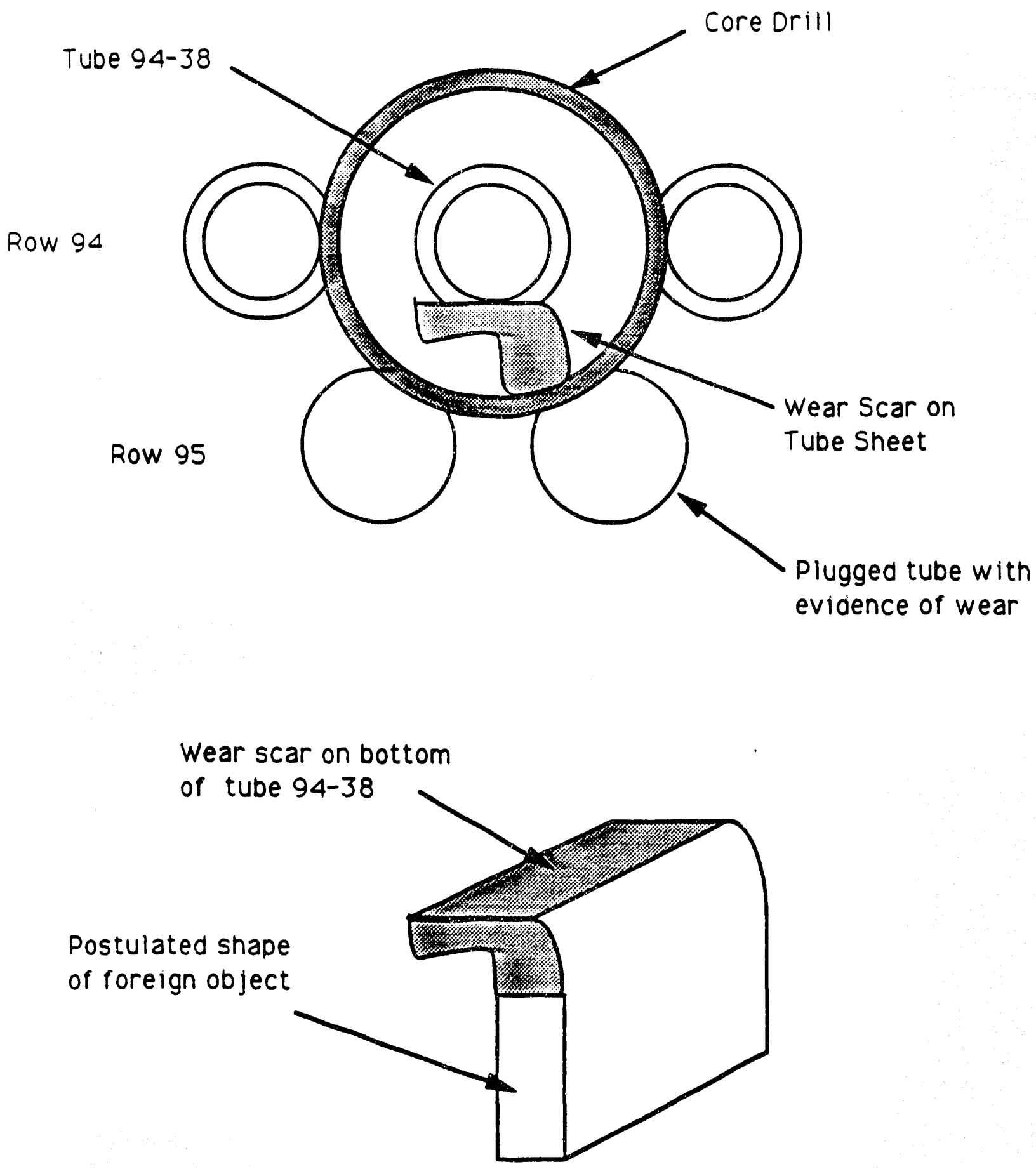


\section{APPENDIX 3}

Figure 8 Topographical Appearance of 600 Grit Polish on Stainless Steel Plate

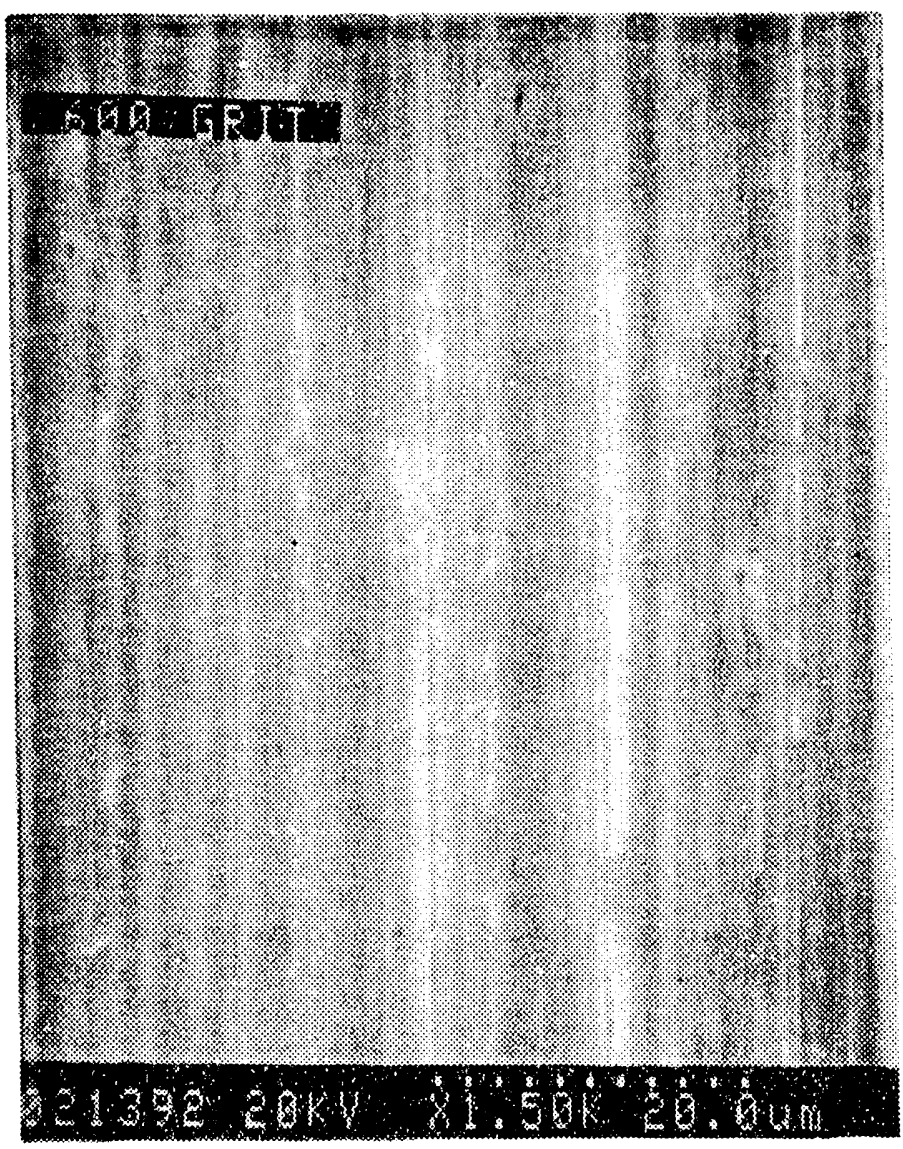




\section{APPENDIX 3}

Figure 9 Scanning Electron Micrograph of Leak Site in Tube 94-38

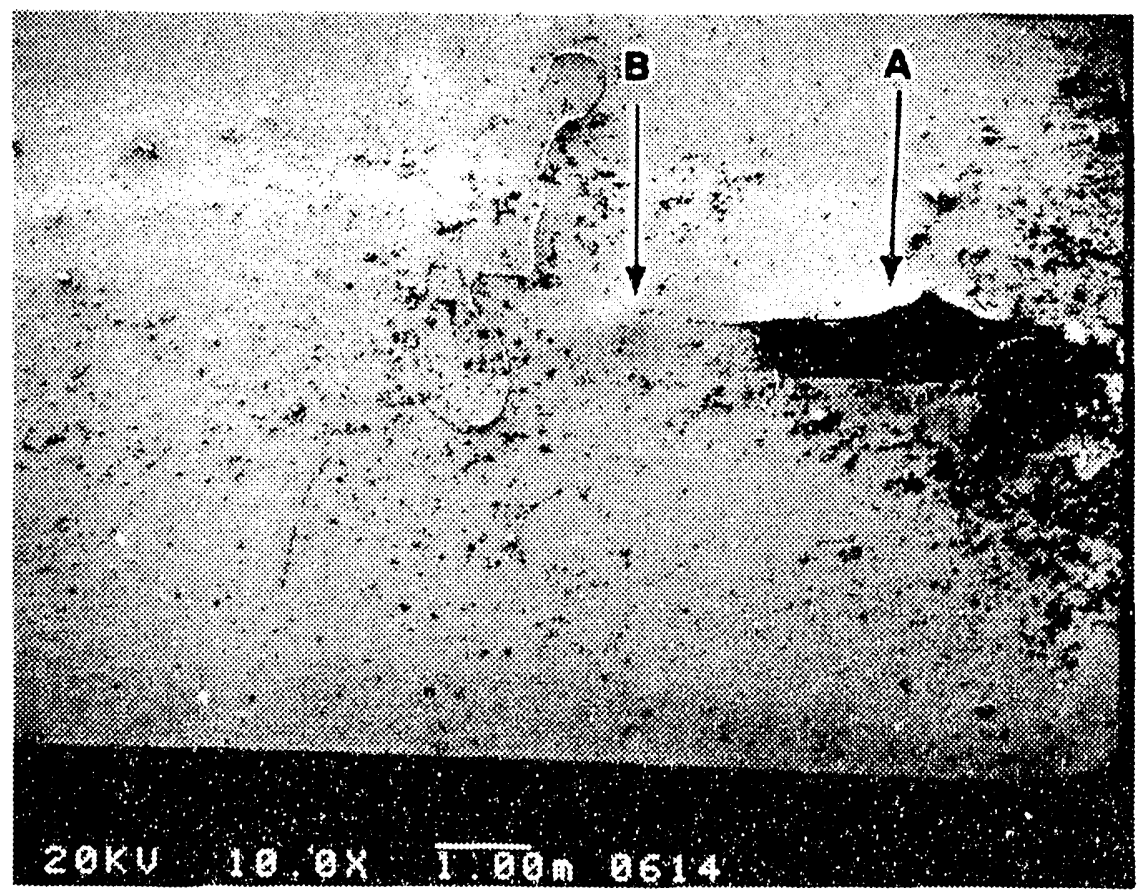




\section{APPENDIX 3}

Figure 10 Damage to Leak Site in Tube 94-38

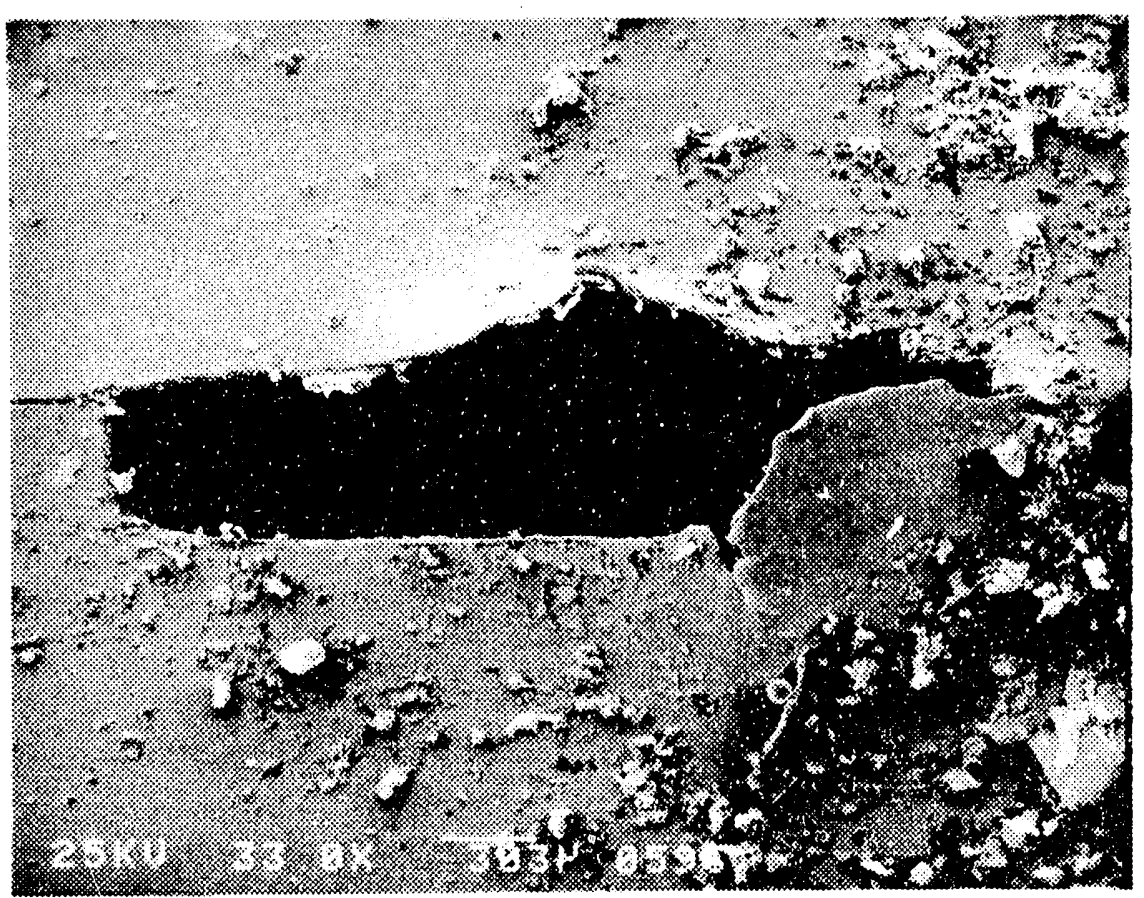


APPENDIX 3

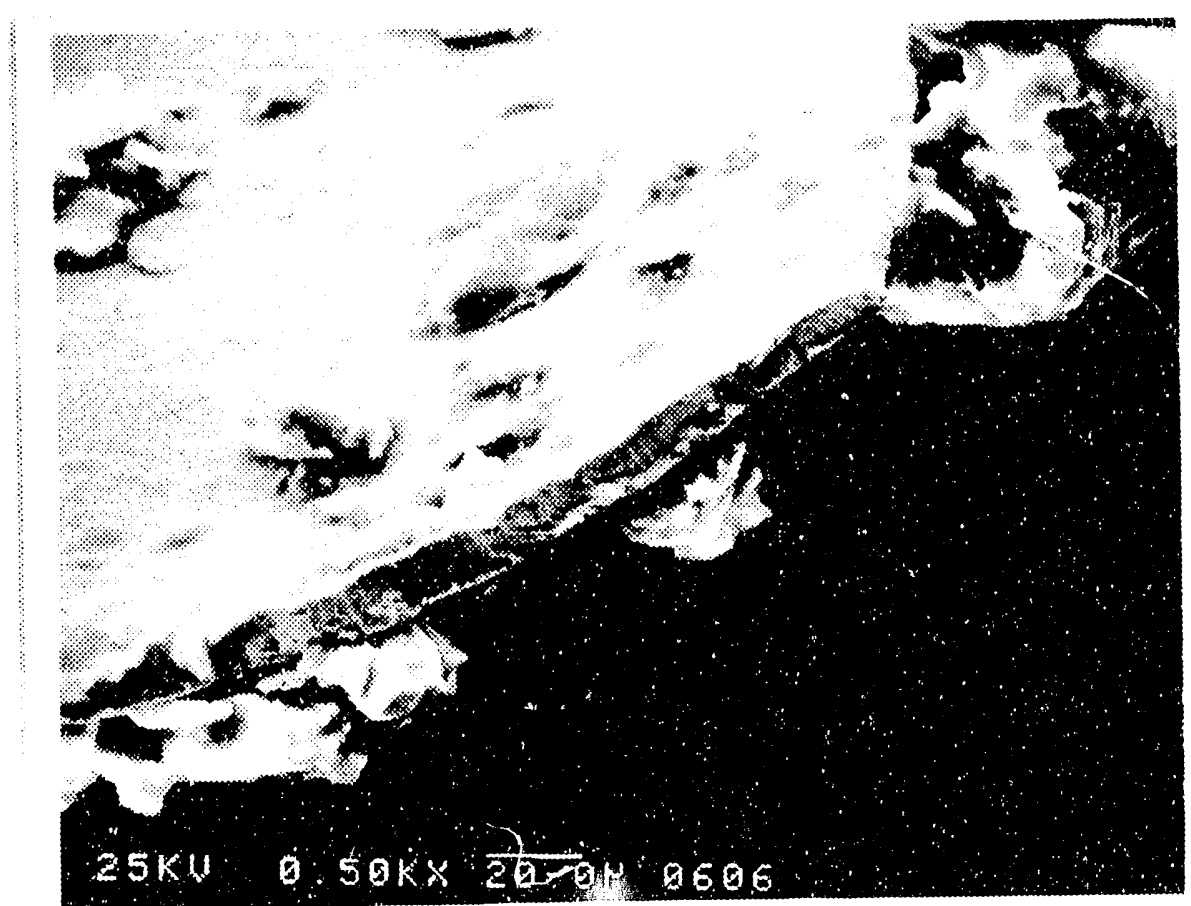

Figure 11 Scanning Electron Micrograph Illustrating Thinness of Wear Region

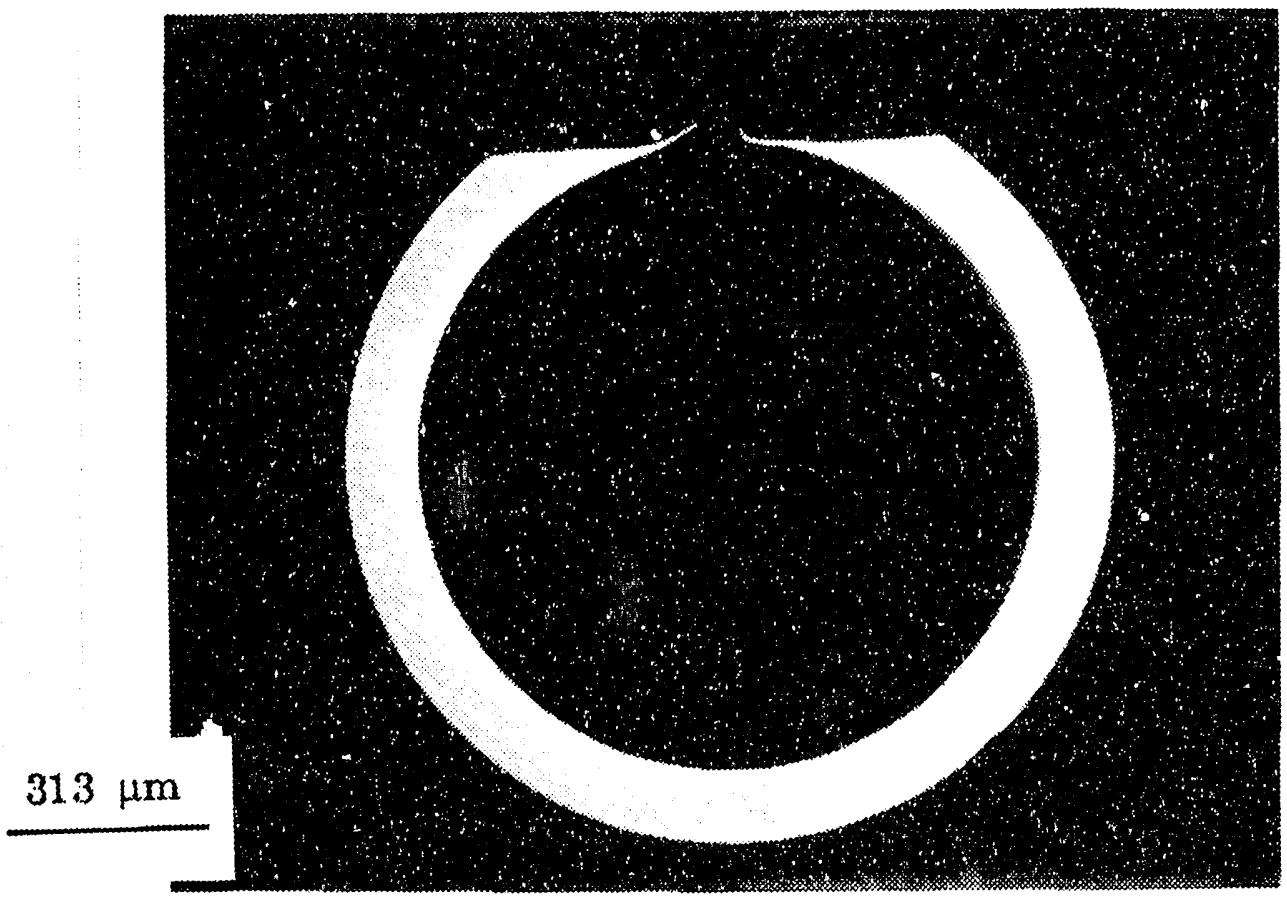

Figure 12 Metallographic Cross Section of Wear Region in Tube 94-38 
WSRC-TR -92-97

Heat Exchanger Restart Evaluation
Revision 1

Page 66 of 73

\section{APPENDIX 3}

Figure 13 Eddy Current Indication Beneath Tube Sheet in Tube 93-45

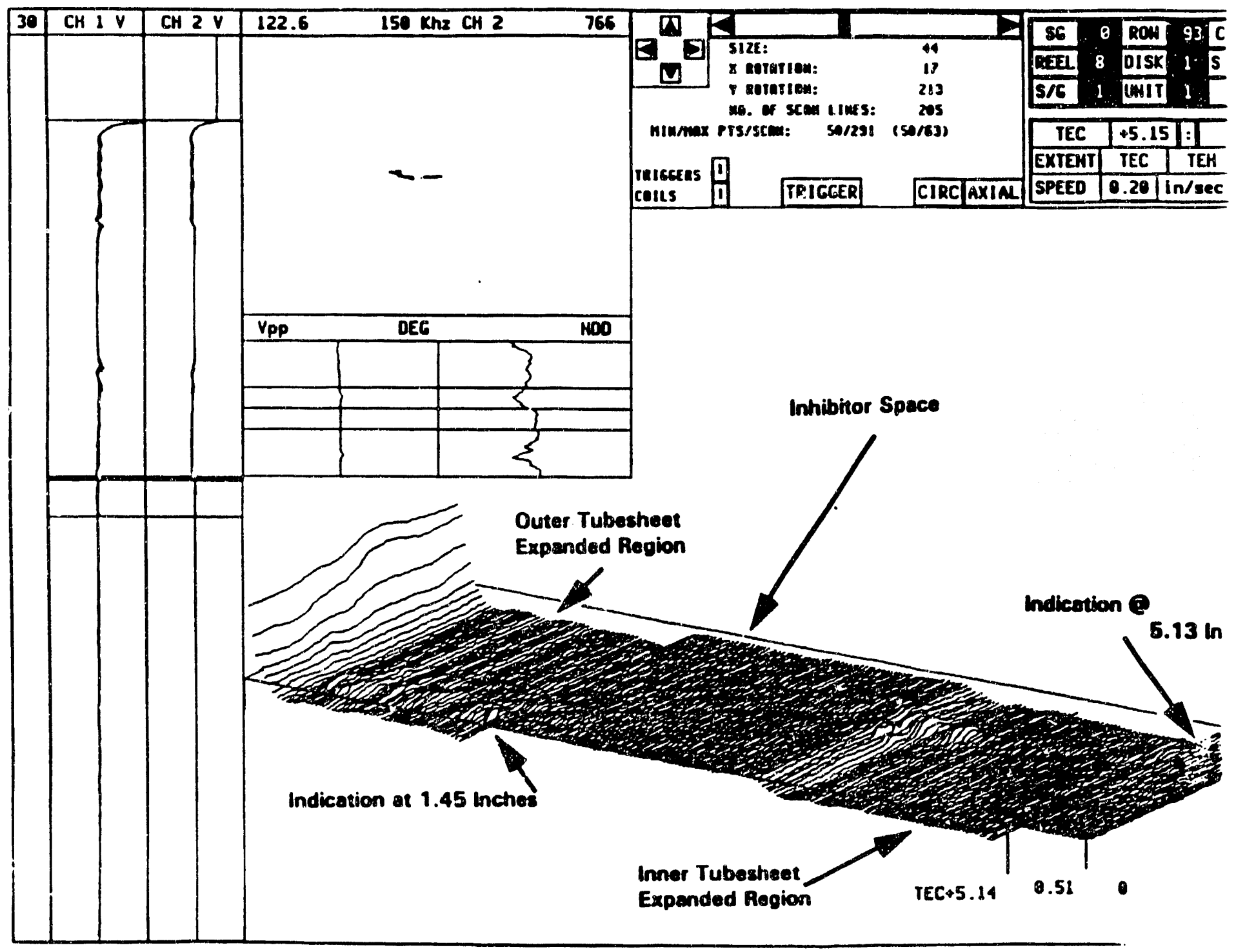




\section{APPENDIX 3}

Figure 14 Eddy Current Indication at Tube-to-Tube Sheet Interface in Tube 94-59

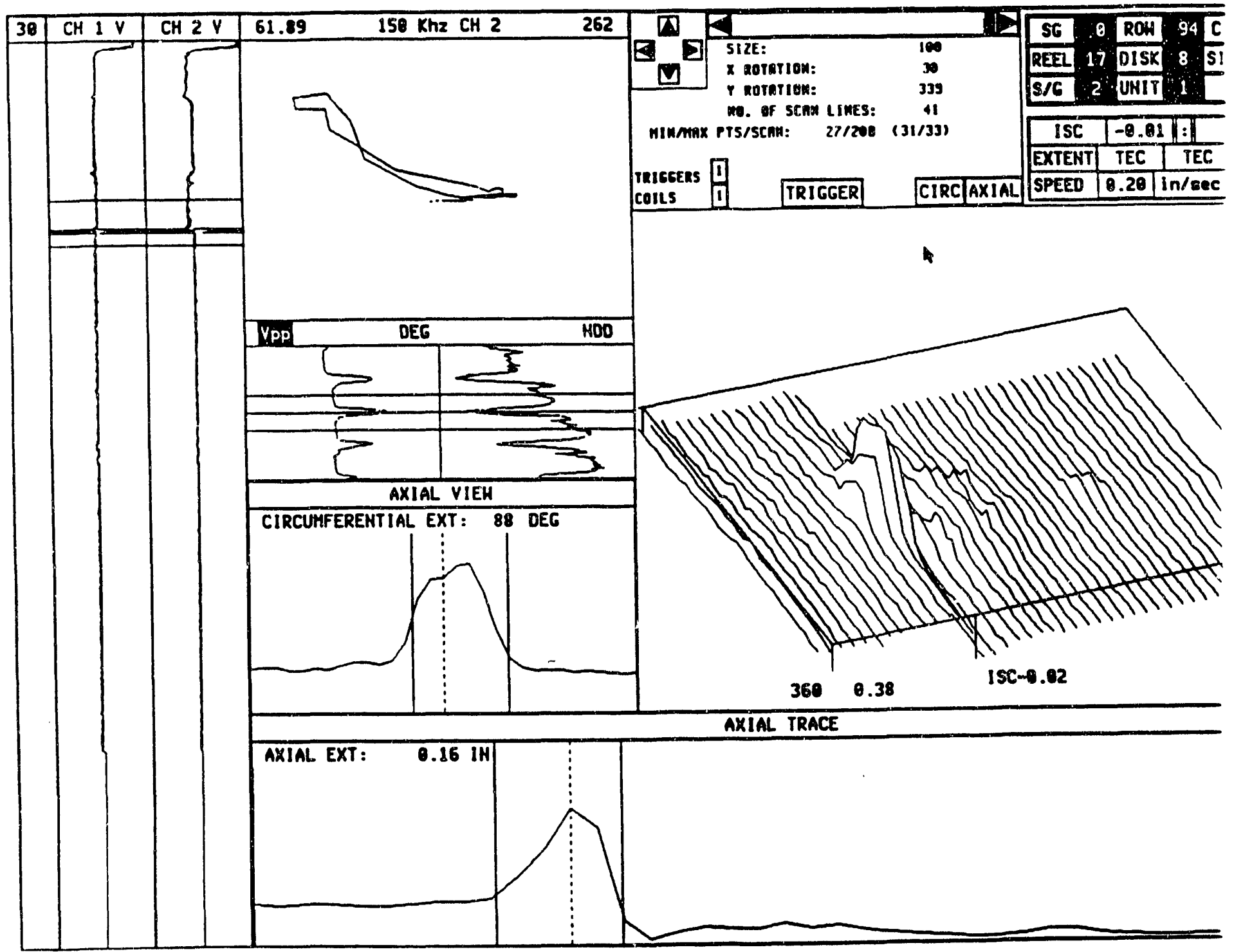




\section{APPENDIX 3}

Figure 15 Small Groove in Tube 94-59

(This was the only defect identified through extensive metallurgical characterization of the tube-to-tube sheet region of the tube)
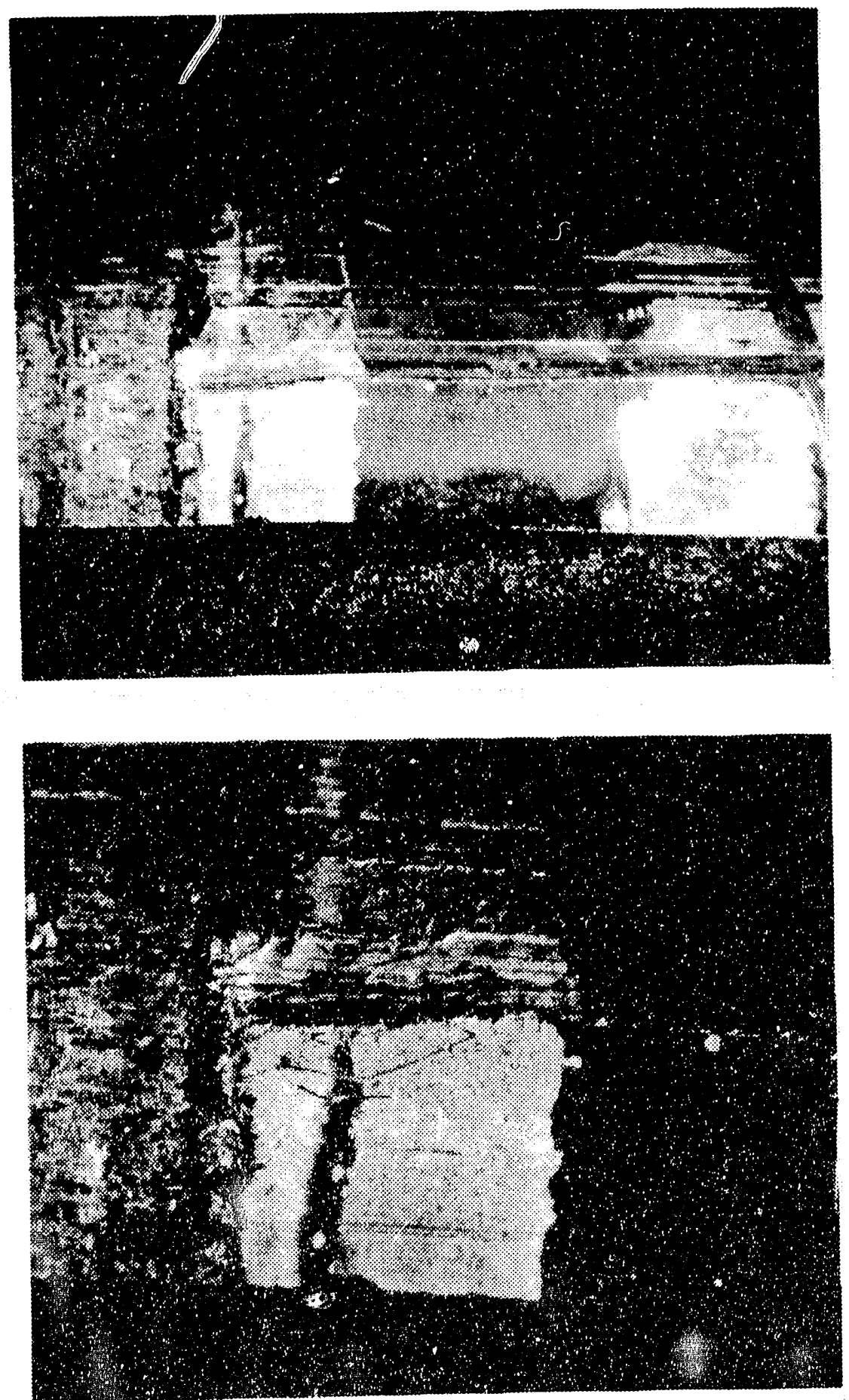


\section{APPENDIX 3}

Figure 16 Graph Illustration Leak History of K-Reactor 4A Heat Exchanger

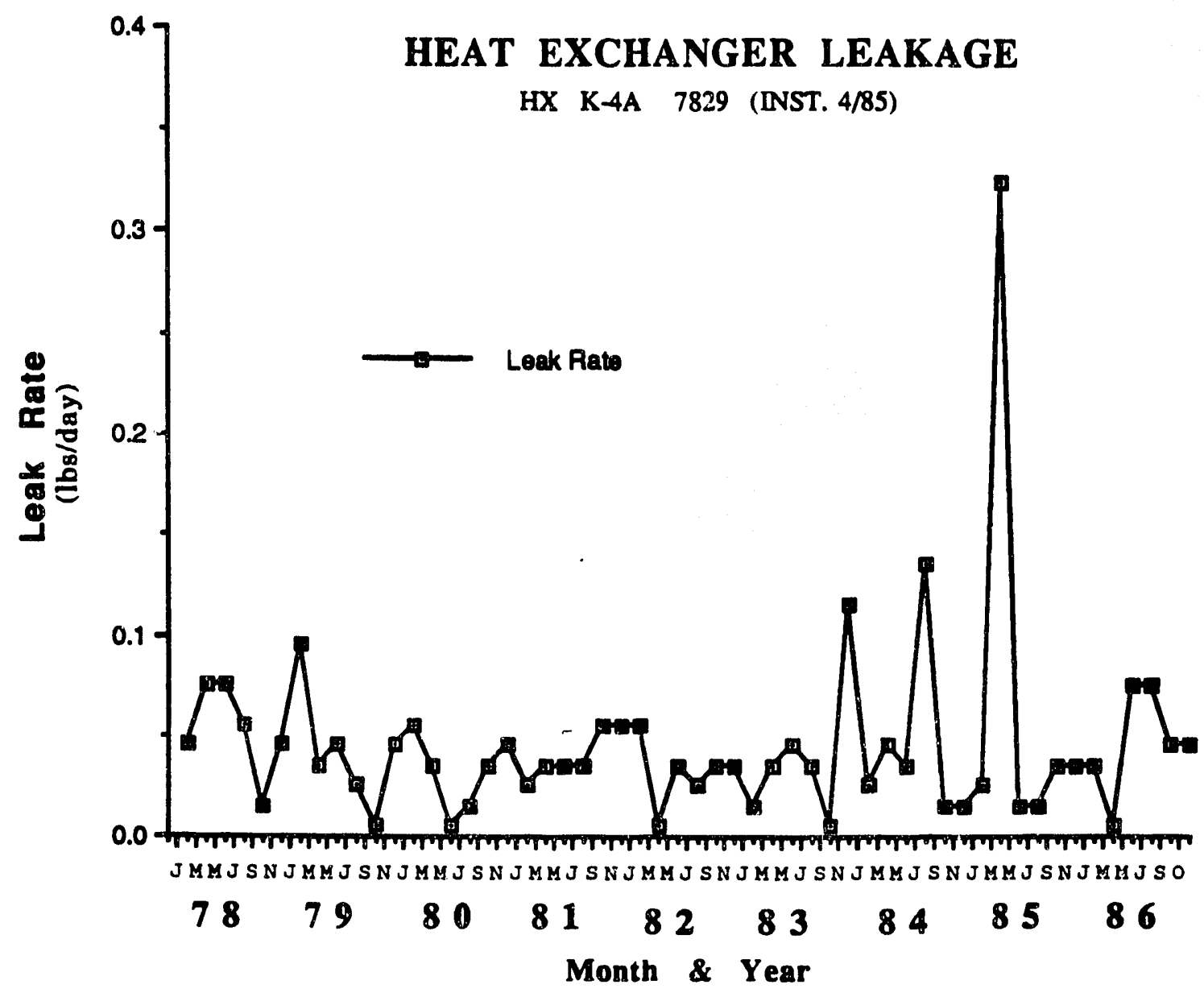


APPENDIX 3

$200 \mu \mathrm{m}$

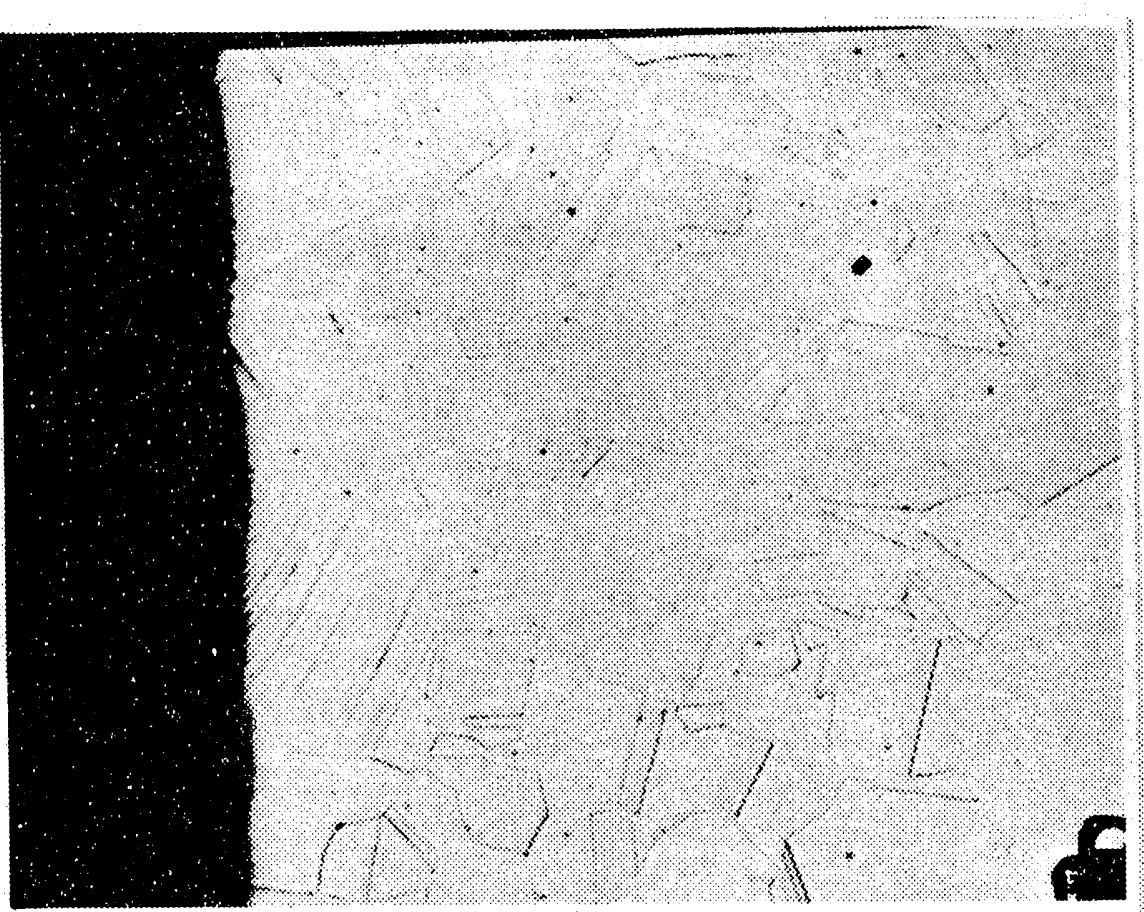

Figure 17 Surface Deformation and Martensite Associated with Burnishing Process
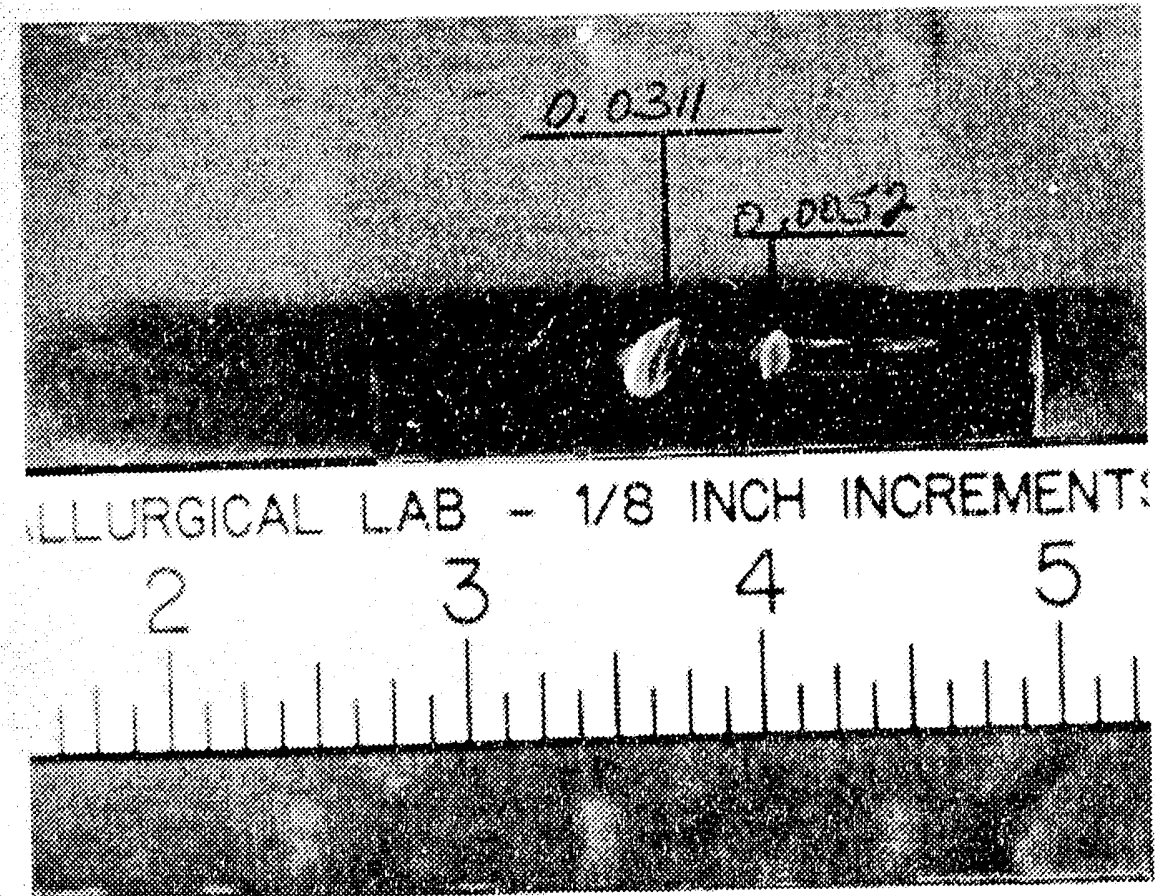

Figure 18 Wear Scars on Tube $93-49$ Portion A 
APPENDIX 3

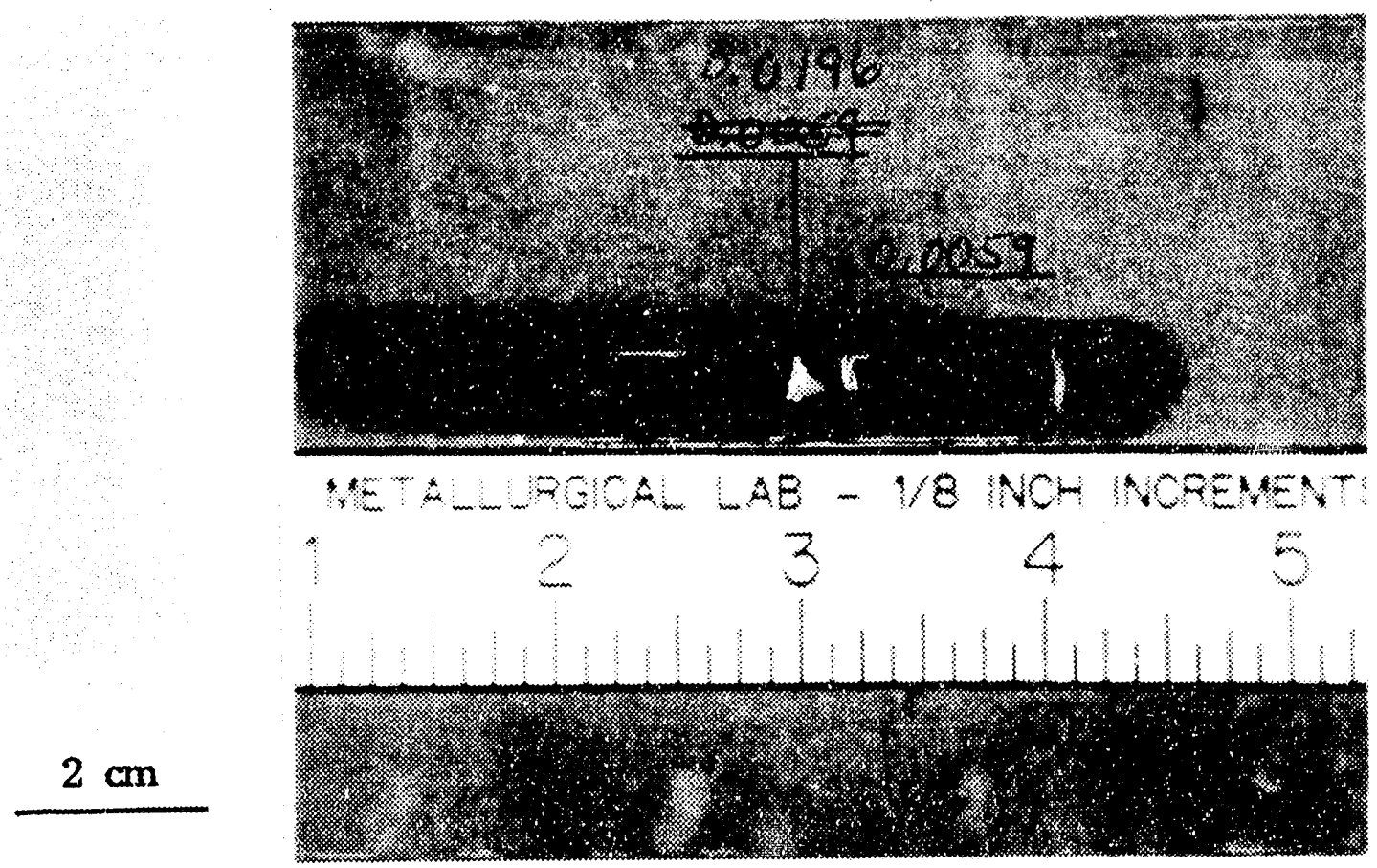

Figure 19 Wear Scars on Tube 93-49 Portion B

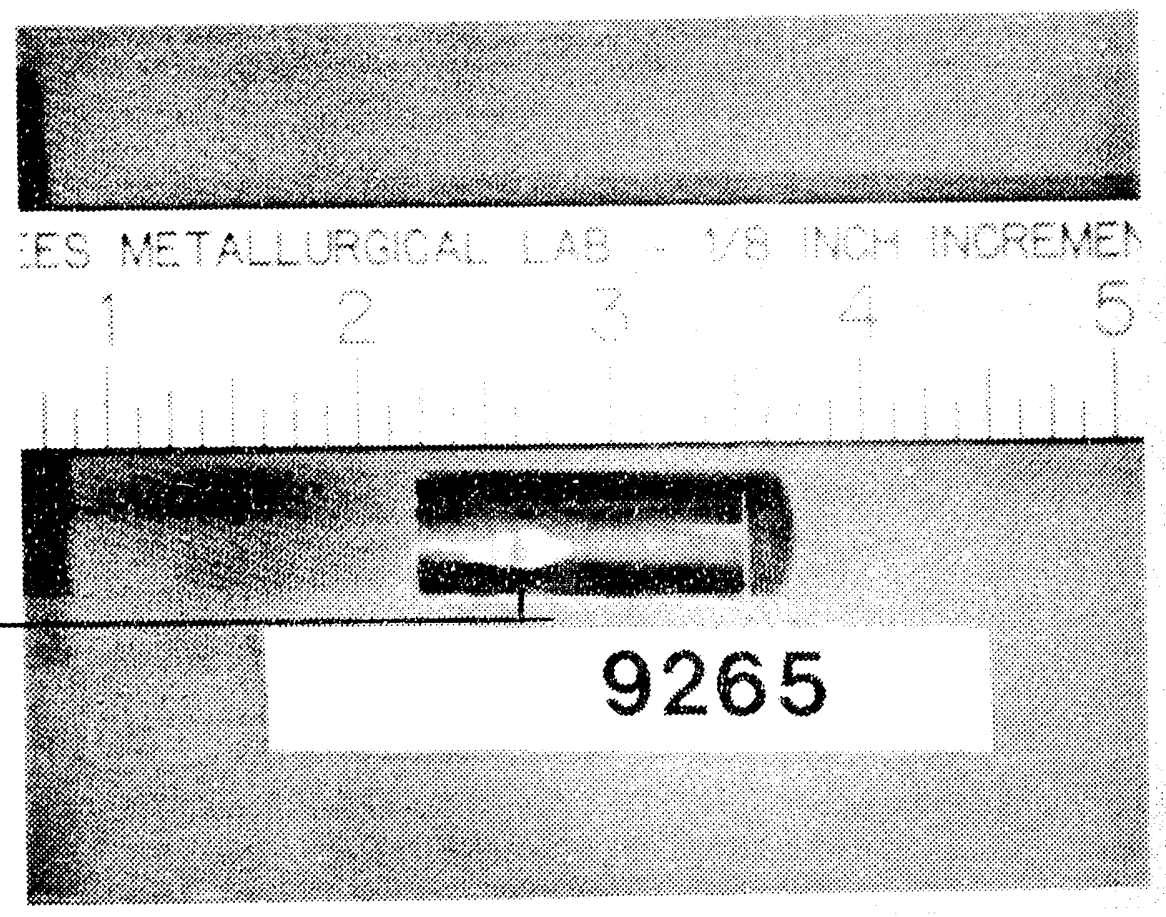

Figure 20 Wear Scar on Tube 92-65 Portion A 


\section{APPENDIX 3}
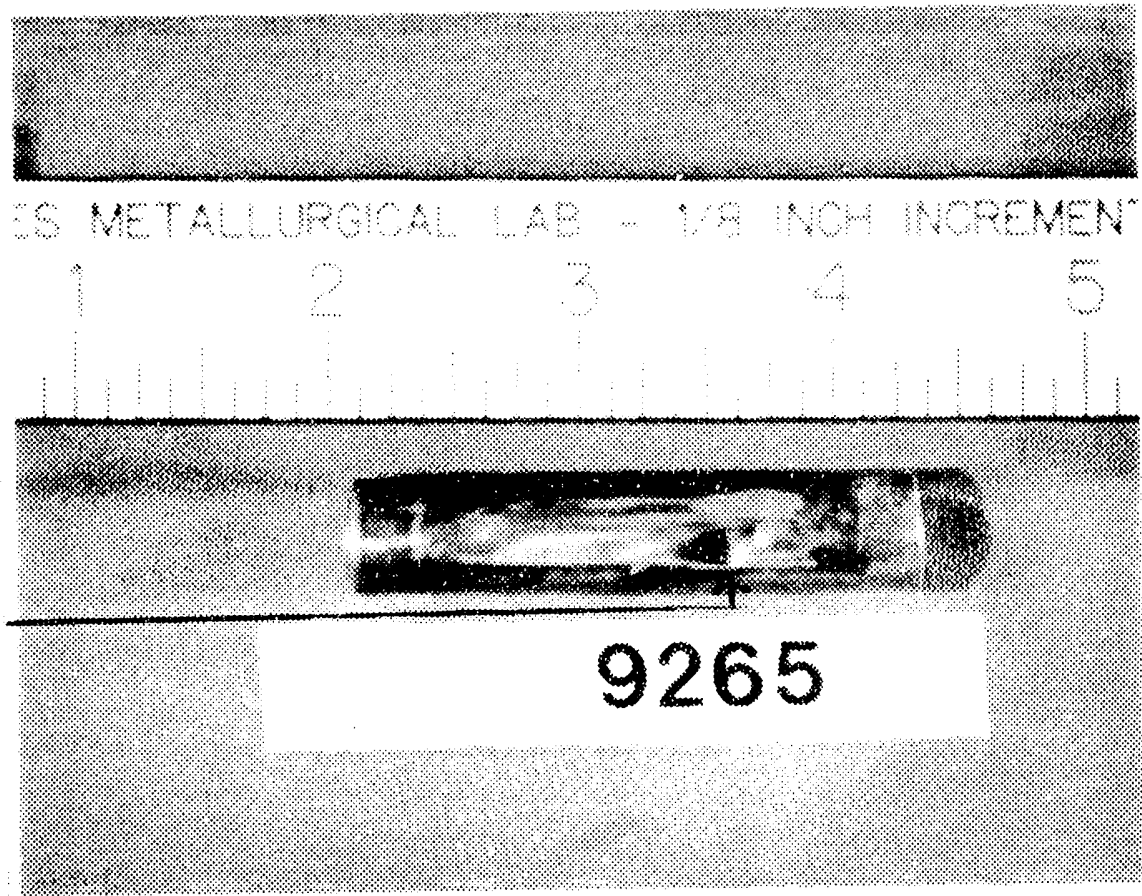

Figure 21 Wear Scar on Tube 92-65 Portion B

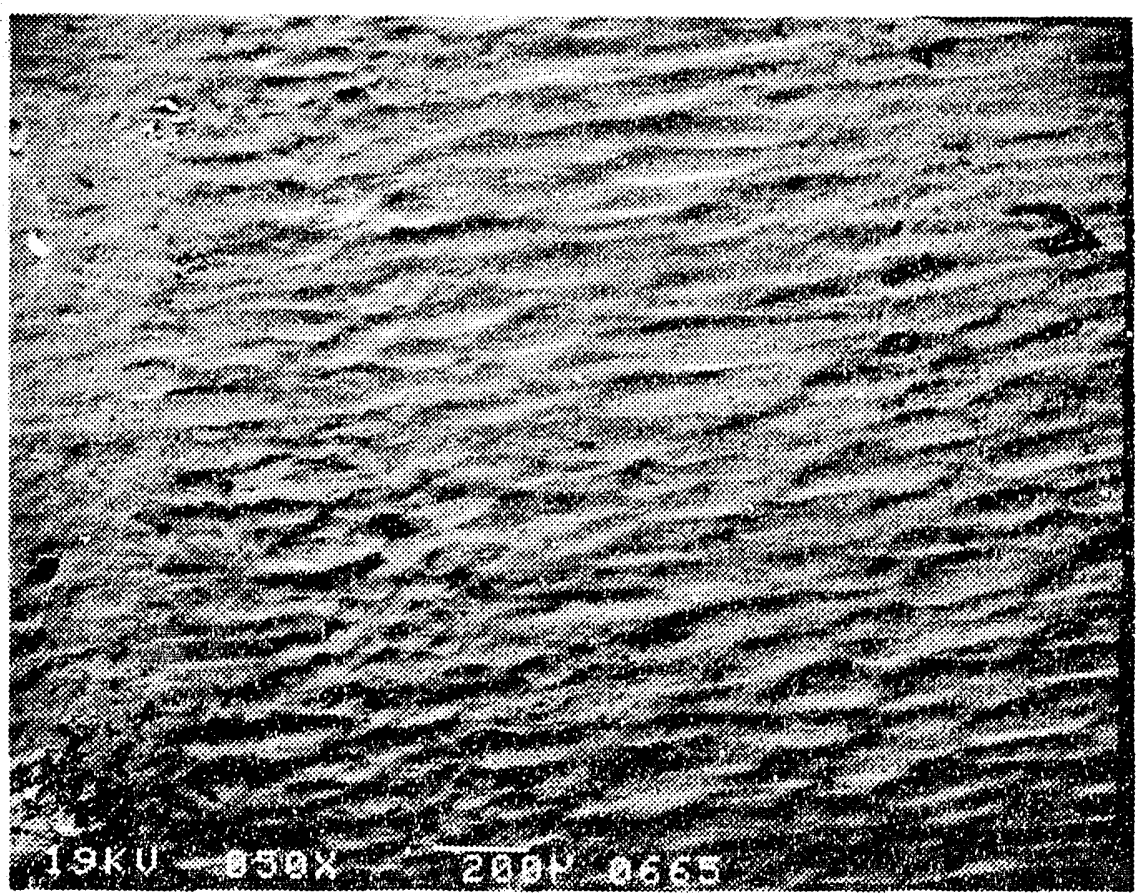

Figure 22 Wear Tracks on Portion A of Tube 93-49 


\section{APPENDIX 3}

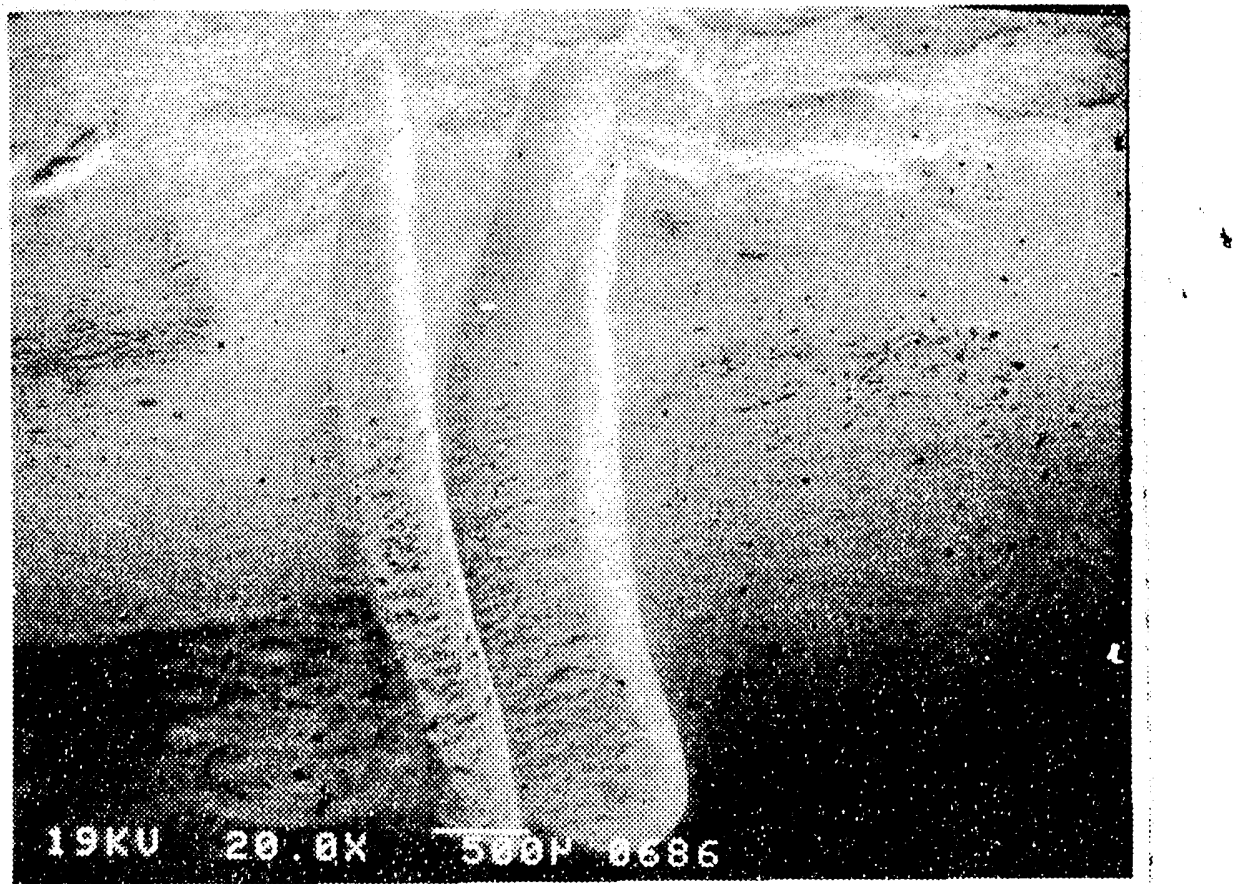

Figure 23 Wear Track on Portion B of Tube $93-49$

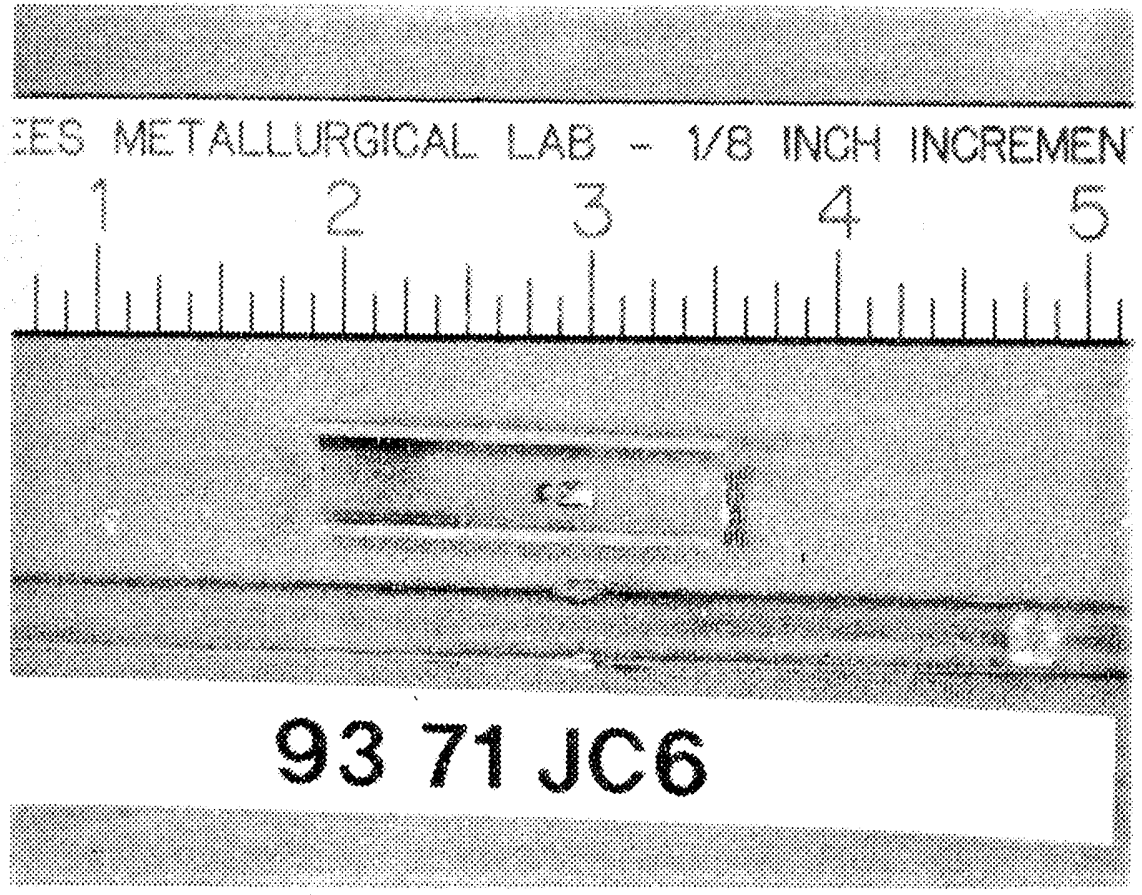

Figure 24 Inner Surface Wear Scar on Tube 93-71 and Photograph of Typical Core $\operatorname{Rod}$ 

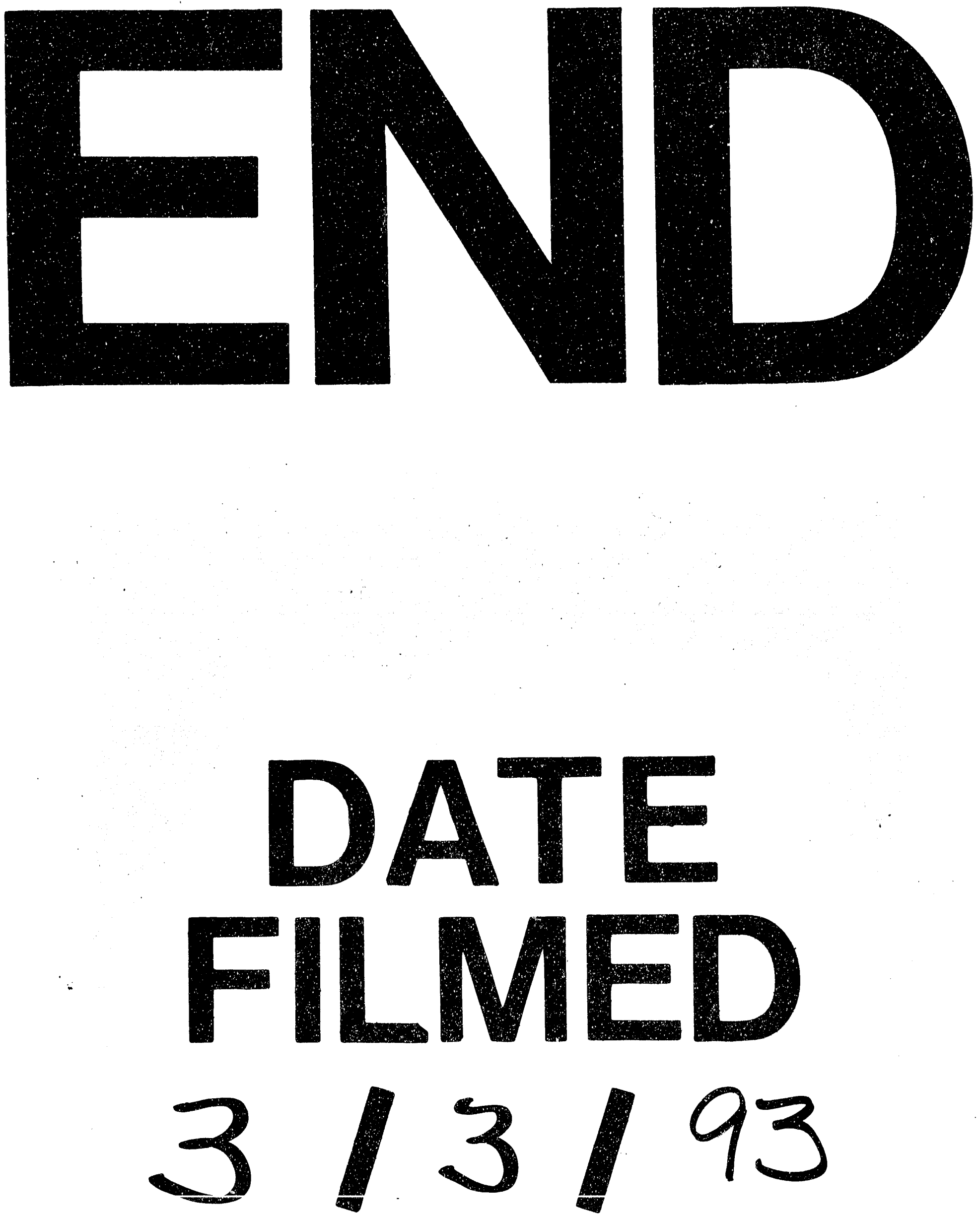
